\title{
Protecting the providers of Indigenous maternal care
}

\author{
by
}

Monika Krzywania

Co-supervised by: Dr. Kahente Horn-Miller and Dr. Sophie Tamas

A thesis submitted to the Faculty of Graduate and Postdoctoral Affairs in partial fulfillment of the requirements for the degree of

Master of Arts

in

Geography and Environmental Studies

Carleton University

Ottawa, Ontario

(C) 2018, Monika Krzywania 


\begin{abstract}
Place is a powerful ontological force which is constitutive of health and well-being for Indigenous peoples. Colonial violence dis-places relationships to land, bodies, and community, leading to the unacceptable and pervasive health inequities suffered by many Indigenous peoples living in the territories now known as Canada. This thesis describes acts of resistance to this dis-place-ment by providers of Indigenous maternal care in their advocacy to return birth to community. By mapping the spatio-legal dimensions of the Indigenous maternal care landscape in Ontario and Québec, this thesis investigates how (neo)colonial governance comes to bear on experiences of providing maternal care. Grounded in the analysis of primary data from interviews with six Knowledge Holders, the findings of this research articulate divergent ontologies of governance within systems of Indigenous and state law. This research calls for a meaningful engagement with Indigenous ontologies of governance to better account for the maternal care needs of pregnant Indigenous women and the providers who care for them.
\end{abstract}




\section{Dedication}

In mourning of all missing and murdered Indigenous Women, and of all life that colonialism has tried, in futility, to extinguish. You are remembered, and your resilience ignites fire.

And for Su, your memory endures. Thank you for the fish and chips at Else's. I hope you found your peace, my friend. 


\section{Acknowledgements}

I begin by acknowledging the unceded Algonquin Territory in which much of this work was completed, as well as the Territories of all of the other Nations in which I have been fortunate to be a visitor over my lifetime.

I would like to offer my heartfelt gratitude to the following humans and more-thanhumans, without whom these words could not have been written;

To my parents, Ewa and Tom Krzywania, for birthing me into this life and loving me unconditionally. You are the most selfless beings I know and forever my most ardent supporters. Thank you for the example you have set.

To my siblings, Stephanie, Jacqueline, and Alex, for making this crazy journey worthwhile, and for galvanizing my reserves of energy with your teasing at my still being in school. You guys are the real deal. To our forever companion, Kuba, for teaching us to see with our hearts.

To Graeme, for indulging in my many quirks and dreaming with me, for loving me the way you do. I can't wait to grow heirloom tomatoes with you (at least now we know that fickle seeds don't like compost! And that one garlic yields many garlics...) and bring our generously floofy Samoyeds on adventures. To airport reunions and ocean-side tacos, and one day, Snoopaca, Tupaca, Biggie, and BTP. 
To my outstanding advisory committee for being patient and gentle with me and for nurturing my growth throughout this challenging process. Thank you for helping me find the courage to write. Sophie, thank you for taking a chance on me when it seemed like everything was falling apart and for letting me wander until I found my way. Thank you for reminding me to always put basic zookeeping first. Kahente, thank you for grounding me and for reminding me to take things one day at a time. You have kept me focused and on track. Thank you to the both of you for your passionate scholarship which has opened up spaces for the (im)possible.

To Kendrick, Ludovico, and Hans for keeping me company while I was reading, writing, pretending to write, reading some more, pulling my hair out, and then dancing my bones off.

To my Carleton community for providing me with an irreproducible backdrop for many spirited musings and meltdowns. Loeb, in all of your brutalist majesty, your enduring unwillingness to sustain an appropriate room temperature kept me on my toes. A big shout-out to my fantastic cohort and mentors for making my grad school experience such a memorable one. Teall, thank you for sharing my love of charcuterie and good red wine (BBB). Memories of crashing in your living room over the summer of 2017 will forever bring us some great laughs. Erin Johnston, I know I am not the only one who thinks you keep our grad program up and running! But beyond your otherworldly organizational skills, you have always been a shoulder to lean on in the tougher times. Thank you. Chris Burn, thank you for the many fascinating conversations about science and the 
philosophies which undergird its pursuits (as well as many other marvelous literary curiosities). When I burst into your office convinced I was dropping out of grad school, you presented me with three doors.

To my McGill crew - Alexa, Alice, Alyssa, Astrid, Emily, Kat \& CJ, Lily, and Simone for our many years of friendship. Our reunions remind me how fortunate I am to have so much love in my life. Astrid and Simone, without the two of you, I never would have stumbled into the wonderful world of geography. Alexa, thank you for joining me on fateful travels which provided fortuitous distractions from this thesis :-

To the myriad places I have encountered on my path, which surreptitiously beckoned to the geographer within, and continue to make me; saturated earth and pine needles while foraging for mushrooms as a wee explorer, cold granite lakes with mysterious, black depths on the Shield, vast unpredictable oceans to jostle the perceived boundaries of the imagination, mountains to teach patience, perseverance, and humility.

And finally, to the women who so generously gave of themselves and entrusted me with their stories, for the opportunity to bear witness to your knowledges. I owe you a debt of gratitude which I am unable to repay.

Thank you, all. 


\section{Table of Contents}

Abstract

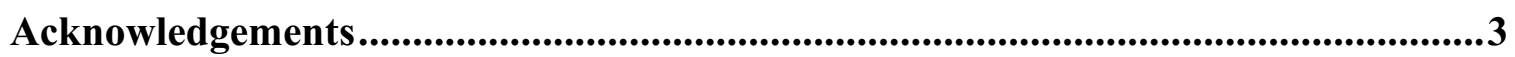

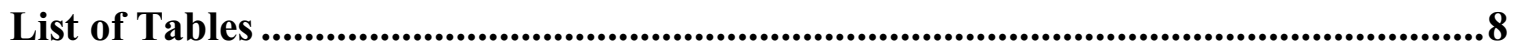

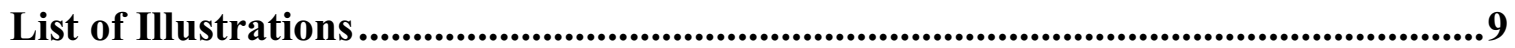

List of Appendices ............................................................................................................10

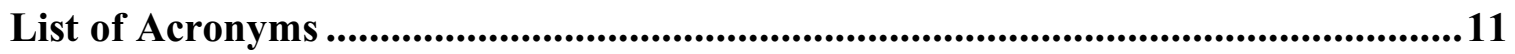

1 Chapter: Conception ................................................................................................................13

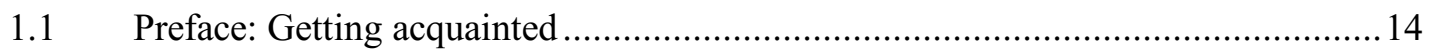

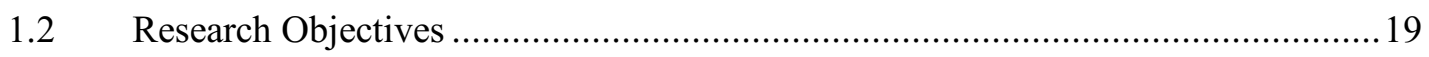

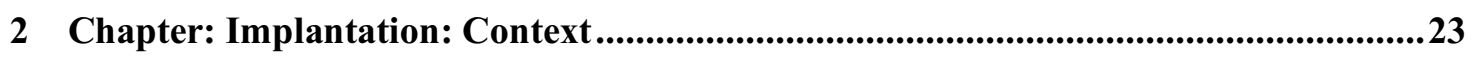

2.1 Health inequities affecting Indigenous peoples living in Canada .........................23

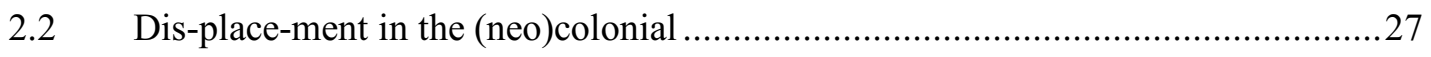

2.3 Returning birth to community through the lens of (settler-colonial) policy ............41

2.4 Returning birth to community through the lens of decolonization.........................44

3 Chapter: Gestation ...............................................................................................................55

3.1 Relational ways of being, knowing, and healing ….......................................56

3.2 Reconciliation through recognition? How a relationship based on recognition hides the truth and fails to reconcile. .60

3.3 "Activating place" in health research: Theorizing legal geographies of Indigenous maternal care governance. .65

4 Chapter: Contractions .................................................................................................. 73

4.1 'Honouring partnership': 'Re/forming' my knowledge about Indigenous peoples.. 73 


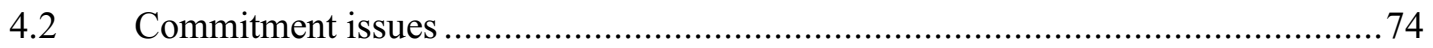

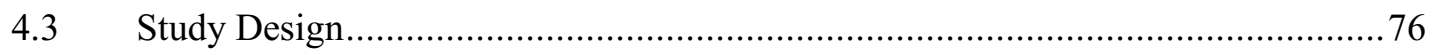

5 Chapter: Birth ..................................................................................................................8 81

5.1 Implications of midwifery legislation for Indigenous maternal care providers .......82

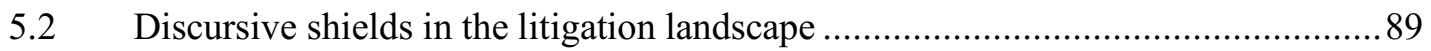

5.3 Learning to "go in both boats": On epistemic violence and living in the grey ........98

5.4 "The place that belongs to me": Understanding the return of birth to community as

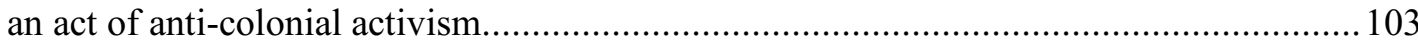

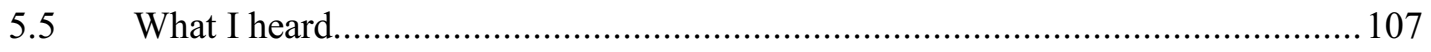

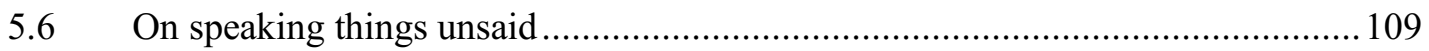

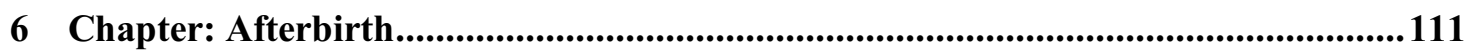

6.1 What I learned: Where do we go from here? ..................................................... 111

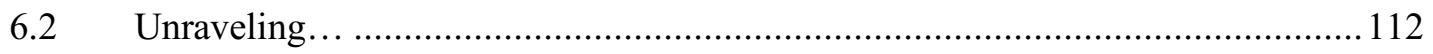

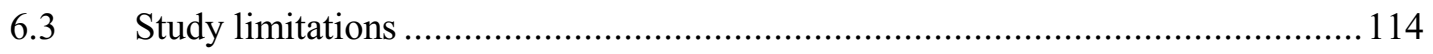

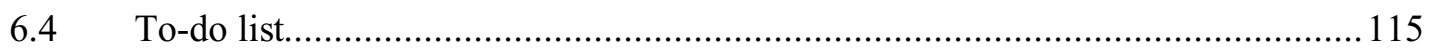

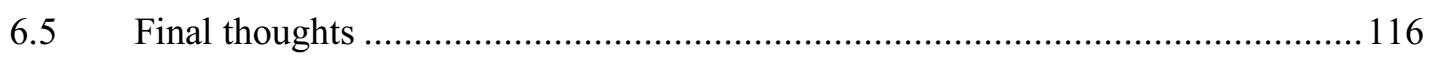

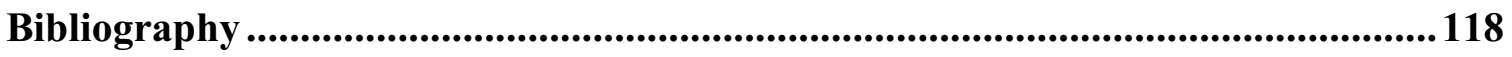

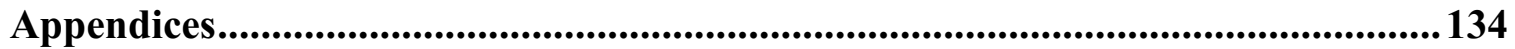




\section{List of Tables}

Table 1: Table of Knowledge Holder characteristics ........................................... 78 


\section{List of Illustrations}

Figure 1: "Keeping together" by Tina St John: Ottawa, 2017. Used with permission of the artist.

Figure 2: "Map of the evacuation policy for a First Nations woman living on reserves in Manitoba. Legend: Diamond: no public services; Heavy outline: federal services; Dotted outline: provincial health services; Thin solid line: travel" reproduced from Lawford (2017, p. 61) with permission from the author. 


\section{List of Appendices}

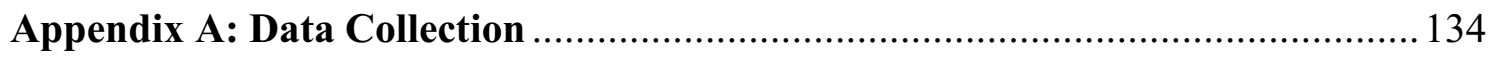

A.1 Letter of Recruitment ........................................................ 134-136

A.2 Oral Consent Script ............................................................. 137-141

A.3 Written Consent Form............................................................. 142-145

A.4 Interview Guide ................................................................. 146-147

Appendix B: Midwifery Legislation in Ontario and Québec............................ 148

B.1 Midwifery Act, 1991, SO 1991, c 31, s 8, "Restricted titles".................... 148

B.2 Regulated Health Professions Act, 1991, SO 1991, c 18, s 35, "Exemption, aboriginal healers and midwives"

B.3 Midwives Act, CQLR 2018, c S-0.1, ss 12-13, "Illegal Practice”. 150

\section{Appendix C: Non-Insured Health Benefits (NIHB) Medical Transportation Policy \\ Framework - Client Escort Policy 151}

C.1 Non-Insured Health Benefits (NIHB) Medical Transportation Policy

Framework; Effective July 2005 $151-152$

C.2 Non-Insured Health Benefits (NIHB) Medical Transportation Policy

Framework (Interim); Effective January 2018

$.153-154$ 


\section{List of Acronyms}

AOM Association of Ontario Midwives

$\mathrm{AM}$

Aboriginal Midwife

CMO College of Midwives of Ontario

CQLR Compilation of Québec Laws and Regulations

FNIHB First Nations and Inuit Health Branch

IRCM Interim Regulatory Council on Midwifery

NACM National Aboriginal Council of Midwives

NIHB Non-Insured Health Benefits

OSFQ Ordre des sages-femmes du Québec

RM Registered Midwife

SO Statutes of Ontario

SQ Statutes of Québec 


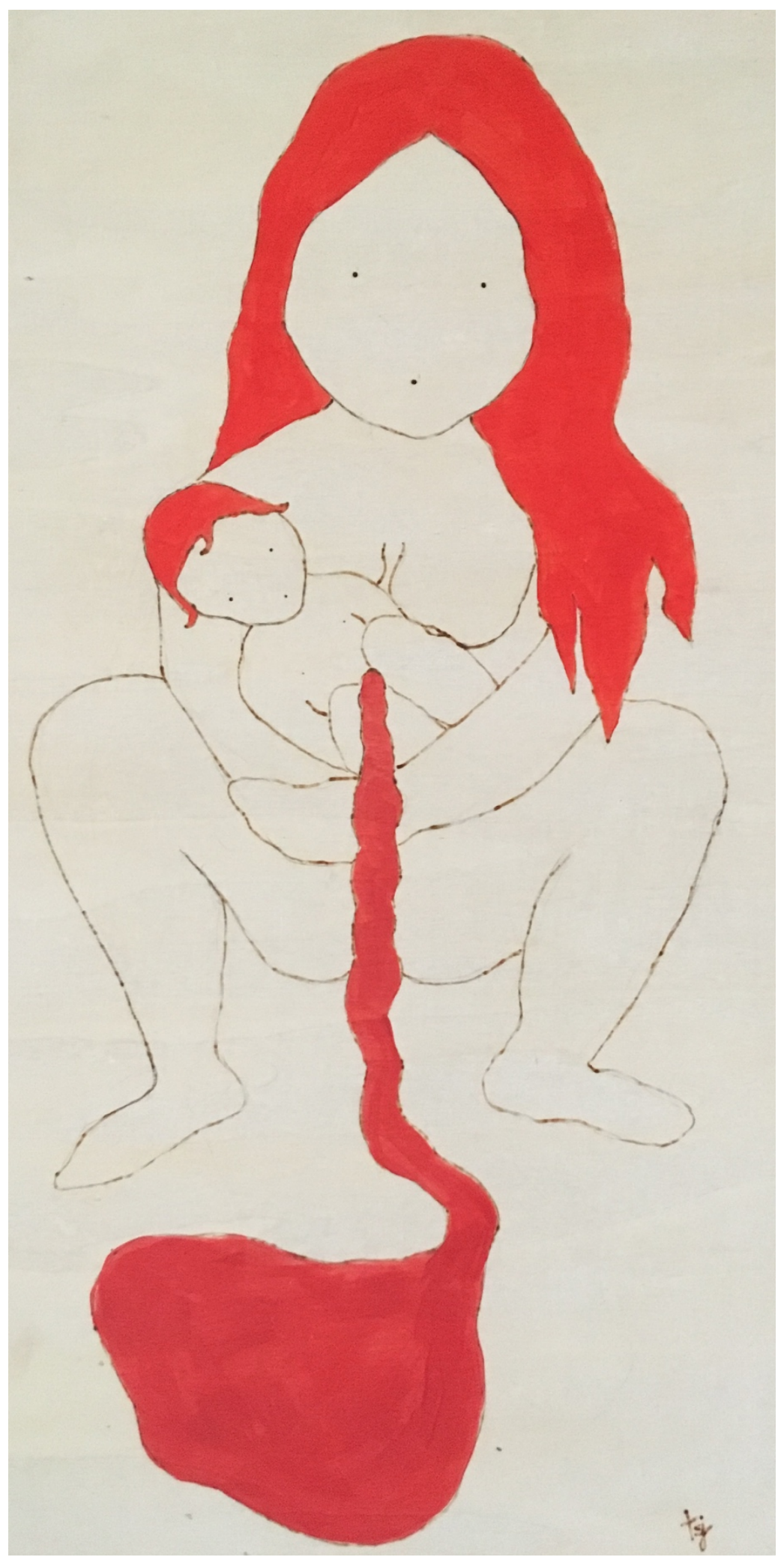

Figure 1: "Keeping together" by Tina St John: Ottawa, 2017. Used with permission of the artist. 


\section{Chapter: Conception}

What does it mean to protect someone or something? In colloquial and everyday uses of the verb, we protect our loved ones from harm, we protect our interests, we protect our identity, culture, values, and beliefs. In the context of Indigenous-state relations, the Government of Canada has a constitutional, fiduciary obligation to Indigenous peoples; Indigenous rights are constitutionally recognized and protected.

This thesis critically examines the governance of maternal care delivery under the guise of protection for Indigenous women living in rural and remote regions of Ontario and Québec. Building on the work of Kwakwaka'wakw geographer Sarah Hunt (2014b), Anishinaabe midwife and scholar Karen Lawford (2017), and Tr'ondek Hwech'in researcher Rachel Olson (2013), my research problematizes the process of (neo)colonial legal categorization that results from the protection of Indigenous rights through the Indian Act and the Constitution Act, 1982 as they interface with provincial midwifery legislation.

The findings of this research contribute to the literature on the repatriation of childbirth to Indigenous communities. By tracing the spatialization of power, my work articulates some of the spatio-legal barriers encountered by Indigenous maternal care providers in their advocacy work to return birth to community. My analysis grapples with the complex question of whose rights and interests are protected by state law in practice? Informed by anti-colonial theorists who problematize the politics of recognition (Coulthard, 2007, 2014; A. Simpson, 2014, 2017; L. B. Simpson, 2017), I write from the position that the goals of state 'protection' are incongruent with the goals of anti-colonial resistance. My research journey began with a conversation in which one of the 
Knowledge Holders told me her story of burnout. She concluded her story by posing the following question: How can we protect providers?

So, I set out to trace some of the causes of burnout in the Indigenous maternal care community in Ontario and Québec. From speaking with providers, I have become convinced that the high levels of burnout experienced by this community are rooted in colonialism. In this thesis, I argue that protecting the providers of Indigenous maternal care means putting an end to the (neo)colonial (re)production of dis-place-ment. Improving maternal and child health in Indigenous communities necessitates addressing the structural violence which is built into the Canadian healthcare system.

I would like to be clear that the title of this thesis should not be interpreted as (re)producing patronizing discourse but is instead my attempt to engage directly with the ironic and deeply troublesome implications of protection. It is my way of honouring that initial conversation which birthed my research journey and giving thanks to the Knowledge Holder who told me her story.

\subsection{Preface: Getting acquainted}

These pages trace my journey of unlearning as a student, which has taken me from dissecting mice in a genetics lab to discussing the repatriation of birth with Indigenous maternal care providers in the intimate spaces of a sunny kitchen table, front yard picnic table, hip café, campus office, and freshwater beach. This is a story about learning to make peace with getting lost, and, perhaps more importantly, how this act of getting lost can become fertile ground for doing academic work (Tamas, 2009b, 2014). I would like to begin by introducing myself, or, to frame this question geographically, describing where I come from. I begin this way to encourage "more humane, inclusive, 
ghost-friendly ways of being and working in the academy" (Tamas, 2016, p. 40) and to acknowledge the rich dataset untapped in the omissions and erasures brought about by the "hypervigilance of neoliberal new managerialist academic audit-cultures" (p. 42). This departure from (normative heteropatriarchal) convention is also part of my attempt to honour Indigenous knowledge protocols, which expect that the motivations underpinning research will be openly stated because they shape our methodology and how we relate to others (S. Wilson, 2008).

I hail from a boisterous household of six, the eldest daughter of two Polish immigrants to Canada. The stage for much of my childhood was Markham, Ontario, a suburb of Toronto that I remember ringed in farmland but today prides itself on its demographic diversity as a rapidly-expanding high-tech hub ('About Markham', 2014).

Growing up, I did a fine job of fulfilling the elder sibling prophecy. I was a bit of a know-it-all who cared too much about school, chauffeured from advanced placement classes to piano lessons to competitive soccer. I dreamed of becoming a surgeon. In keeping with this plan, I found work as a research assistant in a genetics lab in the second year of my undergraduate studies. I was entrusted with a nifty microscopy project aimed at deriving one of the mechanisms that drive pathology in Polycystic Kidney Disease. The work was monumentally tedious, but the results were elegant, and innovating an alternative to dialysis and transplantation seemed pretty darn noble. My fellow biologists will know that the mouse is a model organism in human genetics, an arbiter of future progression to clinical trial. Most of the time, I worked with P5s and P10s (pups that are five and ten days old). At P5, the mice are still squirmy and embryo-like but at P10 their fur has come in and they are full-fledged in their cuteness. 
I guess I hadn't connected the dots that in order to take microscopic pictures of kidneys, I would need to become an organ harvester. My supervisor was an incredibly kind, spunky, and tenacious $\mathrm{PhD}$ candidate who had come to Canada as a refugee fleeing genocide. She performed the dissections with expediency and efficiency. I watched with horror as the razor blade passed swiftly through the neck. In one swift motion, she flipped the little body and snipped a portion of the still-squirming tail to plop into an Eppendorf tube of digestive enzyme for genotyping. Then the kidneys into vials of toxic formalin. I still remember the sheer confusion on her face when she turned to find me blinking away tears.

Before long, I was performing my own necropsies with detached and meticulous professionalism. This did not escape the notice of the principal investigator and so I was tasked with more advanced methods. In immunohistochemistry, the goal is to achieve the most life-like preparation you can. Perfusion (see for example Gage, Kipke, \& Shain, 2012), where you co-opt the critter's own cardiovascular system to do your dirty work, is considered a gold standard. I would know that I had executed the procedure correctly if, within a minute or so, the tail would stiffen, shoot up, and scare the bejeebers out of me. But with the thrill of a successful perfusion came a shudder of disgust. The excavated carcass-on-cardboard before me had been genetically engineered to die at my hands and become the subject of my experimentation.

I share this story with you to draw attention to the lived and embodied scale at which knowledge - biomedical or otherwise - is produced (Hunt, 2014a). I came to know biomedicine with beleaguered reverence and this history informs my present perspective. To be clear, I am not instigating a critique of biomedical knowledge production. That is 
not the topic of this thesis. Instead, I would like to emphasize that the ways that we arrive at knowledge are not inconsequential. The important point here, I think, is that writing about knowledge production is scaled differently in different disciplines (Law, 2004). For an interdisciplinary system of inquiry such as health research with/serving Indigenous peoples, this introduces some notable tensions.

As a critical geographer, I will contend, in the vein of my colleagues, that knowledge is partial and always in a state of becoming, that it escapes precise definition, barreling instead toward the malleable and subjective (Hunt, 2014a). The knowledge presented here is grounded in my biased understanding of the world and the issues at hand. For this reason, I have chosen to situate myself explicitly in this work and in these pages.

I feel compelled to make this disclosure for another, more important reason. I am a white academic, taking up space in a settler-colonial society, claiming to investigate health inequities faced by many Indigenous women and their families living in Ontario and Québec. Throughout my studies, my tirelessly patient academic supervisor, Dr. Sophie Tamas, encouraged me to reflect about what this thesis is not. Though it wasn't immediately clear to me at the time, I can see now that sitting with this process has allowed me to adhere to a certain measure of self-reflexivity, of locating myself in my research (Mol, 2006).

Thus, given my positionality - as a white-settler-woman meddling in the academe - I will not be speaking for Indigenous peoples. I do not, and cannot know, what it means to be an Indigenous woman providing maternal care, or to be an Indigenous woman receiving maternal care. Instead, I have set out to trace the ways that birth is multiply, 
relationally understood and enacted in maternal care encounters in a handful of specific Indigenous communities.

To do this, I have interviewed six Knowledge Holders occupying a variety of maternal care roles, who work in Indigenous communities in Ontario and Québec. I am indebted to these women for the selfless investment of their time, the many kindnesses they have shown me, and their thoughtfulness in indulging my endless stream of questions. I feel personally accountable to this group of courageous and resilient women. They continue to persevere, often to the point of exhaustion and burn-out, toward a vision of birth in community. It would be disingenuous and futile to pretend to distance myself from them as an objective and rational observer, or all-knowing 'expert'. In sharing their stories, these women have opened their homes and their hearts to me, and for this gift, I am truly grateful.

Endeavouring to commit the depth of their knowledges to paper has been a clumsy task. Although it is never my intention to mis-represent the stories that have been shared with me, surely, I will fumble at times and I accept personal responsibility for these possible faults and omissions. Along these lines, I should underscore that this research journey has been a process of unlearning (Hunt \& Holmes, 2015; L. B. Simpson, 2017; Tamas, 2014); in many ways, an unearthing of my own settler-colonial baggage.

Now, I recognize that this will teeter on the brink of cliché, but I happened upon Tina St John's work in a local coffee shop as I was thinking about how to structure this personal reflection. A midwife and trauma survivor, Tina approaches art as a form of therapy. When I first saw "Keeping together" (St John, 2017), a memory cue triggered distant pieces of an undergraduate embryology lecture on maternal-fetal circulation. 
Mother and child are, figuratively and literally, bound by blood. At the hands of the colonizer, exalting the bidding of god and queen, a systematic bloodshed was sanctioned in this country that can only be described as genocide of the most appalling degree. Canada was, and continues to be, lacerated by systemic racism which has separated child from mother, and divorced hundreds of Nations from their Birth-Places.

In light of this, 'keeping together' takes on a novel depth of meaning, one quite different from the societal pressure to have it all figured out. In the context of a national history marred by genocide, perpetrated historically by the residential school and child welfare systems and currently in institutions of (neo)colonial governance (the healthcare system among them), the mother holds her child to her breast in a gesture that also symbolizes the return of sovereignty, of land, and of birth. These are the themes that will be explored in this thesis.

So, reader, I've pulled back the curtain ever so slightly to give you a sense of who I am and what I've set out to do. Please be warned that the pages that follow will generate more questions than answers, and you may be left with a whole pile of loose ends. But this somewhat uncomely package is threaded together by an insatiable curiosity and the presupposition that, as a society, we are continuing to fail Indigenous peoples, and that we can and should do better.

\section{$1.2 \quad$ Research Objectives}

I have attempted to sketch how policymaking in the (neo)colonial present comes to bear on the ceremony of birth in Indigenous communities, and, in many ways, exacerbates gaps in maternal care delivery as well as other pre-existing health inequities. To be more specific, my research examines front-line maternal care providers' 
experiences in order to better understand the significance of and barriers to returning birth to Indigenous communities. I will situate this discussion of (neo)colonial maternal care governance within a broader conversation about the politics of recognition (Coulthard, 2007, 2014; A. Simpson, 2014, 2017) and recent work in critical legal geographies (Daigle, 2016; Hunt, 2014b). In summary, this thesis interrogates (neo)colonial structures of governmentality to problematize the ways in which illconceived models of maternal care delivery can perpetuate a violent dis-place-ment of Indigenous mothers and their families.

When I began this project, I framed my research objective in the following way:

This study will seek to evaluate the working conditions of service providers delivering maternal care in Indigenous communities in Ontario and Québec, in order to investigate the implications of a 2010 national policy shift to return birth to communities.

In line with anti-colonial methodologies that highlight the self-reflexive and iterative nature of the research process (Ritenburg et al., 2014; S. Wilson, 2008), my thinking has evolved over the course of this journey. The first iteration of my research objective as written above no longer adequately captures the breadth of this research. Furthermore, its framing is problematic because it privileges settler-colonial spaces of knowledge production to learn about Indigenous maternal care. From my interviews with Knowledge Holders, it became clear to me that anchoring my thesis around the 2010 (settler-colonial) policy shift threatened to eclipse the rich body of knowledge among Indigenous maternal care providers, whose advocacy to return birth is a direct response to the violence of settler-colonialism. The movement to return birth precedes contemporary (settlercolonial) policy discussions; it can be traced back to a far more intimate scale of everyday experiences of birth, where mothers and providers are fiercely challenging the 
normalization of dis-place-ment. I am especially grateful to Karen Lawford for the conversation that was generative of this insight.

To better reflect the knowledge that has been shared with me throughout this journey and my commitment to the process of unlearning as a settler woman seeking to engage in reconciliation, I have expanded my research objective to describe the everyday acts of anti-colonial activism exemplified by Indigenous maternal care providers who are actively engaged in returning birth to their communities. This resistance at the scale of the everyday pushes against systems of (neo)colonial legal categorization and hegemonic approaches to biomedical risk management. The movement to return birth to community aims to redefine the terms of Indigenous engagement with the settler-colonial state.

Providers of Indigenous maternal care are refusing to be subjects at the mercy of state protection when it comes to improving maternal and child health in their communities. They are refusing to devalue and dispense with Indigenous knowledges and practices. They are refusing to forget a precedent, standalone system of maternal care governance which is rooted in relationship and ceremony.

In working toward a vision of birth in community, the Knowledge Holders I interviewed are resisting (neo)colonial governance. These providers are advocating for maternal care spaces where Indigenous women feel safe, valued, and where expectant mothers will be able to choose how they would like to approach their pregnancy and childbirth. The restructuring of Indigenous-state relations is happening in the intimate spaces of the body, home, and community with the movement to return birth. 


\subsubsection{Overview of Chapters}

"Chapter 2: Implantation: Context" will situate the discussion of maternal care provision for Indigenous women within the context of historical and contemporary Indigenous-state relations, focusing on the spatio-legal dimensions of the Indigenous maternal care landscape.

"Chapter 3: Gestation" will examine theories of anti-colonial resistance which challenge the (re)production of (neo)colonial governance.

"Chapter 4: Contractions" will articulate the methodological paradigms which informed my research process and how I went about my research.

"Chapter 5: Birth" will describe my research findings, providing a detailed account of what I heard from the Knowledge Holders I interviewed.

"Chapter 6: Afterbirth" will relate these research findings back to the literature presented in Chapter 2, explain what I learned from my research, and how I understand the way forward through the theoretical framework developed in Chapter 3. 


\section{Chapter: Implantation: Context}

In this chapter, the health inequities which shape the collective health status of Indigenous peoples will be contextualized as the intergenerational effects of colonialism. The (re)production of (neo)colonial relations is facilitated by ongoing dis-place-ment; this loss of place continues to interrupt relationships to land, bodies, and community which nurture health and well-being. I will extend this line of inquiry to governance models of maternal care purportedly serving Indigenous women and their families in the provinces of Ontario and Québec. The argument I would like to advance is that these contemporary systems of governmentality endorse policies which perpetuate dis-placement. This is facilitated in large part by a discursive emphasis on risk and competency in policy discussions concerning the return of birth to community which precludes an open dialogue about reconnecting to place as a necessary pathway to healing from colonial violence.

In particular, this chapter will review the available literature regarding the implications of the federal evacuation policy for the health of Indigenous women and their families. From this body of scholarship, it will become evident that the routine practice of evacuation threatens to perpetuate the dis-place-ment of Indigenous women and their families. I will then discuss the movement to return birth to community, which challenges the normalization and naturalization of evacuation.

\subsection{Health inequities affecting Indigenous peoples living in Canada}

In order to understand the challenging realities of Aboriginal health - specifically, the persistent disparities between the health of Aboriginal peoples and non-Aboriginal people in Canada - it is necessary to examine the interrelated features and relationships of the structural (historical, political, societal, and economic) determinants that shape Aboriginal health. (Reading, 2015, p. 3) 
Michi Saagiig Nishnaabeg artist and theorist Leanne Betasamosake Simpson describes colonialism as "a structure of processes" (L. B. Simpson, 2017, p. 35). This structure of processes is driving the unacceptable and pervasive health inequities experienced by many Indigenous peoples living in the territories now known as Canada (Adelson, 2005; Merrick, 2017; Reading, 2015; Richmond, 2015; Richmond \& Ross, 2009; Skye, 2010). Charlotte Reading (2015) traces the (re)production of colonialism through structural violence. In attending to what she refers to as the distal determinants economic, social, and political structures - she reveals historical injustices gripping contemporary life. Two of her examples illustrate this point saliently. Thousands of stolen childhoods were the outcome of the residential school system and the Sixties Scoop; in the present day, families are torn apart by disproportionate apprehensions of Indigenous children by the Child Welfare system. Secondly, in the violence of the reserve system, wherein Indigenous peoples were divorced from their land and water rights by the brutal governance of the Indian Act of 1876; now, generation after generation must cope with boil water advisories. Adelson (2005) situates the resultant "disproportionate burden of ill health" (p. S45) experienced by Indigenous peoples as the "individual effects of the collective burden of a history of discriminatory practices, unjust laws and economic or political disadvantage" (p. S46).

\subsubsection{Placing Indigenous health and anti-colonial resistance}

This section serves to relate three tenets which are foundational to the theoretical orientation of this thesis:

(1) Place is a powerful ontological force which is constitutive of health and well-being for Indigenous peoples. 
(2) Historical and contemporary dis-place-ment have led to the unacceptable and pervasive health inequities experienced by many Indigenous peoples in Canada.

(3) Mobilizing anti-colonial resistance to dis-place-ment is integral to the process of improving the health and well-being of Indigenous peoples.

Yellowknives Dene scholar Glen Coulthard's (2010) reading of God is Red by Standing Rock Sioux activist Vine Deloria Jr. (1992) foregrounds a critical observation about the divergent orientations of western and Indigenous knowledge systems; whereas the "historical/developmental" (Coulthard, 2010, p. 79) narrative purported by many western knowledge systems privileges the construct of time, Deloria's writing speaks to the foundational importance of place to Indigenous peoples' experiences of being and knowing in the world. According to Coulthard (2010), Deloria is "attempting to explicate the position that land occupies as an ontological framework for understanding relationships" (p. 79, emphasis added). When conceptualized in this way - as an active and relational process of meaning instead of the passive substrate configuration familiar to most westerners - it becomes clear that land and place can inspire and anchor anticolonial resistance:

Place is a way of knowing, experiencing, and relating with the world - and these ways of knowing often guide forms of resistance to power relations that threaten to erase or destroy our senses of place. (Coulthard, 2010, p. 79)

To exemplify the kinds of anti-colonial resistance made possible through this “place-based imaginary" (Coulthard, 2010, p. 82), Coulthard recalls Indigenous resistance to the Mackenzie Valley Pipeline proposal. He examines the senses of place illustrated by the testimony of Philip Blake, a Dene from Fort McPherson: 
I strongly believe that we do have something to offer your nation, however, something other than our minerals. I believe it is in the self-interest of your own nation to allow the Indian nation to survive and develop in our own way, on our own land. For thousands of years we have lived with the land, we have taken care of the land, and the land has taken care of us. We did not believe that our society has to grow and expand and conquer new areas in order to fulfill our destiny as Indian people.

\section{$[\ldots]$}

I believe your nation might wish to see us, not as a relic from the past, but as a way of life, a system of values by which you may survive in the future. This we are willing to share. (Philip Blake quoted in Coulthard, 2010, p. 82)

In his testimony to the Mackenzie Valley Pipeline Inquiry, Blake underscores that there is little to gain and everything to lose if the violence of extractive industry is permitted to reap unfettered. The worldview that he advances here does not prefigure humans as separate from the land and all of its relations. He grounds his anti-colonial resistance by placing himself within an ethic of relational accountability (S. Wilson, 2008).

I would like to relate Coulthard's framing of place-making as resistance to geographer Sarah de Leeuw's (2015) call to "activate place" in health research with/serving Indigenous peoples. de Leeuw cautions that a blind attachment to the social determinants of health model $^{1}$ threatens to stagnate health research with Indigenous peoples. Expounding the legacy of Indigenous scholarship which has traced the indelible connections between place and health, de Leeuw problematizes the lack of engagement with place-based methodologies in mainstream research concerning Indigenous peoples' health. Furthermore, she interrogates the (lack of) space available to explore these

\footnotetext{
${ }^{1}$ Readers who are unfamiliar with the social determinants of health model will find the introduction of Determinants of Indigenous Peoples' Health in Canada: Beyond the Social (de Leeuw, Lindsay, \& Greenwood, 2015) a useful reference.
} 
methodologies within the current paradigm of social determinants of health, advocating for a geographical inquiry to address this unmet need:

Very simply put, to think about something geographically, or to account for geography as a determinant of health, is to acknowledge that where we are and how we are in that space matters: place and space are never static or neutral entities upon or in which we simply exist or that we entirely socially construct, but instead are always active, independent, and determining life forces. (de Leeuw, 2015, p. 93)

de Leeuw asserts that Indigenous thinkers have long told us to mind the connections between place and health, that this imperative has not been adequately attended to by health researchers to date, and that its engagement is well supported by a critical geographical praxis. Building upon this insight, "activating place" becomes a way of enacting our ethical obligation as researchers to support anti-colonial resistance.

\subsection{Dis-place-ment in the (neo)colonial}

Anishinaabe scholar Chantelle Richmond's (2015) community-based research study with 46 Anishinaabe Elders from Batchewana and Pic River First Nations on the north shore of Lake Superior describes mounting concerns over the consequences of land loss and degradation for community health. Nurturing and sustaining a relationship with the land is understood to be necessary for nurturing and sustaining the health of Anishinaabe peoples. This relational and embodied knowledge is epitomized by the following quoted excerpt from an interview with an Elder from Batchewana First Nation:

We are the land - there is a strong spiritual connection, everyone has their role in life, including the land and people. There is a respect that we need to show the land and its relatedness to us. We are the land. If the land is sick, then it isn't going to be very long before we're going to get sick. (Henry (pseudonym) quoted in Richmond, 2015, p. 51) 
It is not just that Anishinaabe derive physical and spiritual sustenance in this relationship, but that their identity is contiguous with that of the land. In the words of the Elder quoted above, Anishinaabe are the land.

This concept of "relatedness" is also explored in the work of Choctaw scholar Karina Walters and her colleagues (Walters, Beltran, Huh, \& Evans-Campbell, 2011). Echoing the words of the Anishinaabe Elder from Batchewana First Nation, Walters et al. (2011) position connections to place as being constitutive of identity for Indigenous peoples:

The earth (or land) is both literally and figuratively the first and final teacher in our understanding of our world, communities, families, selves, and bodies. With such understanding it can be argued that as the land or relationship to land is impacted physically or metaphorically - so are bodies, minds, and spirits. (Walters et al., 2011, p. 167)

Conversely, "dis-placement" is understood as "being without place/spirit" (Walters et al., 2011, p. 174) resulting in "soul loss" (Cajete quoted in Walters et al., 2011, p. 174).

Sarah Hunt (2014a) describes the discursive-material machinery of dis-place-ment:

Colonialism in Canada has involved the imposition of western worldviews and the simultaneous suppression of Indigenous worldviews - those heterogenous, place-based ways of knowing through which Indigeneity comes into being. Processes of colonialism in North America involved representational strategies that transformed Indigenous peoples and their lands conceptually and materially, in order to facilitate their displacement and to render them less than human. (p. 29)

Walters et al. (2011) emphasize that the consequences of dis-place-ment do not attenuate with distance, nor are they bound by flesh, but lacerate entire kinship networks and haunt generations not yet born:

Assaults on the land are akin to assault on the body and the people; dis- placement from land is akin to being stripped from 
one's family of origin; seizing the land is akin to stealing from a relative and forbidding any Native family members their rights of access to that family member; disrespecting the land and its relatives through toxins, dumping, or mismanagement is akin to neglecting or hurting a relative. (pp. 182-183)

From the work of these scholars, we see that place as an ontological force is central to ontologies of Indigeneity. The intergenerational effects of colonialism on the health of Indigenous peoples are derived not only from the violent theft and desecration of land and resources but also through the subjugation and attempted erasure of "heterogenous, place-based ways of knowing" (Hunt, 2014a, p. 29). Dis-place-ment then can be understood as operating both discursively and materially and at multiple scales to obfuscate, demonize, and sever ties to one's relations. This is how I understand Tewa author Gregory Cajete's phenomenon of "soul loss" (Cajete quoted in Walters et al., 2011, p. 174).

\subsubsection{The dis-place-ment of birth}

The evacuation of pregnant Indigenous women living in rural and remote regions to deliver in urban hospitals is a longstanding and routine practice endorsed by the Canadian federal government (Fletcher, 1994; Hiebert, 2003; Jasen, 1997; Jennings Linehan, 1992; Kaufert \& O’Neil, 1990; Lawford, 2011, 2016, 2017; Lawford \& Giles, 2012b, 2012a; Olson, 2013; Pauktuutit: Inuit Women's Association of Canada, 1995; Van Wagner, Epoo, Nastapoka, \& Harney, 2007). Lawford's (2011) master's research traced the origin of the practice of maternal evacuation to the year 1892. This is a critical research finding because the practice of evacuation has been described elsewhere as having originated between the 1960s-1980s as a result of institutional changes, primarily in an effort to decrease maternal and infant mortality rates (see, for example, Couchie \& 
Sanderson, 2007; Fletcher, 1994; Olson, 2013; Olson \& Couchie, 2013; SOGC, 2010; Van Wagner et al., 2007). A specific case study by Jude Kornelsen and colleagues (Kornelsen, Kotaska, Waterfall, Willie, \& Wilson, 2010, 2011) has also examined the impact of mandatory evacuation as a result of rural maternity services closures and centralization in the 2000s. Lawford and Giles (2012a) contribute vital nuance to this body of literature by positioning the evacuation policy "as an instrument that perpetuates colonialism" (p. 337).

Although the practice of evacuation is well documented, Lawford $(2016,2017)$ has noted that concrete descriptions of the federal policy regime governing evacuation are elusive. The singular description of the evacuation policy appears in Health Canada's Clinical Practice Guidelines for Nurses in Primary Care, developed by the First Nations and Inuit Health Branch (First Nations and Inuit Health Branch, Health Canada, 2011; Health Canada, 2015). The federal evacuation policy is described in "Chapter 12 Obstetrics" of this document, advising federally employed nurses to "[a]rrange for transfer to hospital for delivery at 36-38 weeks' gestational age according to regional policy (sooner if a high-risk pregnancy)" (First Nations and Inuit Health Branch, Health Canada, 2011, p. 6).

In her research on the maternal evacuation of First Nations women living onreserve in rural and remote regions of Manitoba, Lawford (2017) states that the lack of publicly available information on the evacuation policy constitutes a serious barrier to improving maternal care delivery and has deemed it an "invisible policy" (2016). It is important to note that while the process of maternal evacuation has been documented as affecting First Nations (Hiebert, 2003; Lawford, 2011, 2017; Olson, 2013) and Inuit 
(Fletcher, 1994; Jasen, 1997; Jennings Linehan, 1992; Kaufert \& O’Neil, 1990;

Pauktuutit: Inuit Women's Association of Canada, 1995; Van Wagner et al., 2007) women, the Clinical Practice Guidelines for Nurses in Primary Care are intended "for use by community health nurses employed by Health Canada providing primary care in isolated, semi-isolated, and remote First Nations communities" (Health Canada, 2015). Nevertheless, "the evacuation policy" for Inuit women is described in virtually the same way as in "Chapter 12 - Obstetrics" of the Clinical Practice Guidelines for Nurses in Primary Care (Fletcher, 1994; Van Wagner et al., 2007).

There are several birth centres in Inuit Nunangat ${ }^{2}$ committed to the repatriation of birth and these case studies provide valuable insight into the development of communityled governance models (Douglas, 2010, 2011; Ordre des sage-femmes du Québec, n.d.-c; Van Wagner et al., 2007). Unfortunately, I did not interview any Inuit maternal care providers practising in the Nunavik region of Québec; however, two of the providers that I interviewed had completed locums in the Nunavik region and attested to the "gold standard" (Interview with Registered Midwives; August 26, 2017) of these centres. Based on the 1951 amendment to exclude Inuit from the Indian Act, the legal status of Inuit in Canada is distinct from that of First Nations (Bonesteel, 2008). There are "variations in the administration of Inuit healthcare throughout the North" (Bonesteel, 2008, p. 77) due to decentralization of services and the unique governance systems pursuant to the four comprehensive land claim agreements with the federal government:

These agreements are: the James Bay and Northern Quebec Agreement and Complementary Agreements (JBNQA), which were reached in 1975 in northern Quebec; the Inuvialuit Final

\footnotetext{
${ }^{2}$ Inuit Nunangat collectively refers to the four Inuit regions in Canada, the Inuvialuit Settlement Region, Nunavut, Nunavik, and Nunatsiavut, and "includes land, water, and ice" (Inuit Tapiriit Kanatami, 2018)
} 
Agreement, which was reached in 1984 in the western Arctic; the Nunavut Land Claims Agreement, which was settled in 1993 in the eastern Arctic; and the Labrador Inuit Land Claims

Agreement, which was settled in 2003 in northern Labrador. (Bonesteel, 2008, p. ix)

As one might expect, these spatio-legal dimensions surrounding the governance of maternal care in Inuit communities are markedly different from those which impinge on First Nations communities. Based on her research in Manitoba, Lawford (2017) has argued that the process of evacuation and how it is experienced by clients of maternal care services are structured by "the unique legal and constitutional positioning of First Nations women" (p. 157). Since "the Constitution Act, 1982 and the Indian Act establish and manage the very basis of their existence in the eyes of the Canadian state" (Lawford, 2017, p. 134), First Nations women are subject to federally mandated policy (in this case, the Clinical Practice Guidelines for Nurses in Primary Care) and have little to no choice in their option of maternal care. The governmentality enabled by the Indian Act and the Constitution Act, 1982 “is deliberately detrimental to Indian women’s identities and has substantially changed the pre-contact roles of women" (Lawford, 2017, p. 131). The vehicle of state law is a means of exerting control over reproduction, further entrenching the gender discrimination reinforced through the patrilineality of the Indian Act (de Leeuw, 2016; Hunt, 2014b; Lawford, 2017; Olson, 2013; Stote, 2012).

For First Nations women, birthing outside of the community necessitates a complex coordination of federal, provincial, and municipal services and navigating these multiple jurisdictions can prove challenging:

The Government of Canada, through the First Nations and Inuit Health Branch (FNIHB) of Health Canada, provides primary health care services to First Nations who live on rural and remote reserves. Community health nurses employed by the federal 
government use Health Canada's Clinical Practice Guidelines for Nurses in Primary Care to provide primary care services for on reserve populations, of which prenatal and post partum care is a component. Labour and birthing services, however, are not components of these primary care services, so First Nations women are evacuated out of their communities between 36 and 38 weeks gestational age. When any First Nations person leaves her/his reserve community to receive care, the care is provided by provincially employed caregivers; thus, First Nations engage with the provincial health care system. While in the city, a First Nations person may receive municipal health services, such as vaccinations, which are provided by municipally employed public health nurses. Unfortunately, the provision of health care services across these three health care systems - federal, provincial, and municipal - is neither seamless nor coordinated. (Lawford, 2017, pp. 4-5)

Lawford (2017, p. 61) has created an evacuation map to represent this process visually, which is reproduced with permission from the author on page 35 of this thesis.

A case study from the community of Bella Bella/Waglisla on Campbell Island in British Columbia - where the decline of maternal care services due to closures after 2000 has forced all women to leave the community to give birth since 2001 - describes the experiences of women birthing in and away from their community (Kornelsen et al., 2010, 2011). This case study presents a unique platform where many women were able to contrast the experiences of birthing within and then outside of the community. Women describe the economic and psychological burden of being isolated from family, the toll on children left behind, and the theft of "celebration" (Kornelsen et al., 2011, p. 59). More importantly, Kornelsen et al. (2011) point out that a woman's sense of agency is an influential factor in whether or not she will have a positive experience. A few women chose to leave before the budget cuts and would have done so regardless.

The "therapeutic network" (Kornelsen et al., 2010, p. 643) - circle of family and friends and other types of support - which buffered negative experiences was tied to the 
geography of the community. The authors suggest that in cases where local birthing is not possible, an adequate support system should be put in place to counter alienation and to bolster resilience. They also advocate for the use of qualitative methodologies to document acts of resilience, which may otherwise go unnoticed. In interviewing First Nations women and their families from Manitoba about their experiences of evacuation, Lawford (2017), identified three main themes: (1) the practice of evacuation was normalized to such an extent that women felt resigned to their lack of choice in the matter; (2) women demonstrated resilience in finding ways to meet their maternal care needs despite the policy restrictions and contested the erasure of Indigenous knowledges of birth and; (3) women resisted the practice of evacuation by questioning the status quo and acquiring access to information. 


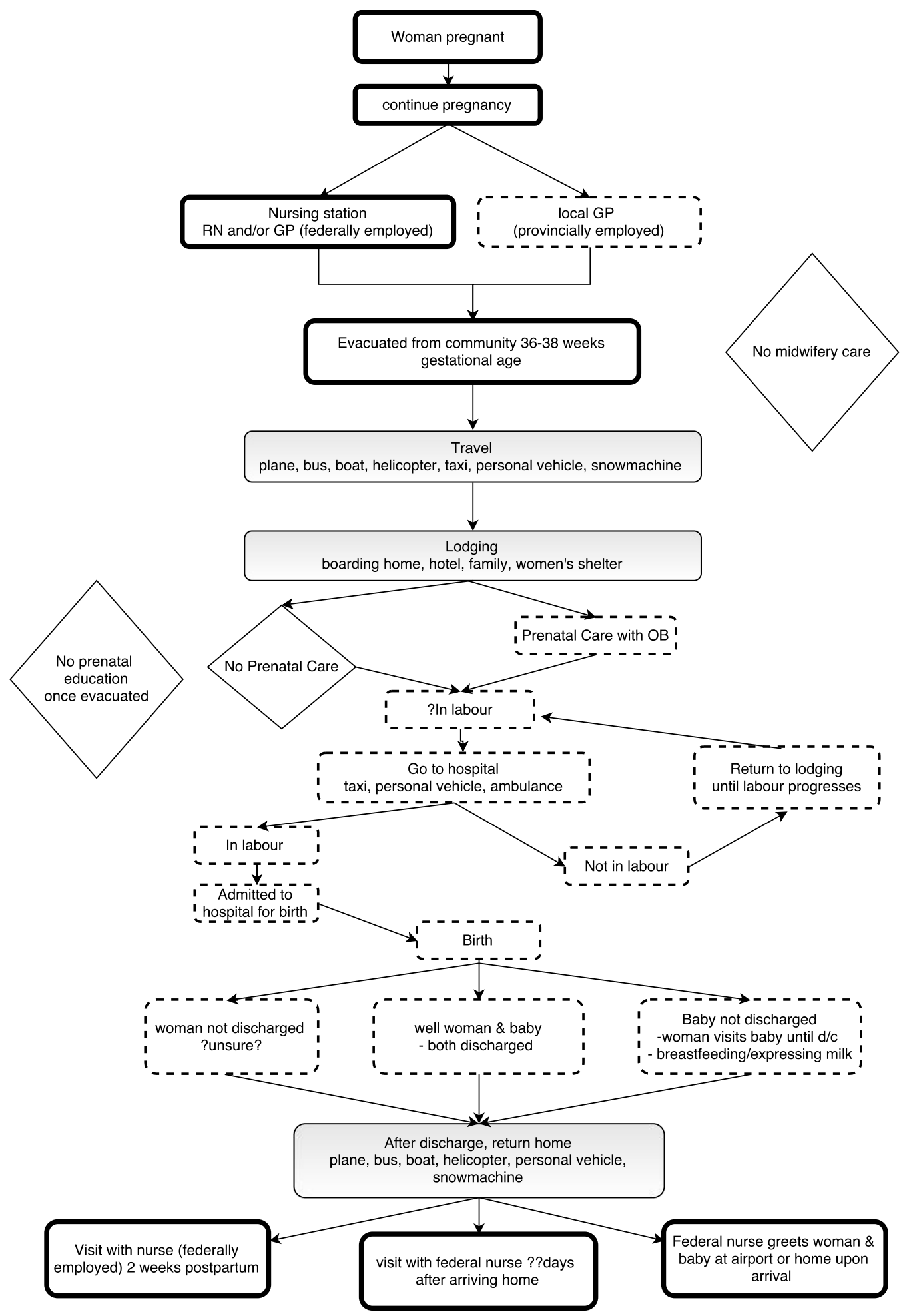

Figure 2: "Map of the evacuation policy for a First Nations woman living on reserves in Manitoba. Legend: Diamond: no public services; Heavy outline: federal services; Dotted outline: provincial health services; Thin solid line: travel” reproduced from Lawford (2017, p. 61) with permission from the author. 


\subsubsection{On science and medicine as instruments of colonial power}

Science! Medicine! still feature prominently in many health care spaces. Within the biomedical model, the client of care has been understood as a "passive and compliant 'patient' for whom treatments are prescribed"' (Adelson, 2005, p. S46). In the blanket application of the federal evacuation policy, Lawford (2017) contends that " $[\mathrm{b}] \mathrm{y}$ forcibly inserting the Euro-Canadian biomedical model of care during pregnancy and childbirth, First Nations women's bodies became one of the sites upon which Canada's colonial goals of civilization and assimilation could be realized" (p. 9).

If we are to reconceive maternal care delivery for Indigenous women in an effort to effect meaningful change, the history of Indigenous-state relations in scientific and biomedical spaces cannot be ignored. Western science and medicine - or more precisely, the imposition of gaps in scientific and medical literacy - were mobilized by settlercolonists to dissect, section, cordon off, police, and govern land, bodies, and relationships. Thus, Indigenous peoples have much cause to be cautious and even fearful of these spaces.

The work of Lawford and Giles (2012b) suggests that "First Nations' concepts of health are largely incongruent with the Euro-Canadian bio-medical model" (p. 330). Charlotte Reading (2015) describes how this model was used to spur the denigration of Indigenous peoples as wards of the state, stripping them of their right to self-govern: "Medicine was instrumental in not only shaping ideas about Indigenous peoples and their communities but in perpetuating a medical discourse that described them as inherently pathological, making the provision of health care a colonial obligation" (p. 7). Relocation under the auspices of medical treatment is a recurrent theme in the history of biomedical 
relations with Indigenous peoples (Olson, 2013); one salient example is the forced removal of Indigenous peoples, especially children, for tuberculosis treatment to 'convalesce' in urban sanatoria (Adelson, 2005; Olson, 2013). In this way, "[s]ickness facilitated the intrusion of the colonial power into the intimacies of family life and its paternalism was reproduced continuously in the highly emotional context of the medical encounter, the evacuation of the patient, and the breaking apart of families" (O'Neil and Kaufert quoted in Olson, 2013, p. 65).

\subsubsection{Risk}

From the perspective of critical medical anthropology, Rachel Olson (2013) traces the ways in which First Nations peoples are constructed as a high-risk population in maternal care discourses. This label of high-risk status is deployed by the state to justify continued intervention in the health of Indigenous populations and communities:

The emphasis on risk management is locating the body within certain spaces in order for the proper management to occur, which is manifested in two forms: first, seeking to get women into the hospitals for their labour and delivery; second, once the women are there, managing childbirth. The result of this type of management is that it transforms the mother into the object of risk that must be controlled in order to ensure the safe delivery of the baby. (Olson, 2013, p. 130)

Olson's (2013) findings articulate how the management of biomedical risk often "takes precedence" (p. 134) over mitigating social risks, such as delivering in isolation without the support of family and friends.

As part of her multi-sited ethnography, Olson (2013) attended a meeting of the Maternal and Child Health Taskforce Relocation Committee in Manitoba where it was discussed that placing evacuated mothers in boarding homes is the preferred option for 
FNIHB because it allows them to "keep track of their location" (p. 135). Olson (2013) describes how this state surveillance extends to the perinatal period with the potential intervention of Child and Family Services in issuing a "Birth Alert" (p. 136) to identify high-risk mothers whose ability to care for their newborn is compromised. One of the Knowledge Holders that I interviewed relayed similar experiences about the threat of apprehension, lending a dark irony to the discursive construction of the hospital as "the safest and best place to give birth" (Olson, 2013, p. 136).

Intimate knowledge of the space of the hospital is reserved for designated technicians:

In the discourse of returning birth to the community, the notion of the hospital is often characterised as an oppressive institution that limits choice and exposes women to unnecessary intervention; the hospital is an exclusive place, and knowledge of that place is limited to expert medical knowledge of the body and its treatment through technology. (Olson, 2013, pp. 136-137)

Olson pushes against the above framing of the hospital as a "black box" (Federal doctor quoted in Olson, 2013, p. 137) because it reserves access to knowledge and authority in this space for biomedical practitioners. In her examination of Indigenous-state relations in the governance of maternal care, Olson (2013) asked the following questions: "Why did [the state] care so much about where babies were being born? What was at stake, and for whom?" (p. 49). In her account of the integration of the Kinosao Sipi Midwifery Clinic within the local hospital serving Norway House Cree Nation, Olson (2013) points out that "the everyday practices of the medical staff at the Norway House hospital" (p. 178) were exclusionary; the access of midwives to patient records was restricted and midwives were not integrated into the call list when one of their patients presented at the hospital emergency. 
While noting these negative aspects of the biomedical model of care and its associated risk management practices, Olson is also apt not to paint biomedical interventions as unilaterally inappropriate. For example, during her fieldwork, Olson was present at a birth where an emergency Caesarian was necessary to save the life of a newborn. In an interview with a nurse, she also provides much-needed context about the perspectives of nursing station staff regarding emergency obstetrical care:

It's pretty scary to be a nurse and having a license to protect and always having sort of thoughts in the back of your head that you're going to make mistakes and if you do make a mistake, the system is not set up to support you. It's set up to punish you. So for instance if you have a breech baby unexpectedly then if you panic, or you potentially do something that could cause harm to the mum or baby, and there is an actual adverse outcome, you are the one that is going to be dealing with that issue in terms of the College of Registered Nurses and not the woman.... The onus is not on the woman at all, it is entirely on your practice. That's why we have so much fear when it comes to delivering babies in the nursing stations. (Nurse quoted in Olson, 2013, pp. 156-157, emphasis added)

Olson's work makes a strong case "for a critical re-examination of how risk is understood and managed within the process of evacuation, as well as in the process of repatriating birth back to communities" (Olson, 2013, p. 198). Risk management practices reflect the ways in which the legal obligations of the state to Indigenous peoples are perceived. While approaches to risk management that are solely or mainly biomedical may be longstanding and commonplace, they cannot account for the unique circumstances faced by Indigenous women. Lawford (2017) recounts a profoundly traumatic research finding that poignantly underscores this point: "Two health researchers, who were interviewed independently from each other, described the recruitment of evacuated pregnant women by gangs operating in Winnipeg for the purposes of selling sex" (p. 54). 
The conclusions about risk drawn from Olson's (2013) research are consistent with the work of other groups (see for example, Barclay et al., 2016; Kildea, 2006; Kornelsen \& Grzybowski, 2004, 2012; Kornelsen \& MacKie, 2013) who argue for an accounting of risk in maternal care governance that extends beyond the hegemonic biomedical paradigm. A culmination of efforts to address the unique barriers faced by Indigenous women navigating the health care system has called on decision-makers and providers to take up the concept of cultural safety (Birch, Ruttan, Muth, \& Baydala, 2009; Brown, Varcoe, \& Calam, 2011; Browne et al., 2009; Browne, Smye, \& Varcoe, 2005; de Leeuw \& Greenwood, 2017; Dyck \& Kearns, 1995; Gerlach, 2012; Hole et al., 2015). Geographers Isabel Dyck and Robin Kearns (1995) describe the evolution of cultural safety as a paradigm rooted in "Maori resistance to dominant ways of thinking, seeing and doing health care" (p. 138) to grapple with the pervasive effects of colonialism on the health and well-being of Maori peoples in Aotearoa/New Zealand. In foregrounding colonialism as an enduring determinant of ill health, “[c]ultural safety requires that the taken-for-granted character of health care interactions be unveiled and that their power-ladenness be exposed" (Dyck \& Kearns, 1995, p. 142). In the Canadian context, geographer Sarah de Leeuw and Cree scholar Margo Greenwood (2017) advance an understanding of cultural safety as practice. More than a concept, culturally safe practice is "a means of broadening and solidifying decolonizing discourses" (de Leeuw \& Greenwood, 2017, p. 146).

At the same time, I think it is important to acknowledge that the paradigm of cultural safety is a settler concept which is not immune to (neo)colonial intrusion. In fact, I would argue that this paradigm is quite susceptible to co-optation by a benevolence 
rhetoric which glorifies 'good' intentions, waffling on the cusp of settling unsettling (de Leeuw, 2017; de Leeuw, Greenwood, \& Lindsay, 2013). At the heart of this paradox is the issue of accountability; who gets to decide what does or does not constitute culturally safe practice? And, by extension, who gets to determine whether or not an attempt at decolonization is successful? Relegated to a single course in a professional curriculum or an afterthought to organizational reform, does cultural safety retain its relevance?

\subsection{Returning birth to community through the lens of (settler-colonial) policy}

Initially, the impetus for this work was anchored in an examination of the December 2010 Policy Statement, "Returning Birth to Aboriginal, Rural, and Remote Communities", of the Society of Obstetricians and Gynaecologists of Canada (SOGC, 2010): "The SOGC strongly supports and promotes the return of birth to rural and remote communities for women at low risk of complications. Training and protocols need to be established to ensure proper identification of women with low-risk pregnancies" (p. 1187, emphasis added). However, my interviews with Knowledge Holders informed me that this policy statement has not facilitated the movement to return birth to community in a tangible or meaningful way on the ground, perhaps because the ways in which the management of risk is embodied and enacted by the SOGC differ from the approaches to risk management practised by Indigenous maternal care providers.

My focus on the 2010 SOGC policy statement suggests that I may have privileged biomedical spaces of knowledge production as uniquely authoritative in the early stages of my research. It is nevertheless quite interesting from a geographical perspective for its conceptualization of rurality as "a powerful determinant of women's health" (SOGC, 2010, p. 1186), arguing that "considerations of rural maternity care services and health 
care must take both place and culture into account" (p. 1186). Curiously, the framing of the guidelines does not allow for a meaningful or productive accounting of the connections between health and "place" or "culture". This is in large part due to the conflation of 'Aboriginal', 'rural', and 'remote' within the same categorical plane. ${ }^{3}$ While the statement may be considered progressive in the sense that it acknowledges the personal and family stress and social and economic costs of birthing outside of the community, it does not interface with colonialism.

For example, the normalization of hospital deliveries is attributed to "efforts to decrease maternal mortality and morbidity in the general population" (SOGC, 2010, p. 1186). Additionally, maternal care is characterised as having suffered due to a provider shortage and service centralization. While the centralization of maternal care services is the result of a complex and multi-faceted system of structural factors, it is also acknowledged that the impacts of such unilateral policy changes can be "felt more acutely" (Kornelsen et al., 2010, p. 638) by Indigenous communities. More importantly, we saw from the work of Karen Lawford and Audrey Giles (Lawford, 2011, 2016, 2017; Lawford \& Giles, 2012b, 2012a) that in the case of Indigenous communities, the evacuation policy pre-dates funding cuts and is historically rooted in a colonial spatiolegal apparatus designed to assimilate.

A spectrum of risk epistemologies is acknowledged in the policy statement:

"Because residents of remote communities are exposed to risks those in urban centres

\footnotetext{
${ }^{3}$ It is interesting to note that the 2007 SOGC report, "A Report on Best Practices for Returning Birth to Rural and Remote Aboriginal Communities", authored by Anishinaabe midwife Carol Couchie and Sheila Sanderson, is conversely very specific in this regard; policy recommendations are tailored for contexts in "Rural and Remote Aboriginal Communities" as opposed to "Aboriginal, Rural, and Remote Communities".
} 
would find unusual or unacceptable, they often view risk from a different perspective" (SOGC, 2010, p. 1187). This is a crucial point, but it is framed in a way that invokes an 'Aboriginal/rural/remote' versus 'urban' dualism. The paragraph then goes on to say that, "Aboriginal women know there are risks attached to giving birth in the community, but for many, these risks are outweighed by the benefit of having the support of family and community members before and during the birth" (SOGC, 2010, p. 1187). Despite acknowledging a pluralistic understanding of risk, it is clear that the SOGC feels the need to qualify their endorsement of birthing in community from a biomedical risk perspective:

The SOGC believes that women with low-risk pregnancies should have the option of giving birth in their own communities but emphasizes the need to be vigilant and to encourage continuous monitoring and evaluation of outcome and safety. This will help women to feel confident in choosing to give birth in their communities. (SOGC, 2010, p. 1187, emphasis added)

In my view, the most interesting thing about the SOGC policy statement is what is missing; the policy statement officially endorses the return of birth but then qualifies this recommendation with concerns over mitigating risk and ensuring competency. What is arguably the most important aspect of returning birth to community for Indigenous peoples - the benefits of reconnecting with the land (this of course does not go far enough because this land was stolen) - is omitted. Presumably, this is because the categories of 'Aboriginal', 'rural', and 'remote' are conflated in this blanket policy statement, obfuscating the unique Indigenous context of returning birth as intrinsic to the anti-colonial goal of sovereign governance.

To insist that contemporary policy-making insufficiently accounts for the maternal care needs of Indigenous women (as well as, of course, the needs of providers 
of this care more specifically) is not to suggest that all work originating from a biomedical paradigm is inherently bad or futile. There are many Indigenous activists, academics, and other professionals educated in western scholarly traditions who do fantastic anti-colonial work. I think, however, that there is a pressing need to more fully account for the role of western scientific and medical institutions in facilitating the colonial project. When this accounting is not done, there is a real possibility of not only developing maligned, unhelpful policy but compromising the health of patients.

\subsection{Returning birth to community through the lens of decolonization}

According to Lawford and Giles (2012b), “[d]ecolonization facilitates the recognition that colonialism is embedded in Canadian health legislation and policy to influence deliberately and negatively First Nations individuals, families and communities" (p. 333). Following from this definition, what does it mean to return birth to community through the lens of decolonization? In the context of the evacuation policy, “colonialism and isolation work synergistically" (Lawford \& Giles, 2012a, p. 333) to subjugate Indigenous knowledge, a view that is shared by other researchers (see in particular Fletcher, 1994; Hiebert, 2003).

In her account of receiving teachings from Elder women in Norway House Cree Nation, Olson (2013) traces the articulation of traditional knowledge about birth through ceremony. One such practice that is revealed to her is the "tissy button" ceremony, which instructs families on how to care for the umbilical cord after birth:

Once it dries up, you don't just ... throw it away in the garbage. Our people always looked after those things. And there were ceremonies, little ceremonies, that they did for [a] girl's umbilical cord, and certain ones for boys. For us, back home [NHCN] it was for girls wrapping the umbilical cord with needles, thread, cloth, leather, and tying it in a bundle and putting it in a tree or 
stump or burying it, so that she would be able to sew, you know, to look after her family's clothing in a good way. That is what they did with the girls. With the boy's they put it in a little leather pouch with a bow and arrow or a little fishing rod ... so that he would be a good provider of food for his family. (Elder Kathy Bird quoted in Olson, 2013, p. 121)

The materiality of this practice of burying the "tissy button" is a way of honouring relationships to the land and to one another; through this ceremony, the newborn baby is connected to their Birth-Place. Community members are reminded of their obligations to take care of the Earth and to learn about "how each gender is expected to take care and provide for family" (Olson, 2013, p. 121). Conversely, Elder Kathy Bird describes how this ceremony is threatened by hospital births, where "tissy buttons" are thrown out with the garbage:

They [the grandmothers] said that the reason today our youth are so scattered and so bewildered so much ... is because a lot of those things [tissy buttons] are being discarded in the garbage. They said, "So they are looking for their tissy buttons in the garbage". That is exactly the words they use.... So the more we get back to doing this, the stronger our youth are going to be. (Elder Kathy Bird quoted in Olson, 2013, p. 122)

Based on the knowledge that "pregnancy is carrying sacred water" (Olson, 2013, p. 119), the connection between the health of the individual and the health of the place they inhabit is made explicit. This knowledge is passed on through ceremony as an affirmation that "the rights to maternal health and the rights to access to land are not mutually exclusive, but are an interconnected part of the indigenous landscape" (Olson, 2013, p. 21).

The available literature positions Indigenous midwifery as playing a vital role in the decolonization and repatriation of birth because it honours the ceremony of birth through its embodiment of traditional knowledge and cultural practices (Carroll \& 
Benoit, 2004; Couchie \& Sanderson, 2007; National Aboriginal Health Organization, 2008; Olson, 2013; Olson \& Couchie, 2013; Pauktuutit: Inuit Women's Association of Canada, 1995; Skye, 2010; Van Wagner et al., 2007). Lawford and Giles (2012b) assert that returning birth to community "would require a non-hierarchical team approach" ( $p$. 337); possible barriers to implementing such multi-stakeholder care teams include "remuneration between providers, restrictive scopes of practices defined by legislation, and limited understanding and appreciation of the skill sets held by those in various health care professions involved in maternity services" (p. 337). Lawford and Giles (2012b) note the reluctance of the federal government "to acknowledge the expertise and quality of care of midwifery" (p. 338) within the formal spectrum of maternal care provision.

Much of the research on maternal care delivery for First Nations women has focused on communities in Manitoba (Hiebert, 2003; Kaufert \& O’Neil, 1990; Lawford, 2011, 2017; Olson, 2013) where efforts to mainstream Indigenous midwifery services have encountered significant challenges. The kanaci otinawawasowin Baccalaureate Program, an innovative Aboriginal midwifery program affiliated with the University College of the North, was stopped in 2014 and amalgamated into a joint program with the University of Manitoba (Bellrichard, 2014; 'UCN Midwifery (KOBP) 2011-2014 [archived]', n.d.). The funding for this joint program was then cut in 2016, leaving the province without a midwifery education program (CBC News, 2016; Ingram, 2016). Next, we will consider the unique context surrounding the movement to repatriate birth in Ontario and Québec, where several midwifery education programs and Indigenous midwifery practices are currently operating. 


\subsubsection{Midwifery legislation in Ontario and Québec}

The Indigenous maternal care landscape was substantively impacted by the legalization of midwifery in Ontario on December 31, 1993 (Nestel, 2000). Through this process, midwifery became "a state-regulated and state-funded health profession" (Nestel, 2000, p. 187). However, clauses were written into the Midwifery Act, 1991 and the Regulated Health Professions Act, 1991 recognizing the extralegal status of Aboriginal midwifery. Thus, an important outcome of legislation was that it created the distinct titles of Registered Midwife (RM) and Aboriginal Midwife (AM). A similar qualifier was included in the Midwives Act when midwifery became legalized in Québec in 1999. The relevant excerpts of these pieces of legislation are provided in Appendix B of this thesis and interview data presented in Chapter 5 will speak to the implications of the recognition of extralegal status.

Provincial regulatory bodies, whose mission is to serve the public, implement the pieces of legislation listed above; the College of Midwives of Ontario (CMO) regulates the profession of midwifery in accordance with the Midwifery Act, 1991 and Regulated Health Professions Act, 1991 and the Ordre des sages-femmes du Québec (OSFQ) regulates the profession of midwifery in accordance with the Midwives Act. Only practitioners who are registered members of their respective regulatory body are legally permitted to provide midwifery services in that province and to use the RM title. To be eligible for registration with the $\mathrm{CMO}$, applicants must have completed either the Midwifery Education Program, which is a four-year baccalaureate degree offered at Ryerson University, Laurentian University, and McMaster University or, alternatively, if they have international credentials, the International Midwifery Pre-Registration 
Program, which is a one-year bridging program at Ryerson University (College of Midwives of Ontario, 2018). Eligibility for registration with the OSFQ also typically requires a four-year baccalaureate degree in midwifery offered by the Université du Québec à Trois-Rivières (Ordre des sage-femmes du Québec, n.d.-b), with a mutual recognition arrangement available for midwives educated in France (Ordre des sagefemmes du Québec, n.d.-a).

As was mentioned previously, Indigenous midwifery practitioners can be conferred extralegal status in lieu of registration to provide midwifery services and not be in violation of the law. In Ontario, this is in accordance with section 8(3) of the Midwifery Act, 1991: "Exception for aboriginal midwives" (Midwifery Act, 1991, SO 1991, c 31, s 8(3); see Appendix B.1) and section 35(1) of the Regulated Health Professions Act, 1991: "Exemption, aboriginal healers and midwives" (Regulated Health Professions Act, 1991, SO 1991, c 18, s 35(1); see Appendix B.2). Together, these pieces of legislation permit "an aboriginal person who provides traditional midwifery services" (Regulated Health Professions Act, 1991, SO 1991, c 18, s 35(3)) to practise under the AM title. In Québec, extralegal status can be conferred in accordance with section 12(2) of the Midwives Act, under "Illegal Practice" (Midwives Act, CQLR 2018, c S-0.1, s 12(2); see Appendix B.3) which states that an agreement can be reached between the government and a "Native group" to allow a "Native person who is not a member of the order [OSFQ]" (Midwives Act, CQLR 2018, c S-0.1, s 12(2)) to provide midwifery services $^{4}$. In summary, Indigenous midwifery practitioners have two options to practise

\footnotetext{
${ }^{4}$ This clause was necessary to reflect the special agreement already in place between the province of Québec and Inuit midwives in the Nunavik region when this legislation was drafted in 1999; the first Inuit maternity in the Nunavik region opened in Puvirnituq in 1986, with subsequent maternity openings in
} 
legally; they can pursue one of the baccalaureate degree programs that makes them eligible for registration or seek extralegal recognition, through the Aboriginal midwifery clauses in the Ontario midwifery legislation or on a case-by-case basis through a special agreement between their community and the Government of Québec.

Nestel (2000) cautions that despite mainstream approbation of midwifery legalization as a transformational feminist achievement, "the benefits resulting from the legalization of midwifery have been very unevenly distributed" (p. 187). In her study of the underrepresentation of immigrant midwives of colour in Ontario, Nestel (2006) argues that the process of legislation served to advance the professional legitimization of white, affluent midwives at the same time that it marginalized immigrant midwives of colour:

The assumption that guided Ontario midwifery was that women were oppressed in similar ways and that race, class, and sexuality only complicated a fundamental gender oppression. Such a stance does not require that relations of domination between women be taken into account, and thus a path is cleared for racial domination to be re-enacted within a feminist context. (Nestel, 2006 , p. 5, emphasis in the original)

Nestel's (2006) analysis is particularly interesting from a geographical perspective because she attends to the spatialization of power. Her account of the development of the Aboriginal midwifery clauses is tangential to her main argument albeit still relevant for our present discussion, particularly because her work is framed using a critical anti-racist methodology.

Inukjuak, Salluit, and Ungava Bay (Ordre des sage-femmes du Québec, n.d.-c). Since the birth centre in Puvirnituq pre-dated legalization, the Illegal Practice clause "was intended to allow arrangements for Aboriginal communities to be negotiated" (Van Wagner et al., 2007, p. 389). 
According to Nestel (2006), Indigenous midwives rallied against the legislation of their profession. Their spokesperson was a Métis woman named Jesse Russell who was "the only racialized minority person" (Nestel, 2006, p. 48) to serve on the Interim Regulatory Council on Midwifery (IRCM). Russell proposed a mandate for an equity committee to advise the IRCM, which subsequently became a platform for First Nations voices $^{5}$, which overwhelmingly opposed the legislation of Indigenous midwifery practice. It was widely perceived that "exemption was the very condition upon which Aboriginal midwifery and other forms of traditional healing might be protected and expanded" (Couchie and Nabigon paraphrased in Nestel, 2006, p. 46, emphasis added). These positions are epitomized in an August 1991 statement by the Ontario Native Women's Association:

It is obviously evident the social issues and conditions in Native Communities ... are the result of Natives not being in the control of their affairs ... Again it seems that the same mistakes are reoccurring with the midwifery issue. In the report that was prepared by the task force [TFIMO], it is clear that once again, government agencies are assuming control of issues that clearly affect Native people and Native communities. The task force has only suggested that Native people ... will receive special treatments such as flexible admission policies. This clearly is not enough. Native people ultimately have to be in control [of] their own affairs to improve the social issues ... It would be counterproductive to continue with any strategies which involve Natives and Native communities without the involvement of Native people. (Ontario Native Women's Association quoted in Nestel, 2006, pp. 45-46)

In response to this outcry of opposition, representatives from the Minister of Health met with First Nations stakeholders in October 1991 and agreed to "exempt Aboriginal

\footnotetext{
${ }^{5}$ Nestel (2006) brings up the equity committee because she argues that it "inoculated" (p. 44) the IRCM from accusations of exclusion and discrimination. Nevertheless, her historical account of the development of the Exemption Clause is remarkably thorough.
} 
midwives and healers" (Nestel, 2006, p. 46) from the Regulated Health Professions Act, 1991. A subsequent statement by the Ontario Native Women's Association in July 1993, however, expressed concerns that the Bachelor of Midwifery degree program of the Michener Institute at Ryerson University did not reflect Aboriginal needs and the markedly low admission numbers of Aboriginal candidates into the program was unacceptable. In her analysis of the engagement of the IRCM with Aboriginal midwifery, Nestel suggests that the IRCM co-opted the equity committee to position themselves as benevolent actors:

...it is safer for white groups making claims to multicultural sensitivity to promote the equality of those who offer no imminent threat to their dominance than to champion those whose threat is more immediate. In distinct contrast to numerically significant, urban-dwelling immigrant midwives of colour, the few Aboriginal midwives practising in geographical locations outside the major Ontario cities where midwifery activity was centred hardly threatened to overtake the midwifery movement. They often pursued parallel, rather than competing, routes to midwifery practice, routes that constituted only a minimal threat to the Ontario midwifery project. (Nestel, 2006, pp. 47-48)

The legalization of midwifery in Québec in 1999 also implicated the spatio-legal identities of Inuit midwives working in the Inuulitsivik midwifery service and education program in the Nunavik region. Collective action and activism on the part of Inuit women and local government officials led to the opening of the first birth center in this region in Puvirnituq in 1986; therefore, the Inuulitsivik midwifery service and education program "predate[d] the legal recognition of midwifery in Quebec by more than a decade" (Van Wagner et al., 2007, p. 389). The passing of the Midwives Act in June of 1999, "recognized and registered the currently practicing Nunavik midwives, but did not provide for continuing recognition of graduates" (Van Wagner et al., 2007, p. 389). 
Despite the documented success of the Puvirnituq program (Fletcher, 1994), including its evaluation as part of a provincially-funded pilot study (Van Wagner et al., 2007), the baccalaureate program at the Université du Québec à Trois-Rivières was the only recognized pathway of midwifery education when the Midwives Act came into effect in 1999 (Ordre des sage-femmes du Québec, n.d.-c). This position was rescinded in 2008 with "the insertion of the Regulation respecting the standards for equivalence of diplomas and training in the purpose of issuing a permit by the Ordre des sages-femmes du Québec" granting Nunavik midwives "regular licenses, without territorial restrictions" (Ordre des sage-femmes du Québec, n.d.-c).

\subsubsection{Current political landscape}

There were two policy decisions arising from the Trudeau government's 2017 federal budget (Department of Finance Canada, 2017) that are particularly salient for our present discussion about returning birth to community. In Budget 2017 (Department of Finance Canada, 2017), the Trudeau government allocated a total of $\$ 828.2$ million to invest in First Nations and Inuit health over five years, from 2017-2018 onward (p. 164). In April of 2017, Health Minister Jane Philpott announced that Health Canada would begin funding non-medical escorts for First Nations and Inuit women who are being evacuated to give birth (Kirkup, 2017). Previously, coverage for non-medical escorts was only available under exceptional circumstances (see Appendix C.1), as outlined in the Medical Transportation Policy Framework under the Non-Insured Health Benefits (NIHB) Program of the First Nations and Inuit Health Branch (FNIHB) of Health Canada (First Nations and Inuit Health Branch, Health Canada, 2005). 
At the time of the Minister's announcement, there were reports of confusion regarding how the policy change would be implemented (Bird, 2017). An interim version of the Medical Transportation Policy Framework came into effect in January of 2018 to reflect the preliminary recommendations of a Joint Review of the NIHB program by FNIHB and the Assembly of First Nations (First Nations and Inuit Health Branch, Health Canada, 2018); the client escort policy has been amended to include standard coverage for non-medical escorts for pregnant First Nations and Inuit women who are evacuated for maternal care (see Appendix C.2). The cost of implementing the policy change for the 2017-2018 year was estimated at \$22 million (Kirkup, 2017) and will come from the \$305 million investment in the NIHB Program (Department of Finance Canada, 2017, p. 164).

The second policy decision that is relevant here is a funding pledge by Minister Philpott to support midwifery in Indigenous communities. Of the $\$ 828.2$ million allocated for First Nations and Inuit health in Budget 2017, \$83.2 million was slated for maternal and child health (Department of Finance Canada, 2017, p. 164). In June 2017, Minister Philpott announced that \$6 million would be pledged specifically "to support culturally-safe midwifery in communities" (Health Canada, 2017). The official statements which accompanied the news release were conciliatory in tone. Minister Philpott stated that "it is vital to support midwifery care which will bring traditional birthing practices back to these communities, better support mothers and their babies and build strong families" (Health Minister Jane Philpott quoted in Health Canada, 2017). Minister of Indigenous and Northern Affairs Carolyn Bennett added:

Midwives play an essential role in improving the quality of maternal-child health in communities around the world. As 
Minister of Indigenous and Northern Affairs and as a former family physician who had the privilege of attending over 2000 births, often with the support and wise counsel of midwives, I want to express my sincere appreciation for your invaluable work and for all the work that we will get to do together in the future. (Indigenous and Northern Affairs Minister Carolyn Bennett quoted in Health Canada, 2017)

These two policy decisions - (1) routine coverage for non-medical escorts to accompany women evacuated for maternal care and (2) \$6 million over five years for culturally-safe midwifery - are important and unprecedented investments in First Nations and Inuit health. But key questions remain with respect to how the policy changes will be implemented and whether these investments signal a restructuring of Indigenous-state relations. Interview data presented in Chapter 5 will lend nuance to this discussion. 


\section{Chapter: Gestation}

Heeding the advice of Indigenous scholars who warn against the (re)production of epistemic violence ${ }^{6}$ (Hunt, 2014a; Todd, 2016), I have tried to be conscious of my citational praxis in this research. To build the backbone of this thesis, I have sought to educate myself primarily through the work of Indigenous theorists (working in and outside of the academy) who have articulated the connections between historical/colonial and contemporary/(neo)colonial dis-place-ment. Because citational praxis in the academy has historically silenced Indigenous voices (Hunt in Deerchild, 2018; L. B. Simpson, 2017; Todd, 2016), positioning Indigenous lived experience as the most important and relevant body of knowledge to inform research with Indigenous peoples is an attempt to reconfigure this power imbalance. At the same time, I acknowledge that there is something about this practice which seems too categorically neat. Surficial engagements with settler-colonialism which are thinly veiled as attempts at decolonization threaten the (re)production of (neo)colonial violence (de Leeuw et al., 2013). I relate my understanding of anti-colonial scholarship to the assertion that " $[\mathrm{u}] \mathrm{nsettling}$ settler colonialism can never be instrumental, nor can it be finished" (de Leeuw et al., 2013, p. 391).

The objective of this chapter is to articulate how colonialism persists in contemporary settler-colonial society; how it is circulated through structural violence in an attempt to delegitimize Feminine expressions of agency (Horn-Miller, 2016; Watts, 2013) and how it is masked by a politics of recognition (Coulthard, 2007, 2014; A.

\footnotetext{
${ }^{6}$ Epistemic violence is defined by Sarah Hunt (2014a) as "the work of discourse in creating and sustaining boundaries around what is considered real and, by extension, what is unable to be seen as real (or to be seen at all)" (p. 29).
} 
Simpson, 2014, 2017). Alternatives to recognition-based paradigms of governance challenge the foundations of colonial architecture and open up space for the reclamation of sovereign territory (Coulthard, 2007, 2014; Daigle, 2016; Hunt, 2014b; A. Simpson, 2014, 2017; L. B. Simpson, 2017). Colonization is enacted through the theft of territory and relationships; ongoing dis-place-ment undergirds the present-day health inequities which face Indigenous peoples in this country. Given these linkages, theorizing geographically can be mobilized as a valuable lens through which to consider the health inequities experienced by many Indigenous peoples, in Canada and in other settlercolonial societies (de Leeuw, 2015, 2017).

This chapter will define and contextualize the core theoretical concepts that will inform the analysis of my interview data. These core theoretical concepts are the following: recognition and grounded normativity (Coulthard, 2007, 2014); refusal (A. Simpson, 2014, 2017) and nested sovereignty (Alfred, 1995; A. Simpson, 2014); legal pluralism and colonialscape (Hunt, 2014b), and spatio-legal identity (Daigle, 2016; Hunt, 2014b).

\subsection{Relational ways of being, knowing, and healing}

Women are the first environment. We are an embodiment of our Mother Earth. From the bodies of women flows the relationship of the generations both to society and the natural world. With our bodies we nourish, sustain and create connected relationships and interdependence. In this way the Earth is our mother, our ancestors said. In this way, we as women are earth. (Elder Mohawk midwife Katsi Cook quoted in Our Bodies, Ourselves: 'Katsi Cook', 2018)

Indigenous ways of being and knowing celebrate the creation power of the earth and the feminine (Horn-Miller, 2016; Lawford \& Giles, 2012a; L. B. Simpson, 2017; Watts, 2013). The systematic targeting of Indigenous land and Indigenous women as sites 
of colonial violence is a deliberate and malicious attempt to dispossess Indigenous peoples of their agency (Horn-Miller, 2016; Kahealani Pacheco \& Konsmo, 2016; Lawford \& Giles, 2012a; L. B. Simpson, 2017; Watts, 2013). Kanien'kehá:ka scholar Kahente Horn-Miller (2016) has referred to this in her writing as "the social and political distortion of the role of Indigenous women" (p. 34). Drawing on examples from the Haudenosaunee Confederacy, Horn-Miller's work shows that Indigenous women have been "silenced and legislated away" (p. 34) in the Euro-North American historical record. In her telling of Sky Woman's story, the ceremony of birth - and the vital roles of women in social and political reproduction in the broadest sense - is positioned as integral to the fabric of community life and a source of healing: "Just as the Sky Woman story is a metaphor for Kanien'kehá:ka women, Kanien'kehá:ka women are a metaphor for Mother Earth, which provides everything necessary for survival. Through our ability to procreate, we represent the power of creation" (p. 36). A decisive rebuke of the subjugated gender roles of western patriarchy, Horn-Miller's concept of “Indigenous womanism" (p. 35) advances a worldview "in which traditional roles of women are empowered and valued"' (p. 35).

Horn-Miller (2016) weaves the everyday lived experience of women in her community into her telling of Sky Woman's story to reflect the ongoing fluidity of distortion and healing: "Every woman's story offers a clear connection, a path to the Sky Road where our Grandmother, Sky Woman, lives and watches over us. It is through this story that we reconnect with our ancestors in the Sky World" (p. 36). In Horn-Miller's (2016) writing we are presented with an understanding of health that is fluid and cyclical: "As Sky Woman watches out for the cycles of birth, life, death, and rebirth, she ensures 
that we remain true to our feminine essence and integrate distortion and corruption into growth and healing" (p. 37).

Vanessa Watts (2013), who is a scholar of Anishinaabe and Haudenosaunee ancestry, also problematizes theorizations of ontology and epistemology in the (neo)colonial. Watts (2013) articulates divergences in the framing of agency through her conceptualization of "Place-Thought", informed by Haudenosaunee and Anishinaabe cosmologies:

Place-Thought is the non-distinctive space where place and thought were never separated because they never could or can be separated. Place-Thought is based upon the premise that land is alive and thinking and that humans and non-humans derive agency through the extensions of these thoughts. (p. 21)

Since Euro-Western theoretical frameworks "exist in the abstract" (Watts, 2013, p. 22), a distinction is made between the "epistemological/theoretical" and the “ontological/praxis" (p. 22). This distinction is incongruent with Place-Thought, where theory is embodied as “a literal and animate extension of Sky Woman's and First Woman's thoughts" (p. 22):

When Sky Woman falls from the sky and lies on the back of a turtle, she is not only able to create land but becomes territory itself. Therefore, Place-Thought is an extension of her circumstance, desire, and communication with the water and animals - her agency. Through this communication she is able to become the basis by which all future societies will be built upon land. (Watts, 2013, p. 23)

Colonial dis-place-ment severs the relationship between Indigenous peoples and land and is thus a desecration of Place-Thought; that is, colonization is not simply a restructuring of relations but an attempt to eradicate agency. It undermines the inherent agency of the more-than-human, thereby compromising the agency of humans who 
depend on relations with the more-than-human in order to be self-determining: "The female earth or the feminine is intrinsically tied to the notion of sovereignty and how humans interact with non-human creatures in the formation of governance" (Watts, 2013, p. 27). Colonialism deprives Indigenous peoples of the capacity to communicate with and fulfill their obligations to the land and the more-than-human.

A parallel understanding of the consequences of dis-place-ment is found in the work of Walters et al. (2011):

While cognitive processes are important in the articulation of ideas, it does not take a human mind to make meaning because meanings have already been set by ancestral knowledge. The meanings generated by the mind are instead seen as offerings of gratitude back to the ancestors for the wisdoms and lessons of place they have helped us discover, but which were already there. In essence, we are receptors accepting what is revealed by place. Thus, place is not a cultural product: rather, cultural products are defined by their relationship with and to place. (p. 167)

This relational understanding of agency and well-being is consistent with the communitybased work of Adelson (2005) which states that, "[w]ellness involves the physical, emotional, mental and spiritual aspects of a person and always in connection to his or her family and community" (Adelson, 2005, p. S46, emphasis added). Karen Lawford and Audrey Giles (2012b) have called for a sustained and meaningful engagement with First Nations epistemologies in their investigation of the federal evacuation policy; policymaking with/serving Indigenous peoples must be informed by Indigenous ways of being and knowing in the world. 


\subsection{Reconciliation through recognition? How a relationship based on recognition hides the truth and fails to reconcile}

Drawing substantively on the work of Frantz Fanon, Coulthard $(2007,2014)$ has argued that a 'politics of recognition' - typified by the post- $1969^{7}$ discursive endorsement of a nation-to-nation dialogue characterising Indigenous-state relations - threatens to entrench the very dimensions of colonialism that anti-colonial resistance seeks to dismantle and overthrow. Enacted by "the delegation of land, capital and political power from the state to Indigenous communities through land claims, economic development initiatives, and self-government processes" (Coulthard, 2007, p. 438, emphasis added), 'recognition' leaves the colonial architecture intact, even confers protection to pathways of ongoing violence.

To explain how this is the case, Coulthard revisits Fanon's assertion that the economic and political subjugation of 'colonized' peoples by colonialism is maintained through “psycho-affective attachments" (Fanon, paraphrased in Coulthard, 2007, p. 439) to the 'colonized identity'; in other words, colonialism becomes internalized, assuages the fire of revolution by producing "subjects of empire" (Coulthard, 2007, p. 439), and is thus perpetuated. Because it falls short of disturbing these "interrelated structural and psycho-affective dimensions" (Coulthard, 2007, p. 439), a politics of recognition cannot be mobilized to support anti-colonial resistance. Anti-colonial resistance must challenge both the structural violence of capitalist extraction and exploitation and the psychoaffective violence of embodied historical trauma (Coulthard, 2007, 2014).

\footnotetext{
${ }^{7}$ Coulthard (2014) situates the "hegemonization of the recognition paradigm" (p. 4) as beginning with the 1969 Statement of the Government of Canada on Indian Policy or 'White Paper' (pp. 3-6).
} 
In an interesting paradox, our contemporary liberal politics of recognition - which Coulthard frames as a bulwark against anti-colonial resistance - derives its warrant from philosophers like Charles Taylor, whose work in this regard also relies on the anticolonial writings of Fanon (Coulthard, 2007). So how do Taylor and Coulthard, who both validate their analyses in dialoguing with Fanon, arrive at diametric conclusions? Coulthard qualifies his interpretation of Fanon's appraisal of Hegel's 'master/slave dialectic' to arrive at the source of the incompatibility.

Coulthard (2007) reiterates that according to Hegel, human subjectivity is relationally constructed through recognizing and being recognized. Human freedom is realized through recognizing oneself as self-determining and also by being recognized by another self-consciousness that is self-determining; this parameterises recognition in terms of 'reciprocity' (Coulthard, 2007). In Hegel's classic example of the master/slave dialectic, the lack of self-determination afforded by the slave's position disallows the master of the possibility of freedom, and through their "transformative labour" (Coulthard, 2007, p. 440), the slave can become free.

In his work, Taylor recapitulates these ideas by contending that "nonrecognition or misrecognition can inflict harm, can be a form of oppression, imprisoning one in a false, distorted, and reduced mode of being" (Taylor, quoted in Coulthard, 2007, p. 442), and advances recognition as an anti-oppressive and emancipatory antidote (Coulthard, 2007). But as Coulthard (2007) deftly points out, "grant[ing]" (Taylor, quoted in Coulthard, 2007, p. 442) or "accord[ing]" (Taylor, quoted in Coulthard, 2007, p. 442) recognition as Taylor suggests does not grapple with the apparatus of capitalism nor the 
apparatus of psycho-affective internalization. And in Coulthard's reading, Fanon himself foreshadows this conundrum.

Fanon argued that in contemporary settings of colonialism where political independence is superimposed, "negotiated, achieved through constitutional amendment, or simply 'declared' by the settler-state" (Coulthard, 2007, p. 448), the colonized do not "struggle" (p. 448) for their freedom (recall the transformative labour of the slave), and so are not truly free. What is more, the (un)colonized begin to identify with the emancipatory discourse that is bestowed upon them, precipitating their continued enslavement by "fail[ing] to reestablish themselves as truly self-determining: that is, as the creators of the terms and values by which they are to be recognized" (Fanon, paraphrased in Coulthard, 2007, p. 450, emphasis added).

The final and crucial insight that Coulthard references from Fanon is that the colonial context does not meet the condition of Hegelian reciprocity; when the master is "the colonial state and state society" (Coulthard, 2007, p. 451), the colonizer does not seek recognition from the colonized. For Fanon, the path forward was "self-affirmation" (Fanon in Coulthard, 2007, p. 453), a form of transformative labour "on [one's] own terms and in accordance with [one's] own values," (Fanon, paraphrased in Coulthard, 2007 , p. 454) purportedly attainable through violent struggle. For Coulthard, the answer lies in "critical individual and collective self-recognition" (Coulthard, 2007, p. 456) moving away from the politics of recognition and toward "on-the-ground practices of freedom" (p. 456). In essence, this is affirmation outside of the colonial architecture, where the 'colonized' no longer seek recognition from the 'colonizer', "critically revaluating, reconstructing and redeploying culture and tradition in ways that seek to 
prefigure, alongside those with similar ethical commitments, a radical alternative to the

structural and psycho-affective facets of colonial domination" (Coulthard, 2007, p. 456).

Coulthard elaborates on this "radical alternative" in Red Skin, White Masks (2014):

Stated bluntly, the theory and practice of Indigenous

anticolonialism, including Indigenous anticapitalism, is best

understood as a struggle primarily inspired by and oriented

around the question of land - a struggle not only for land in the material sense, but also deeply informed by what the land as system of reciprocal relations and obligations can teach us about living our lives in relation to one another and the natural world in nondominating and nonexploitative terms - and less around our emergent status as "rightless proletarians." I call this place-based foundation of Indigenous decolonial thought and practice grounded normativity, by which I mean the modalities of landconnected practices and longstanding experiential knowledge that inform and structure our ethical engagements with the world and our relationships with human and nonhuman others over time. (Coulthard, 2014, p. 13, emphasis in the original)

Coulthard's reading of Fanon foreshadows the limits to the possibility of freedom afforded by the engine of state recognition. In the historical analysis of the spatio-legal dimensions of the Indigenous midwifery landscape discussed in the previous chapter, we saw that both the preclusion and conferral of state recognition had a material effect on the everyday practice of Indigenous midwives.

\subsubsection{Audra Simpson on 'refusal' and 'nested sovereignty'}

Mohawk scholar Audra Simpson $(2014,2017)$ posits an engine of 'refusal' as an alternative to 'recognition':

Refusal comes with the requirement of having one's political sovereignty acknowledged and upheld, and raises the question of legitimacy for those who are usually in the position of recognizing: What is their authority to do so? Where does it come from? Who are they to do so? (A. Simpson, 2014, p. 11, emphasis in the original) 
One example that informs Simpson's rich analysis highlights the complexity of the issues at hand. She references the valiant efforts of Haudenosaunee chief Deskaheh to solicit international recognition from the League of Nations for the Six Nations Confederacy in an act of refusal of federal assimilation:

We refused to take more abuse and disrespect from Canada - they had dismantled the traditional government at Six Nations reserve and seized the wampum belts that encode our governance system - so we went International. What then does one do? If one knows law has been contravened (yours or theirs) and you know you stand outside of law but law tries to capture you through citizenship. Do you then consent to notions of 'just law', of 'just governance'? Is this possible in an ongoing context of theft's disavowal not to mention its ongoing life? While there is the lawful theft of your governance system, your land to ponder, to live through? (A. Simpson, 2017, p. 9)

As Simpson $(2014,2017)$ frames her own ethnographic practice as an act of refusal, we are reminded that research can and, in some cases, should be reconstituted as an act of "turning away" (A. Simpson, 2017, p. 12). Another critical insight is Simpson's (2014) assertion that "sovereignty may exist within sovereignty" (p. 10), drawing on the term "nested sovereignty" (Alfred, 1995; A. Simpson, 2014, p. 11) to describe this process.

This theory of nested sovereignty seems counterintuitive; if an entity is recognized as sovereign, it immediately calls into question the legitimacy of sovereign claims by other entities to the same territory. Explaining how this can be the case in settler-colonial geographies, Simpson (2014) adds, “[1]ike Indigenous bodies, Indigenous sovereignties and Indigenous political orders prevail within and apart from settler governance" (p. 11, emphasis added). Nested sovereignty is a useful analytical tool for thinking through how pregnant Indigenous women and Indigenous maternal care 
providers must navigate multiple jurisdictions of layered spatio-legal regimes that are rarely, if ever, coordinated.

\section{3 "Activating place" in health research: Theorizing legal geographies of Indigenous maternal care governance}

Geography continues to be complicit in the (re)production of (neo)colonial relations (de Leeuw, 2016, 2017; Hunt, 2014a, 2014b). In her work, Hunt (2014b) has described colonialism as "a process of creating spaces which were orderly, easily commodified and clearly defined through the imposition of Western socio-legal property regimes" (p. 62). There is no denying that a geographical toolkit was used to advance the colonial project. The reserve system was thrust upon Indigenous peoples in Canada with the Indian Act of 1876 to deny their physical and political mobility (Reading, 2015). Through the production of reserve spaces, "native people became trespassers in their own territories" (Hunt, 2014b, p. 60); the implementation of the reserve system served "to empty space of Indigenous tenure" (p. 61). Resource allocation was controlled by settlers and wealth diverted to other settlers, land use changes rendered traditional lands no longer suitable to support subsistence harvesting, and what limited water remained was often contaminated by colonial industry (Reading, 2015).

In light of this dark history, a sustained engagement with anti-colonial praxis is required. Efforts to decolonize the discipline must position Indigenous ways of being and knowing as legitimate on their own terms instead of pigeon-holing them within networks of western intellectual referents (Hunt, 2014a; Todd, 2016). To this effect, Mushkegowuk Cree geographer Michelle Daigle (2016) engages with the alternative politics envisioned

\footnotetext{
${ }^{8}$ This is in reference to Sarah de Leeuw's (2015) chapter: “Activating Place: Geography as a Determinant of Indigenous Peoples' Health and Well-being"
} 
by Coulthard $(2007,2014)$ and Simpson $(2014,2017)$ to demonstrate how we might attend to "everyday relational geographies of resurgence" (Daigle, 2016, p. 261). Daigle draws on her own and fellow community members' lived experiences of the Omushkegowuk Cree law of awawanenitakik in her community of Achikamaw (Constance Lake First Nation). In depicting ceremonial regeneration at the scale of her home community, Daigle reveals a system of governance "mobilized through kinship relations" (p. 261) that transcends colonial boundaries.

The role of ceremony is to articulate responsibilities to kin, among them the land and the plant and animal relatives (Daigle, 2016). Generations of colonial intervention had removed ceremony from Achikamaw. Ceremonial regeneration was led by one community member who sought to re-build relations with Anishinaabe and Cree kin from other communities. This process of entering into renewed relationship with muskeg lands transcended "colonial spatio-legal identities" (Daigle, 2016, p. 267) of reserve and treaty territory.

In the way that Daigle (2016) relates to the land as kin, we are introduced to a conceptualization of "land as an animate being imbued with political agency" (p. 268):

In this sense, it is not just place that is endemic to awawanenitakik, but land as an animate being, a relative, a food provider, and a teacher of law and governance to whom we are accountable. It is through this accountability to land and to our human relatives, that Cree self-determination is lived and mobilized from the place of our muskeg lands as opposed to our reserves and treaty territories. Further, awawanenitakik travels with us as it guides the way we approach relationships with other human and non-human kin beyond our muskeg lands. (Daigle, 2016, p. 266)

In this vein, for Kwakwaka'wakw geographer Sarah Hunt and her non-Indigenous colleague Cindy Holmes (2015), writing everyday decolonization is to "acknowledge that 
Indigenous peoples' resistance to colonialism has unfolded in daily acts of embodying and living Indigeneity, honoring longstanding relationships with the land and with one another" (p. 157). The everyday is recast in a language of activism and resistance through an examination of "intimate geographies of allyship" (Hunt \& Holmes, 2015, p. 157).

Hunt (2014b) turns to this level of intimate relationships to scale her research on the normalization of colonial violence. She argues that the disproportionate level of violence suffered by Indigenous peoples hinges on the construction of the normalizing categories of 'Indian' versus 'settler' (Hunt, 2014b). This colonial imaginary is spatialized through the materiality of Indian reserves "as spaces of assumed violence, while 'Indians', inherently 'of the reserve', are produced as subjects of this naturalized violence" (Hunt, 2014b, p. 71). If the law has rendered Indigenous peoples 'Indians' and thus "subhuman subjects of naturalized violence" (Hunt, 2014b, p. 20), then is it possible to arrive at justice using the vehicle of state law?

Taking the position that Canada is a legally pluralistic state, Hunt argues that Indigenous peoples are legal actors navigating and forming relationships to multiple legal orders. The intimacy of these everyday relationships to space and law is constitutive of identity. She cautions that seeking legal recognition for violent acts often (re)produces or further entrenches violence, but the lens of legal pluralism can redefine these terms of recognition: "The activation of more than one legal order within a given space and time raises the possibility that a particular legal subject or issue can be recognized within more than one system of law" (Hunt, 2014b, p. 15).

Hunt explains that in western spatio-legal relations, the rule of law is seen as separate from the "materiality" (Hunt, 2014b, p. 17) of everyday life. In this way, the 
naturalization of knowledge categories is constitutive of hegemonic power relations:

"Law in general, and property in particular, derive their power from the degree to which they appear to stand as a universal abstraction, set apart from the messy realities of local particularities" (Blomley quoted in Hunt, 2014b, p. 17). On the other hand, many Indigenous spatio-legal systems refute this abstraction of the messiness of everyday life. Hunt (2014b) refers to this process as "categorical dehumanization" (p. 20):

The Canadian legal system has been used to entrench colonial power relations between Indigenous peoples and the Canadian government, and has shaped all aspects of Indigenous peoples lives. So while Canadians largely take for granted the neutrality of Canadian law and governance, Indigenous people's experiences reflect the culturally- specific, power-laden nature of law. (Hunt, 2014b, p. 67)

Reflecting on the work of critical spatial theorists (Pratt, 2005; Razack, 2002)

who engage with Giorgio Agamben's work on exception (see for e.g. Agamben, 2005), Hunt argues that the space of the reserve can be mobilized discursively to render Indigenous peoples reserved subjects anywhere they go: "Reserves are spaces of exception and anywhere can become the reserve" (Hunt, 2014b, p. 76). She invokes the geographical metaphor of 'landscape' to describe the consequences of this process of the spatialization of violence as the 'colonialscape':

In logics of the colonialscape, the naturalization of violence on reserves entails a certain kind of temporal warping, as reserves are always stuck in the past, beyond the realm of progress. Their inherent violence and neglect remains unchanged. As subjects of the reserve, 'Indians' are also stuck in the past, forever at risk of being transported to these spaces in which justice cannot be achieved. (Hunt, 2014b, p. 77)

Hunt describes the influence of the colonialscape on the everyday lives of Indigenous peoples: 
Indigenous people individually and collectively continue to experience the imposition of systems of categorization which render not only our specific identities as marginal, but that further render Indigenous systems of meaning as impossibilities beyond the knowable/nameable world. What this means in daily life is that Indigenous people continue to try to fit our diversely understood experiences and systems of knowledge into preexisting colonial categories through which to gain recognition, not only as viable socio-legal subjects, but as coherent and knowable to western thought. (Hunt, 2014b, p. 19)

This understanding of the implications of (neo)colonial legal categorization is echoed by Sarah de Leeuw (2016), who writes that categorization “works to displace Indigenous peoples' place-specific identities, which were intergenerationally tied to the maintenance of Indigenous systems of knowledge, rights, and governance" (p. 17).

A common thread within this body of scholarship (Daigle, 2016; Hunt, 2014a, 2014b; Hunt \& Holmes, 2015) is the embodied and relational scale of everyday geographies. Sarah de Leeuw (2016) has argued that attending to these more intimate spaces is needed to "complicate dominant epistemologies and ontologies of violence and power" (p. 21) in research about colonial geographies. Walters et al. (2011) similarly highlight the chronic stress that is frequently induced by microagressive environments that "serve to diminish identity and render invisible indigenous presence and realities" (p. 182). For example, historical sites of 'massacre' are euphemized as 'battle grounds' on commemorative plaques and Indigenous place names are re-named to obfuscate sacred ties (Walters et al., 2011).

In summary, this body of work demonstrates the vitality of an alternative politics to state recognition located in systems of Indigenous law. Through the lens of legal pluralism, we can confront the (neo)colonial erasure of Indigenous spatio-legal identities across landscapes of maternal care governance. This raises the possibility of troubling the 
boundaries of (neo)colonial categories to ask which identities are legible, appropriate, and relevant within Indigenous legal orders.

For example, recalling Olson's (2013) description of the "tissy button" ceremony, we are reminded of the rich set of traditional knowledges and practices with which maternal care has long been governed in intimate spaces across the Nations in the territories now called Canada. Although the implementation of the settler-colonial policy of evacuation aimed to deliberately undermine and obfuscate these ontologies of governance in many Nations, Indigenous midwives are working to challenge the (neo)colonial erasure of these alternative models to federally-mandated maternal evacuation. With the understanding, however, that the extralegal clauses of the statutes regarding Indigenous midwifery are situated within a politics of recognition, anti-colonial activism can draw strength from interpretations according to Indigenous law.

\subsubsection{On grappling with the ontological}

My understanding of the concept of ontology is rooted in the work of Opaskwayak Cree researcher Shawn Wilson, who defines "ontology" in the following way:

Ontology is the theory of the nature of existence, or the nature of reality. Is there one "real" world that each of us observes differently through our own senses, or do various worlds exist, depending upon the point of view of the observer? There is no way to come to a definite answer to this question, so people develop an ontological set of beliefs and take it on faith from there. Once a set of beliefs is established regarding just what is "real", research then follows these beliefs in an attempt to discover more about this agreed upon reality. Ontology is thus asking, "What is real?" (S. Wilson, 2008, p. 33)

I believe that this question of "What is real?" is very important for my present research. As we saw in the previous section, Hunt (2014b) troubles the (neo)colonial 
ontological categories of 'Indian' and 'reserve'. The Indigenous thinkers who inform my work have challenged the imposed divide between ontology and praxis, arguing that a foundational component of an Indigenous paradigm of research is the embodied, engaged, placed nature of being and knowing in the world (Horn-Miller, 2016; Hunt, 2014a; Watts, 2013; S. Wilson, 2008). While I have endeavoured to trace these ontologies in my work, I cannot (and should not) write Indigenous geography as a nonIndigenous person given that, "[i]nvestigations into western ontological possibilities are bounded in ways that limit their ability to fully account for Indigenous worldviews" (Hunt, 2014a, p. 27). Hunt's view is also shared by Métis scholar Zoe Todd: So it is so important to think, deeply, about how the Ontological Turn-with its breathless 'realisations' that animals, the climate, water, 'atmospheres' and non-human presences like ancestors and spirits are sentient and possess agency, that 'nature' and 'culture', 'human' and 'animal' may not be so separate after all-is itself perpetuating the exploitation of Indigenous peoples. (Todd, 2016, p. 16)

While I am unable to embody or perform Indigenous ontology in my research ${ }^{9}$ as a non-Indigenous person, I would like to advance the argument that my work can still be centrally informed by Indigenous ontologies in a respectful and productive way. For example, in her study of the midlife health experiences of Elder Mi'kmaq women in Nova Scotia, non-Indigenous researcher Charlotte Loppie (2007) "attempted to incorporate Western scientific and Indigenous principles into the research process" (p. 276). Reflecting on the analysis of her research findings, Loppie (2007) describes an iterative process that is positioned in relation to the experiential knowledge of the Elders she learned from:

\footnotetext{
${ }^{9}$ See for example the decolonizing work of Anishinaabe midwife and scholar Karen Lawford (2017) in developing a First Nations feminist theory
} 
This process was both intellectual and intuitive, and was based on my relationship with the women, my knowledge of women's health and menopause, and my understanding of Indigenous philosophies, First Nations history, and Mi'kmaq culture. This process was also emotionally, psychologically, and spiritually laborious, because it required the prolonged and intimate engagement of my consciousness regarding the challenges continuing to face Aboriginal women. (Loppie, 2007, p. 282)

Loppie acknowledges that her frame and methods are western, but the knowledge generated from her research is shaped by her relationships with the Elder women who were her teachers. As a result, she proceeds with the understanding that her findings cannot (nor should they) be extricated from this relational context, reiterating the previous assertions made by Vanessa Watts (2013):

From a theoretical standpoint, the material (body/land) becomes abstracted into epistemological spaces as a resource for nonIndigenous scholars to implode their hegemonic borders. The excavated First Woman and all of her teachings, ontologies, and actions are interpreted as sexy lore and points of theoretical jumpoffs to dismantle and dissect that which oppresses. (p. 31)

Working from an ontological frame that acknowledges the plural and fluid construction of reality, Loppie draws on her relationships with the Elder women who participated in her research to not only strengthen but anchor and guide her analysis. 


\section{Chapter: Contractions}

\section{1 'Honouring partnership': 'Re/forming ${ }^{10}$ my knowledge about Indigenous peoples}

When I was an undergrad and the world was knowable and shiny, I volunteered at a conference about Indigenous peoples' health. The title of this conference was 'Honouring Partnership' and it was held at a big inner-city teaching hospital. With the exuberance of someone who has not yet been jaded by post-structuralism ${ }^{11}$, I bounded over to the hospital entrance to greet people. Like a heat-seeking missile, I homed in on every hospital-goer that 'looked Indigenous' ${ }^{12}$ and ushered them toward the conference. You can imagine my embarrassment and confusion when none of these unsuspecting folks turned out to be conference attendees, and the hall brimmed with white academics and clinicians eager to 'tackle Indigenous health issues'. This was my introduction to the field of Indigenous health research, a disorienting experience that instigated what I now understand to be a lifelong process of unlearning (Hunt \& Holmes, 2015; Tamas, 2014).

\subsubsection{Unsettling}

As a white settler woman, I cannot proclaim to be an ally to Indigenous peoples.

To put it simply, that is not for me to decide. What I can and should do is listen, and learn to listen well (Smithers Graeme \& Mandawe, 2017). Sarah Hunt (2014a) has shared some welcome advice in this regard.

As I suggest, for non-Indigenous people interested in engaging with Indigenous ontologies, this may involve becoming unhinged, uncomfortable, or stepping beyond the position of 'expert' in order to also be a witness or listener. Geographers must begin

\footnotetext{
${ }^{10}$ In reference to (de Leeuw, 2017)

${ }^{11}$ See (Tamas, 2009b) for a poignant discussion on the messiness of education

12 Yes, I am cringing at this too...
} 
grappling with the unsettling nature of engaging Indigenous knowledge in processes that are rarely clear, neat, linear or straight-forward, but are instead productively confusing. (p. 31, emphasis added)

Having been educated in the western system, engaging with the "productively confusing" is not a skillset that I have been fortunate to hone. In fact, I struggle with this tremendously. The (white male) scientific method that I am used to has indeed historically championed the "clear, neat, linear, [and] straight-forward". ${ }^{13}$ As an MSc student who had not yet made my foray into the humanities, I recall getting feedback on a paper where the professor - an individual I very much respect and admire - had cautioned in the margins: "Some of this verges on the polemic".

Situating this current research alongside the work of critical praxis geographers, I seek to respect the affirmation that colonial violence cannot and should not be settled nor made sense of (de Leeuw, 2017). Now, this is not to say that I can't generate some useful knowledge. So, what are the parameters that adjudicate upon the utility of this knowledge? The next section will attempt to dialogue with Sarah de Leeuw's (2017) call for geographers to ask ourselves: "How do we write right?” (p. 316).

\subsection{Commitment issues}

By striving to engage in anti-colonial research, I entered into a relationship with each of the Knowledge Holders that I endeavoured to learn from (S. Wilson, 2008). Furthermore, I made a commitment to these women to bear witness to their knowledges in a way that respects their goals and motivations. The onus of responsibility to get this

\footnotetext{
${ }^{13}$ I think it is important to mention here that many contemporary scientists, particularly those who cohabitate in Science and Technology Studies and Feminist Science Studies, have made tremendous strides in challenging this hegemonic paradigm; see for example, the work of Karen Barad (2007) and Elizabeth Wilson (2015)
} 
right falls on me. Inspired by the work of Hunt and Holmes (2015), I seek to enact the understanding that "allyship requires accountability on the part of members of the dominant group and is not predicated on reciprocity by those who are marginalized" (p. 162).

In light of this guiding principle, I strive to be accountable in my research to the Knowledge Holders who shared their stories with me and to re-present their knowledge in a way that support their goals of anti-colonial activism. In places where I have erred, I will be accountable to my mistakes. I kindly invite you as the reader to address these mistakes in your own writing so that I and others may learn to do better.

There's a constant role clarification that happens when you are doing research. The balance of power evades fixity (Tamas, 2009a). Colleague, interviewee, reader: who am I to you? When I started this project, I felt compelled to present myself to the world as Non-Indigenous-Woman-Researcher. Preparing for my interviews, I was excited, nervous, and very white. I wanted my interviewees to like me and I felt guilty that I was mining their stories for a degree. I mulled over how I would perform myself, how they would see me, and what they would think of me. Are these linen pants too $19^{\text {th }}$ century anthropologist? Do Converse ${ }^{T M}$ sneakers make me seem cool and radical or do they betray the reality that I can't afford adult shoes? Mid-drive: I can't bring this French pastry, that's SO colonial!

Before I began my interviews, Dr. Kahente Horn-Miller taught me about tobacco ties. I was so uncomfortable at the thought of presenting one and being taken for an apologist phony. Addressing my insecurities, she patiently insisted that there was no right or wrong way to assemble one, and that what matters is that they are a gesture of respect 
and gratitude, a symbol of one's intentions. I embarked on my fieldwork experience with a bag of nerves and an open heart, offering up my tobacco ties (with the exception of my last interview, when of course I managed to forget them at home!). I'm certain there were many moments when I was awkward. But I think I was the only one fretting over my whiteness.

This thesis is rooted in my re-presentations of the knowledge shared with me during my interviews. I am Non-Indigenous-Woman-Researcher at the same time that I am Monika who drinks pretentious black Americanos, loves a quality face mask, and dreams of one day having a farm-cum-bed \& breakfast. I have a hard time choosing the right hat, so I am grateful to stand on the shoulders of scholars who deftly argue against the bifurcation of the Academic and Non-Academic Self (Hunt, 2014a; Tamas, 2013, 2016). Noting, however, that it is crucial to continually navigate my positionality, I have tried to respect an anti-colonial methodology and Indigenous paradigm of research (Ritenburg et al., 2014; S. Wilson, 2008). I also take in stride that you have come here to read about the maternal care needs of Indigenous communities, and not about me; I share parts of my Self so that you can feel comfortable with my intentions and frame of reference but (hopefully) not too much so that you get bored or my narcissism gets out of hand.

\subsection{Study Design}

The rationale for this study was jointly conceived during a conversation with one of the Knowledge Holders. Recruitment was also done by this Knowledge Holder because she was already known to and trusted by the network of Indigenous maternal care providers in Ontario and Québec. After this Knowledge Holder had brokered initial 
contact with the others by providing them with an informational letter of recruitment (see Appendix A.1), I connected with prospective participants using their preferred method of communication (telephone or email) to follow-up, give them more details, and answer any questions. If, after speaking with me, the individual was interested in participating, we negotiated consent using either an oral script (see Appendix A.2) or written contract (see Appendix A.3). Participants chose the date, time, and location of their one-one-one, semi-structured interview to minimize possible inconvenience for them and to attenuate/diffuse the potential of a researcher-interviewee power asymmetry. In one instance, I conducted a joint interview when an interviewee's colleague happened to be nearby.

Flexible options for anonymity were made available to best accommodate the Knowledge Holders. This was done to acknowledge their role as co-researchers and coowners of the study findings, as elucidated by the OCAP principles of "Ownership", "Control", "Access", and "Possession" (First Nations Information Governance Centre, 2018). Following from this mandate, each Knowledge Holder was given a copy of her transcript to review and any annotations or requested redactions were obliged. 
Table 1: Table of Knowledge Holder characteristics ${ }^{14}$

\begin{tabular}{|c|c|c|c|c|}
\hline Interview & $\begin{array}{c}\text { Knowledge Holder } \\
\text { Role }\end{array}$ & $\begin{array}{l}\text { How they are } \\
\text { named in the } \\
\text { thesis }\end{array}$ & $\begin{array}{c}\text { Place(s) } \\
\text { where they } \\
\text { practise(d) } \\
\end{array}$ & $\begin{array}{c}\text { Place where the } \\
\text { interview was } \\
\text { held }\end{array}$ \\
\hline $16 / 7 / 2017$ & $\begin{array}{l}\text { Family physician, } \\
\text { specializing in } \\
\text { maternal and child } \\
\text { health }\end{array}$ & $\begin{array}{l}\text { Family } \\
\text { physician }\end{array}$ & $\begin{array}{l}\text { Semi-urban- } \\
\text { rural }\end{array}$ & $\begin{array}{l}\text { Knowledge } \\
\text { Holder's home, at } \\
\text { the kitchen table }\end{array}$ \\
\hline $23 / 7 / 2017$ & Aboriginal Midwife & $\begin{array}{l}\text { Aboriginal } \\
\text { Midwife }\end{array}$ & $\begin{array}{l}\text { Semi-urban- } \\
\text { rural }\end{array}$ & $\begin{array}{c}\text { Knowledge } \\
\text { Holder's home, } \\
\text { outside in the front } \\
\text { yard }\end{array}$ \\
\hline $5 / 8 / 2017$ & $\begin{array}{l}\text { Director, Indigenous } \\
\text { midwifery; } \\
\text { Aboriginal Midwife }\end{array}$ & $\begin{array}{l}\text { Director, } \\
\text { Indigenous } \\
\text { midwifery }\end{array}$ & Urban & Café \\
\hline $25 / 8 / 2017$ & $\begin{array}{l}\text { Aboriginal Midwife, } \\
\text { Namegosibiing (Lac } \\
\text { Seul First Nation, } \\
\text { Treaty 3); Registered } \\
\text { Midwife; Academic } \\
\text { Researcher }\end{array}$ & $\begin{array}{l}\text { Karen } \\
\text { Lawford }\end{array}$ & Urban & $\begin{array}{c}\text { Knowledge } \\
\text { Holder's campus } \\
\text { office }\end{array}$ \\
\hline $26 / 8 / 2017$ & $\begin{array}{c}\text { Registered Midwife, } \\
\text { Anishinaabe } \\
\text { (Algonquin) }\end{array}$ & $\begin{array}{l}\text { Registered } \\
\text { Midwife, } \\
\text { Anishinaabe } \\
\text { (Algonquin) }\end{array}$ & $\begin{array}{l}\text { Urban \& } \\
\text { remote } \\
\text { locums }\end{array}$ & $\begin{array}{l}\text { *Outdoors by a } \\
\text { lake }\end{array}$ \\
\hline $26 / 8 / 2017$ & $\begin{array}{c}\text { Registered Midwife, } \\
\text { Anishinaabe } \\
\text { (Nipissing First } \\
\text { Nation) } \\
\end{array}$ & $\begin{array}{l}\text { Carol } \\
\text { Couchie }\end{array}$ & $\begin{array}{l}\text { Rural \& } \\
\text { remote } \\
\text { locums }\end{array}$ & $\begin{array}{l}\text { *Outdoors by a } \\
\text { lake }\end{array}$ \\
\hline
\end{tabular}

*joint interview

\subsubsection{Semi-structured interviews}

To enact an anti-colonial methodology, I sought out a method that would reposition the hegemonic balance of power between 'researcher' and 'researched' (Smith, 2012; S. Wilson, 2008). While semi-structured interviews are arguably not the most optimal way to do this (Nunkoosing, 2005), compared to, for example, talking circles,

\footnotetext{
${ }^{14}$ Developed in consultation with Knowledge Holders; the six women interviewed self-identify as Indigenous persons. I would like to emphasize that the midwifery practitioners all identify as Indigenous midwives; their specific pathway is given here to provide context, not to reinforce (neo)colonial legal categories.
} 
this (western) method was chosen as the most appropriate option due to logistical constraints; my research was time-sensitive with limited financial resources and the study was exploratory in nature as it deals with an under-researched topic. I found precedents for situating western methods within an Indigenous paradigm of research in the work of anti-colonial scholars (Lawford, 2011, 2017; Liamputtong, 2007; Loppie, 2007; Simonds \& Christopher, 2013). Informed by my initial conversation with the recruiting Knowledge Holder, I prepared an interview guide (see Appendix A.4) that also reflected key insights from a preliminary review of the literature. I shared this interview guide with the Knowledge Holders in advance of each interview and emphasized that it was merely a template to frame our conversations insofar as they found the questions relevant.

\subsubsection{Thematic analysis}

I analysed my interview data by drawing from the guidelines for thematic analysis described by Braun and Clarke (2006); in a system consisting of six phases, interview data is first transcribed then read, re-read and initial ideas are noted (Phase 1).

Subsequently, interesting features of the data are coded (Phase 2) and codes are collated into overarching themes (Phase 3). In a retrospective check, themes are verified against the coded extracts as well as the entire data set (Phase 4). After they have been verified, themes are refined and their relationship to the broader story of the research is considered (Phase 5). Lastly, the final analysis of the themes is situated within the context of the research objective and literature review and quotes are chosen to exemplify these findings (Phase 6). This method can be tailored to suit various applications across diverse qualitative methodologies (Clarke \& Braun, 2017), including in health research (Braun \& 
Clarke, 2014). It was chosen for its compatibility with a critical theoretical framework and for its flexibility to accommodate an iterative research process.

The method of thematic analysis structured my understanding of the interview data as four main themes:

(1) Implications of midwifery legislation for Indigenous maternal care providers

(2) Discursive shields in the litigation landscape

(3) Learning to "go in both boats": On epistemic violence and living in the grey

(4) "The place that belongs to me": Understanding the return of birth to community as an act of anti-colonial activism

Some of the codes underlying these themes were apparent at the beginning of the process; these included management of biomedical risk, racism, and burnout which correspond to readily identifiable key terms that resonated with my preliminary literature review and were foundational to Themes 2 and 3. Other codes were more diffuse; Themes 1 and 4 were not pieced together in a puzzle-like fashion through obvious, discrete codes that stood out in the data set. Instead, my understanding of governmentality in the context of Indigenous maternal care delivery emerged over months of iterative analysis and consulting new literature, which produced a layered image. 


\section{Chapter: Birth}

In all of my interviews, the Knowledge Holders emphasized that maternal and child health is foundational to the overall health of a community. Based on this understanding, returning birth to community is perceived as not only crucial for improving maternal care experiences and maternal and child health outcomes, but also imperative for elevating the collective health status of Indigenous peoples. From the knowledge that was shared with me, it became clear that this advocacy movement is rooted in a relational approach to governance that honours the agency of the expectant mother and her family.

This last point came up often. The Knowledge Holders staunchly opposed prescriptive care directives; they were keen to clarify that returning birth does not mean restricting maternal care to birthing in community with an Aboriginal Midwife. Quite the opposite, advocates of this movement are lobbying to ensure that a full spectrum of culturally safe maternal care options can be made readily available to expecting mothers living in Indigenous communities. Furthermore, the Knowledge Holders shared the belief that strong pre-natal education will enable expecting mothers to choose the option that will be most suitable for them and their families, in consultation with their care providers. Respecting the inherent decision-making capacity of the expectant mother in this way honours her political agency. The Knowledge Holders corroborated key insights from my review of the literature in Chapter 2 which point to the paternalism of the federal evacuation policy - and (neo)colonial governance in the broader sense - as effectively erasing the decision-making capacity of the expectant mother. 
While the Knowledge Holders were quite unified in their motivations for advocating for the return of birth, their personal journeys as providers of care have uniquely influenced how they imagine the path forward to implementation. Notably, however, none of the Knowledge Holders felt that the 2010 SOGC policy guidelines (SOGC, 2010) had materialized in improvements on-the-ground to support their advocacy work for returning birth. There was some dissent over the implications of the more recent policy changes announced by the Trudeau government with the unveiling of Budget 2017 (Department of Finance Canada, 2017). Knowledge Holders disagreed over whether the revision to the client escort policy (see Appendix C) signalled a restructuring of Indigenous-state relations with respect to maternal and child health. Dr. Karen Lawford was apt to point out that despite the interim changes to the Non-Insured Health Benefits program, the federal evacuation policy remains unchanged. ${ }^{15}$ Similarly, the announcement of the $\$ 6$ million funding pledge to support community-based midwifery was received by Knowledge Holders with a mixture of optimism, measured support, and skepticism. These perceptions of contemporary policy-making and maternal care governance at large will be weaved throughout the descriptions of the interview data that follow in the text below.

\subsection{Implications of midwifery legislation for Indigenous maternal care providers}

The Aboriginal Midwife that I interviewed had worked without pay for eleven years because she was unable to access state funding prior to 2017. She expressed her frustration that, as a practitioner, she was having to "take on this political role and

\footnotetext{
${ }^{15}$ At the time of writing (June 2018), the Health Canada web page for the Clinical Practice Guidelines for Nurses in Primary Care does however state that "Health Canada is in the process of updating the Clinical Practice Guidelines for Nurses in Primary Care. Updated chapters will be published to the web as they are finalized and approved" (Health Canada, 2015).
} 
advocate for [her] own funding", which caused her tremendous stress. Describing

midwifery care as a fundamental right, she spoke of her perceived marginalization under the midwifery legislation and outlined her reasons for not charging her community members informally:

I'm sure that when they wrote that legislation they were like, 'Okay well we're allowing you to do this...' but it was like setting us up to fail. Because how could we do that? How is it sustainable? How would we be able to be practising unless we were doing it for free? In order to get paid and be practising here, we would have to charge our community, for something that we are entitled to, which is healthcare. Right? And that's not fair. It's an inequity...s so to this day, I've never charged anybody. I've never charged a community member. (Interview with Aboriginal Midwife; July 23, 2017)

Financial constraints at the time of pursuing her schooling ultimately led Carol Couchie to choose the route of Registered Midwifery so that she could have a stable income as the single wage-earner for her family. She suggested that each person has a unique set of circumstances to determine which pathway is better for them and attested to the value of both approaches to Indigenous midwifery care and their equivalence:

I think I've seen a lot of people do a lot of things with that option [Aboriginal Midwifery, practising under the Exception Clause]. That option was not for me at the time so it's hard for me to speak to it. But for other people, my option [Registered Midwifery] is not for them, and when I look across the room at those sisters, the thought of not having them in my circle would really make me sad. Because they're amazing women. And they need to be here. So, I think it's just such an individual thing. And I think that the more pathways we have to this, the better it is. We need to support Indigenous midwifery, period. (Interview with Carol Couchie, RM, Anishinaabe; August 26, 2017)

However, the Director, Indigenous Midwifery remarked that these two different categories of practice can cause tensions in the Indigenous midwifery community: 
So the Aboriginal Midwives, that's the wording that the Exception Clause uses. If you are recognized as an Aboriginal Midwife in your community... That's what the federal government uses, right, in the constitution... They use the word Aboriginal which of course is very broad and problematic. People are tending towards a broader pan global Indigenous approach, people are more comfortable with that word. However, saying that, the Haudenosaunee midwives are clearly saying to me I want to be called an Aboriginal Midwife because it is a protected title in the Midwifery Act. But then some of them want to say I'm a Haudenosaunee midwife or I'm a Mohawk midwife or you know and they would like to be identified by their nation. It's up to them how people want to identify, you know what I mean? But I think they still feel as though they're an Aboriginal Midwife, this is sort of the overarching term... And then they can define themselves however from there. But then there's Registered Midwives that are Indigenous who say don't ever say to me that I'm not an Aboriginal Midwife. I want to be called an Aboriginal Midwife. And they have the right to say that. So it's sort of like, there's a lot of that kind of terminology that has kind of an underpinning... but also in some ways again it's the government creating these false divisions, right? It's like I'm status and you're not. These are words that are used by the governments which are structural and systemic. It has created some tensions between Indigenous midwives. (Interview with Director, Indigenous midwifery; August 5, 2017)

Echoing this insight, the Aboriginal Midwife spoke of "rifts" in the Indigenous midwifery community from the projection of an implied knowledge hierarchy where registered is best:

So there are people who think that way, you know, it's really hard for them to think outside the box. And midwifery under this Exemption Clause is one of those things that requires you having to think outside the box. I see how there's been rifts between individuals saying, 'Oh, well, we want registered everything.' Well, what does that registration mean to you? Like is it about the safety, what is it? Is it about the safety, truly? Or is it about this title? It's not us who created it...do we need it? (Interview with Aboriginal Midwife; July 23, 2017)

Referring to the lateral violence she had experienced during her career, she commented, "When we're not divided among non-Aboriginal and Aboriginal, we're making divisions 
among ourselves" (Interview with Aboriginal Midwife; July 23, 2017); additionally, she feels that she is sometimes perceived as less authentic in her Aboriginal Midwifery role because she pursued her midwifery education outside of Canada as opposed to locally.

At the beginning of her career, this Aboriginal Midwife encountered resistance from her own Health Department, having to address their (mis)conception that Aboriginal Midwifery was not as safe as Registered Midwifery:

I was asked [by a Health Department official]: 'You've come so far and we're really proud of you. Why not just raise the bar to become a Registered Midwife?' It confused me, raise the bar? Like this is not enough? Didn't we do enough? We're not looked at at the same level. We kept having to come back to the fact that we already are equal. We learn and develop the same skills, but for reasons of sovereignty and self-identity, we choose to practice this way. We're holding true to this; this is how midwifery should look like here, and the community has said that this is what they want. (Interview with Aboriginal Midwife; July 23, 2017)

Because she was unable to bill the state for services rendered the way a Registered Midwife would be able to, this Aboriginal Midwife found that her clients' prenatal care experiences were not as seamless as they could have been. Remarking how these built-in barriers put her and her clients at a disadvantage, she lamented, "It's a hard place to be sometimes just being Indigenous" (Interview with Aboriginal Midwife; July 23,2017 . This is a salient example of the influence of funding allocation on provider experience.

On top of this, the Aboriginal Midwife interviewed encountered tremendous difficulty in convincing physicians to collaborate with her; physicians would cite concerns over her lack of registration (implying compromised patient safety), and the threat of malpractice for being implicated in what they perceived to be illegal activity. For this Aboriginal Midwife, the $\$ 6$ million funding pledge from the federal government 
confers official state recognition that Aboriginal Midwives are safe, competent, and

provide care that is on an equal standing with that of Registered Midwives.

She also speculated that some of the hesitation on the part of physicians may have resulted from misconceptions over billing procedures:

...once the funding was in, now we have all these doctors that want to work with us. And it just really comes down to the fact that if I send a client in to see them, they'll see them maybe three times and they'll send in all their requisitions for their bloodwork, etc. They can still invoice for a whole course of care and we can also invoice from a whole separate pocket of funding so there's no overlap. (Interview with Aboriginal Midwife; July 23, 2017)

Despite her overall optimism about the $\$ 6$ million funding pledge, she conceded that

there are logistical constraints that come with state-funding:

....in our community, we face difficulties because we didn't put those borders there, and we have to remember that. The border line was not meant to affect us, but it is because it influences where we can practise. If we're funded by the Ministry of Ontario, we are required to be practising in Ontario only. That's where the funding originates from. (Interview with Aboriginal Midwife; July 23, 2017)

At the time of the funding announcement, she had expected that some of her colleagues would let go of their registration now that a funding pathway had become available for Aboriginal Midwifery:

I was rationalizing it, thinking they want access to this funding because now Aboriginal Midwives under this Exception Clause can be funded. Perhaps a lot of them will let go of their registration and practise this way, because they believe in it. It was a protected title because we practise a certain way. Now it's like we're trying to protect this title and how we practise, because it's not just about the name, or the funding, it's about protecting this sacred title that has always belonged to us. If you start steering away from that sacredness, then it's all about the money. (Interview with Aboriginal Midwife; July 23, 2017) 


\subsubsection{Perceptions of the $\$ 6$ million funding to support culturally safe midwifery}

For the Director, Indigenous midwifery and Chair of the National Aboriginal

Council of Midwives, the $\$ 6$ million funding pledge means that Indigenous stakeholders

are being given a seat at the table and the National Aboriginal Council of Midwives is

"beginning to be recognized as really the experts on Indigenous maternal and child health

in Canada" (Interview with Director, Indigenous Midwifery; August 5, 2017). She stated

that step one of determining the allocation of this funding is supporting "community

engagement strategies and facilitation by midwives" (Interview with Director, Indigenous

Midwifery; August 5, 2017). The Registered Midwives expressed a similar opinion:

Carol Couchie: I think the fact that they're beginning to

acknowledge us, that $\$ 6 \mathrm{M}$ says a lot to me even though it's not

enough, even though it's just the beginning, it says, 'We're here

and we're acknowledging the fact that you're here'. And that's

hope.

Registered Midwife, Anishinaabe (Algonquin): It's a start, you gotta start somewhere. (Interview with Registered Midwives; August 26, 2017)

As was alluded to previously, the Aboriginal Midwife interviewed was more skeptical of the funding pledge from the federal government:

They pledged their support via funding, but left out a few important details, like essential billing numbers. They could say, 'We tried to acknowledge them as competent midwives and see what their midwifery model would look like. We gave them funding so we're trying, we wanted to see that it was safe, but look what happened... [in anticipation of failure] This is what happened; well, we tried.'

Is it going to be like that? It starts to create some kind of stress because it seems like, in a way, all eyes are on us. I already feel that pressure to perform a certain way because it's setting a precedent, yes. But will it be a positive one? The fact that I'm thinking that way is not good, since you shouldn't have to be fearful about going into something if it's a completely positive 
thing. Feelings of skepticism are more prevalent within

Indigenous communities, which a non-native person may never experience or come to know how it feels.

(Interview with Aboriginal Midwife; July 23, 2017)

The Director, Indigenous midwifery added that there will be important decisions to make about how the funding is transferred to midwives:

Because what we said, the Association of Ontario Midwives recommended that midwives should have a choice in the kind of funding based on the model of care they would like to practice. They should have a choice to be either salaried or they should have a choice to be an independent practitioner. Do you want to be working in a health centre with a family care team, or interprofessional primary care team or would you like to set up a community governed midwifery practice? So we have to be careful when we talk about who we're partnering with. Partnering has a political connotation to it too, do you know what I mean? So there are different ways. Who are you working with, who are you allying with? So the terminology has to be very careful. (Interview with Director, Indigenous midwifery; August 5, 2017)

Furthermore, she cautioned against increasing state control and surveillance that typically accompanies state funding:

And we have to be aware at all times regarding community governance because the government is not in the business of regulation of midwives, neither is NACM, neither is the AOM. The community governance model is going to look different in every community. There are more questions than answers right now. It's that community governance model. What does that look like? Who is involved, how is it evolving? (Interview with Director, Indigenous midwifery; August 5, 2017)

Based on these preliminary findings, it would be reasonable to contend that the unique financial barriers facing Aboriginal Midwives merit expedited attention. In light of this, it will be important to ascertain how the $\$ 6$ million funding will be allocated; for example, how much of this funding will go toward supporting existing programming and how much will support independent practitioners with no institutional affiliations? 


\subsection{Discursive shields in the litigation landscape}

From the review of the literature in Chapter 2 regarding biomedical discourses, it was suggested that the concepts of risk and competency are frequently invoked as rhetorical devices to qualify the appropriateness and feasibility of birthing outside of a hospital, whereby "[t]he litigious nature of obstetrical practice and the fear of litigation are very prevalent in the discussion of place of birth" (Olson, 2013, p. 157). This framing - whether employed deliberately or otherwise - appears to reinforce the marginalization of pregnant Indigenous women and their families, as well as Indigenous maternal care providers. From my interview data, it was evident that Indigenous midwives in particular find that their competency to deliver primary care is repeatedly brought into question and that their practice is sometimes perceived by those outside the profession to be risky. In discussing this need to respond to concerns over safety with the Director, Indigenous Midwifery, I learned that the 2017 funding pledge to support Indigenous midwifery will include coverage for malpractice insurance, the same as the type that Registered Midwives already carry.

\subsubsection{Risky business ${ }^{16}$}

The Director, Indigenous midwifery commented on the epistemological tensions regarding divergent conceptualizations of risk, particularly among physicians as opposed to the understandings held by many in the Indigenous midwifery community:

And we talked about like why do you even have to use a risk rhetoric? Like why do we even have to use that word? Midwives are saying that the word 'risk' is being used from a nonIndigenous lens. We need to have discussions about well what's low risk? What's high risk? Who's defining risk? It's really, that

\footnotetext{
${ }^{16}$ In reference to (Kildea, 2006)
} 
really ties in for me with death. We can't have a conversation about birth without having a conversation about death. And so they're sort of juxtaposed together. And we are a part of a litigious-focused society that can come from an individualistic approach to risk and outcomes. And there is some kind of community understanding of what death is, there's some kind of cultural understanding of what death means to the community and how there's less fear of death I think overall. There is a broader community acceptance that death is a part of life. There's that whole continuum. Midwives used to be responsible for taking care of people when they were dying and people when they were coming in. Coming in the East and going out the West. They were part of that whole continuum of coming in and going out, that circle. (Interview with Director, Indigenous midwifery August 5, 2017)

The Registered Midwives expressed similar views:

There's a difference between high-risk and risk factors. A risk factor in birth or in pregnancy is being Indigenous. Why? Because we have a lower health status, right. So, you can have a high-risk pregnancy, anybody can, right. And there are risk factors. But that doesn't mean that that risk factor is going to affect you. So being an Aboriginal person can give you a risk factor, but it just depends whether that risk factor is going to affect the pregnancy. But Aboriginal women deliver very well and very normally. (Interview with Carol Couchie, RM, Anishinaabe; August 26, 2017)

I don't think we even conceive of it [risk] in that way, right. Like I don't think we would have even used that language except that that's the framework that's sort of been thrust upon us when we want to have birth back in our community, right. There's all the talk of like screening out and risking out and that kind of stuff. But I think that's something that's been put onto us. That's not something that came from us. (Interview with Registered Midwife, Anishinaabe (Algonquin); August 26, 2017)

For the Aboriginal Midwife, these lived-in tensions are compounded by widespread (mis)perceptions about registration:

I'm a little bit confused because that's always the thing. For example: 'Okay, you're an Aboriginal Midwife; does that mean that you're as competent as a Registered Midwife?' And so yes, that's always a question. That's something that comes up a lot. 
We're constantly having to defend that we are completely skilled, equal to the Registered Midwives. We have to keep reiterating that we learn the same medical way as a RM, however, we integrate our cultural teachings into what we practice. And the only difference is that we're not registered by choice. (Interview with Aboriginal Midwife; July 23, 2017)

In summary, all of the Knowledge Holders stated that the biomedical definition of risk precludes birthing in community for Indigenous women; this is because being Indigenous is a risk factor. In light of this, a more nuanced understanding of risk is required. Epitomizing the opinions expressed in these conversations, the Aboriginal Midwife stated the following:

Indigenous people, our community as a whole is considered a 'high-risk' population. We've gotten into that term of 'risk'. For example, when we were writing our proposal [for state funding] midwives are supposed to only attend 'low-risk' clients. Under that terminology, it's already beyond our scope because of our demographic. We were trying to take out that term 'high-risk' because it's already who we are. (Interview with Aboriginal Midwife; July 23, 2017)

The Knowledge Holders also emphasized that the level of maternal care education that a woman has received, the strength of her support network, and her capacity to advocate for herself should inform risk assessment. Furthermore, the amount of risk that a woman is comfortable accepting is very specific to the individual; this cannot be generalised for the community or culture. A woman's level of risk is very difficult to predict. The family physician actually suggested that "midwives are probably better at gauging risk because by nature of what they do - being out of hospital - they do take more risk anyway" (Interview with family physician; July 16, 2017). Here is a relevant example given by the family physician which resonates with the above assertions:

...if you have a woman who comes in and she's in an abusive relationship and she is not educated - she's been going to her pre- 
natal care but not really engaging with her doctor and has all this anxiety and panic and is in her labour and is having panic attacks - you can imagine that that woman who doesn't have any physical risk factors but lots of mental and probably spiritual risk factors because of her relationship, and she's not able to advocate for herself. Versus somebody who is in the same situation but has a really good relationship and is able to engage, knows what's going on. They're two different places, same physical thing. (Interview with family physician; July 16, 2017)

Finally, one of the Registered Midwives shared a story to emphasize that Indigenous peoples face ontological risks which are not readily apprehended by western policymakers. In the following quote, the Registered Midwife refers to the testimony of Salluit Elder Jusapie Padlayat which appears in the work of Van Wagner et al. (2007, p. 386):

I can understand that some of you may think that birth in remote areas is dangerous. And we have made it clear what it means for our women to birth in our communities. And you must know that a life without meaning is much more dangerous. (Jusapie Padlayat, a Salluit elder, quoted in Van Wagner et al., 2007, p. 386)

... when they were trying to build the birth centres, up in Nunavik and on the coast, and you know of course all these government people and doctors and whoever were going to the community meetings and saying how dangerous birth is and how they shouldn't be doing this... And finally, one of the Elders stood up and said you know you've told us how dangerous you think this plan is. And we've told you what it means to be bringing birth back to our communities, and what you need to understand is that a life without meaning is also really dangerous. Right. And where does that get put into the ledger book? [...] But that's the crux of that, is that self-determination, and all of the immeasurable things that contribute to the health of a community. (Interview with Registered Midwife, Anishinaabe (Algonquin); August 26, 2017)

The excerpts in this section bring to mind Olson's (2013) assertion that "evacuated women's bodies and the bodies of midwives become the sites in which decisions regarding the acceptability of risk occur" (p. 195). 


\subsubsection{Practising the culturally safe way}

One example of respecting cultural safety that was given was recognizing that some women will not desire a one-on-one appointment with their care provider; they may prefer that their mothers, partners, sisters, aunties, etc. be present with them. In some circumstances, a physician calling for a one-on-one appointment is incongruent with "Indigenous relationality" (Interview with Dr. Karen Lawford, AM, RM; August 25, 2017). The Director, Indigenous midwifery further emphasized that cultural safety means being aware of the unique barriers facing Indigenous women:

So first of all, you come down, there's not enough money for you to get on a streetcar right. So how do you get yourself to your appointment? Or how do you make the systemic changes that would drive the changes for a model that is tailored for the issues in the community and responses to these issues? For example, home visits - midwives already do this. What about a whole other system where you don't have to leave your home? Or maybe you want to leave your home because it's not a very good place to stay. Anyway, so there's getting you from where you are, to the location where your physician is, right? So the person actually makes it to their appointment. And they make it to their appointment on time. But that doesn't always happen either because there's so much going on in the home, crisis, issues going on, people often don't show up to their appointments on time. What if you've got five kids? We need culturally safe care plans, rather than a system that is based on the clients having a certain lifestyle, access to resources, knowledge of how to access resources. It's a major feat to get yourself to the appointment. Then you encounter racism, then you encounter somebody who is just talking down at you, who doesn't really want to get to know you, doesn't know where you're from, doesn't understand why you're not speaking. There's that whole cultural safety thing around how to reach out to someone. So there's that whole huge piece of work there. But then you get somebody who just hands somebody a form and says go there. And first of all, maybe they can't read. Maybe they don't know what that form means. What do you mean I need a referral to a such and such? What is that? Like and then they'll say make a phone call to this person. Well first of all, I don't have a phone and I'm too ashamed to say that. Or I don't have a phone, I can only text after 6 . I can't stay on 
hold because it's costing me money and I'm not going to be calling the doctor's office over and over again to get an appointment about something that I don't even know what I'm going in for, let alone needing three specialist appointments because I have chronic illness, you know? Maybe it hurts for me to walk right now. Like there are all these things, you know. And so all these things are not taken care of. (Interview with Director, Indigenous midwifery; August 5, 2017)

The family physician spoke about the difficulties of communicating these unique barriers to western clinicians:

So I used to give talks to obstetricians and family doctors and it was on culturally competent care, providing culturally competent care to Aboriginal women. And it was like not really a list but it was more of a you know, make sure you ask about the placenta, make sure you ask about the herbs that they're taking, because they're not gonna tell you, they're probably gonna take some slippery elm bark, they're gonna take some raspberry, you want them to be physically active but there's probably a lot of rez dogs so they're not gonna be able to do that. There's a lot of food insecurity so when you want them to watch their diet, they're not gonna be able to follow your directions, your recommendations. So cultural competency was more of a logistic because there was no real culture that I could really teach them. (Interview with family physician; July 16, 2017)

She insisted that "cultural safety means you understand culture but you're also reflecting on yourself and what your biases are based on your culture" (Interview with family physician; July 16, 2017). She stressed that cultural safety must be enacted as a process of relationship building, of learning at a grassroots level how to relate to Indigenous people. She understood culture as "rules of engagement" citing the wampum as an example of how these can be expressed.

Carol Couchie offered a schoolroom analogy to describe cultural safety, stating that, "[As midwives] Our gift is time." (Interview with Carol Couchie, RM, Anishinaabe; 
August 26, 2017); midwives can spend much more time with clients than an obstetrician,

drawing a parallel to a smaller classroom with a lower student to teacher ratio.

So Aboriginal midwifery [inclusive of both AMs and RMs] is cultural. It respects cultural safety. It's something we have always had. It heals us from the residential school system. It's something that was taken away [because of] colonialism. It's part of who we are as a people. And it respects and strengthens the most important ceremony we have, as Indigenous people, the birth of the baby. It is sacred to us. So, I don't know how you can argue any of those things. But people have forgotten. Because it was medicalised and it's still with us in some way, right? We haven't stopped giving birth. They don't think about it being in another place. (Interview with Carol Couchie, RM, Anishinaabe; August $26,2017)$

The Knowledge Holders informed me that they assume that every one of their Indigenous clients has experienced trauma. Indigenous midwives are in a unique position to approach the barriers of lateral violence, Intimate Partner Violence, and intergenerational trauma which stem from colonialism because they have more time to build trust with their clients than other practitioners typically might. Based on their experiential knowledge of the effects of colonialism, Indigenous midwives operate on a 'no-judgement' principle with an awareness of the (neo)colonial processes which normalize violence.

That is where, I respect you and hopefully you won't have to tell me everything, because I'm an Indigenous midwife, I'm at least gonna understand the whole thing of the trauma, the colonisation, your family. I'm gonna assume a lot of things that don't need to be spoken between the two of us. You know what I mean? But you can talk to me about anything and I would hope that I would build enough trust that you would feel safe in telling me anything about who you are as an individual and how you might be different from your neighbours. (Interview with Carol Couchie, RM, Anishinaabe; August 26, 2017) 


\subsubsection{Strong pre-natal education supports self-affirmation}

The Knowledge Holders were unified in their belief that strong pre-natal care is critical to help a woman to deliver confidently under any set of circumstances. All of the Knowledge Holders advocated for more education to support women in making an informed care decision, regardless of their chosen birthing option.

The family physician that I interviewed stressed the importance of the pre-natal component of her practice, as well as her role as an educator more broadly, due to the shortage of physician staffing in many communities. Because in many Indigenous communities, continued care with an obstetrician is not commonplace, incorporating a care relationship with an allied health professional such as a doula or midwife was suggested as a good option to address this service gap. Educating women provides them with the knowledge they need to "healthfully deliver" (Interview with family physician; July 16, 2017). The important caveat here is that providing education requires a tremendous investment of time, and this is work that physicians are not specifically paid to do. This physician was starting a healthy lifestyles clinic to address this need for more education:

I have realized that the more educated a woman is, the more ownership she takes over the decisions that are made and it's less paternal and so they do well regardless of who delivers them. (Interview with family physician; July 16, 2017)

The family physician suggested that to prescribe a treatment to a patient without an explanation would actually "belittle" that patient.

This discussion about pre-natal care also extends to educating physicians unfamiliar with Indigenous midwifery - or midwifery in general - to ensure a smooth transfer of care in the event of an emergency. The family physician mentioned that often 
physicians come to know midwifery in the most "catastrophic" of circumstances during a transfer of care.

All of the Knowledge Holders understood their role as teachers. This was articulated in the following way by the family physician: "when we talk about protecting the provider, ultimately what you're trying to do is make sure that they last long enough and learn enough to be able to hand off their knowledge to somebody else" (Interview with family physician; July 16, 2017). This duty to pass on one's knowledge was also expressed by Carol Couchie, both in the context of educating patients and educating the next generation of providers:

I would say that's the majority of my job, is being an educator. My job is to eliminate fear, like $90 \%$ of my job is eliminating fear. I do a belly check and I make sure that people are healthy and that there's nothing going wrong. And after that, I eliminate fear in the mother so that she can have the confidence to deliver well. And to not be freaked out by all the rest of the noise that is going on in our society. It's absolutely one of the most important things I do. And then my job is also to teach the next generation to do what I do. And that is a role that I take on, not as a midwife, but as Anishinaabekwe. It wouldn't matter what I do that's of value to our society as Indigenous people; your responsibility is to teach the next generation everything that you know about what it is to be a good human being. And in my job, my role is to be a midwife. And so that's what I have to teach them. (Interview with Carol Couchie, RM, Anishinaabe; August 26, 2017) 


\subsection{Learning to "go in both boats": On epistemic violence and living in the grey}

I am dancing not for you, but in the footsteps of my ancestors who taught me how to resignify Indigeneity, or more specifically Kwakwaka'wakw knowledge, such that it does not lose its meaning and power in the face of colonial constraint. I am dancing because I must, in order not to lose my hyphenated existence. I dance in the hopes that future generations of Indigenous students will want to become geographers, finding a space where there is room for them to be seen and heard as both Indigenous and geographer at the same time. (Hunt, 2014a, p. 31, emphasis added)

Several Knowledge Holders shared stories of performing a "hyphenated

existence", bringing to mind what Sarah Hunt (2014a) has described as "dancing between worlds" (p. 28). Karen Lawford described the violence she had experienced during her (western) education as she began her academic career in Women's Studies:

So I'm with these white women that are working so hard to maintain their legitimacy within a male structured system, and so I'm teaching them all about Indigenous stuff, in addition to doing my own work. And it's like none of my work ever fit any of my courses. I had one professor tell me that Indigenous theory doesn't exist. My education has prepared me for the exclusion of Indigenous knowledge, and how hard it will be to push against it. But it also pushes against the idea, like what constitutes legitimate language? (Interview with Dr. Karen Lawford, AM, RM; August 25, 2017)

Karen emphasized that systemic racism cannot be tackled without attending to the culture of permission in management regimes. The family physician agreed that organizational architecture has a profound influence on provider experience:

I used to work in a place where everything was set up in silos. So the doctors worked separately from the nurses and separately from the traditional medicine people and the social workers and the mental health workers. Everybody was separated and not just in space because you know a lot of these workers were down the road and in the next building and we never met them. And so we never worked as a team, we never met these people and so I felt 
very, very isolated as a doctor. (Interview with family physician; July 16, 2017)

Conversely, when this physician began working in an organization that encouraged collaboration, she found her stress levels greatly reduced, and attributed this to how her new work-place "uses paradigms that are culturally and traditionally relevant" (Interview with family physician; July 16, 2017). Instead of feeling isolated, she likened the team approach in this new environment to the process of treaty-building through wampums; the roles and functions of the different departments providing health care radiate outward as the fifty-one strings from the centre, which signifies the common goal of supporting the health and well-being of the community.

Conversely, Knowledge Holders also described scenarios which speak to the divide between settler and Indigenous ways of knowing. The Director, Indigenous midwifery spoke about the epistemic divide that entrenches systemic racism:

And I find that non-Indigenous people, they think black and white, there's a lot of digital thinking. It's on or it's off. It's black or it's white. They just can't live in the grey. They just can't live in the grey. It's too uncomfortable. We have to live in the grey all the time. Marginalised people have to live in the grey all the time. We don't have the resources and the recognition so that things come to you in a straightforward way, you know? We don't have the resources to make it that clear for ourselves. We are creative, we have to think about a lot of go arounds to work within a system that does not acknowledge and respect Aboriginal Midwives. (Interview with Director, Indigenous midwifery; August 5, 2017)

If Indigenous patients avoid care or seek care when they are in the advanced stages of their pregnancy, they are often viewed as non-complaint or negligent (sometimes child welfare is even called); this response fails to account for the structurally embedded barriers which may impact care navigation for Indigenous peoples. As another example 
of this black and white thinking, the Director, Indigenous midwifery offered the following example:

Because child welfare when they work with women, it's violence, you know. Like when child welfare goes into your home and you're pregnant and they're scrutinizing where you're living, who you're living with, what your state of mental health is, what your... who are you? What food do you have in your fridge? What other children do you have? How many other kids were apprehended? Do you know what I mean? It's like you're a criminal. (Interview with Director, Indigenous midwifery; August $5,2017)$

The Knowledge Holders agreed that a strong support network often contributes to positive birth experiences. Partnering with a care navigator ${ }^{17}$ was suggested by the Director, Indigenous midwifery to bolster this support network for women who are more isolated, carefully adding that isolation is not limited to rural and remote communities. She likened this support system to the Sky Woman Creation story, calling on society to provide that safe landing on Turtle's back when Sky Woman fell from above.

Asked whether the contemporary policy shift to increase investment in First Nations and Inuit maternal and child health coincided with an epistemological shift, the Director, Indigenous midwifery informed me that she has noticed a more collaborative ethics and a desire to see from an Indigenous perspective. She cautioned however that there are significant epistemological differences yet to be reconciled with physicians, with respect to Indigenous midwifery:

And so there's so many battles between doctors and midwives on many, many levels like hospital privileges, the power dynamics.

\footnotetext{
${ }^{17}$ Provision of obstetric care navigation services has been tied to improved experiences of hospital delivery for individuals from marginalized populations (Austad et al., 2017). Cancer Care Ontario employs Aboriginal Navigators to "provide support and advocacy for First Nations, Inuit and Métis patients and families" (Cancer Care Ontario, 2017); the Aboriginal Navigator may help with the coordination of services, cultural and spiritual needs, and networking with partners to ensure cultural safety.
} 
We don't have as many midwives as doctors. Everyone knows what a doctor does, nobody knows about midwifery care. Many people don't fully understand what midwives do. We are primary care providers but they still think that we somehow have less status than physicians, lesser than in the system. (Interview with Director, Indigenous midwifery; August 5, 2017)

Carol Couchie stresses that a common understanding must reflect the body of knowledge that is relevant to Indigenous midwifery practitioners:

We have to get everyone knowing about Indigenous science, Indigenous ways of knowing, Indigenous thinking, you know healing of colonial trauma. Educating them about what reversing that stuff will actually mean. And it's not about what they think we need. It's about what we think we need. And what we know we need. (Interview with Carol Couchie, RM, Anishinaabe; August 26, 2017)

The Knowledge Holder testimony in this section echoes the violent ways in which "the colonialscape works dynamically to produce 'Indians' as subjects of spaces which they fail to fully occupy, claim, or govern: their lands, their homes, and their bodies" (Hunt, 2014b, p. 74) while simultaneously describing acts of resistance to succumb to colonialscape categories.

\subsection{1 "Protecting the provider goes hand in hand with protecting your women"}

The six Knowledge Holders interviewed had all experienced burnout in their respective careers in large part due to the epistemic violence they faced. Based on Sarah Hunt's (2014a) work described earlier in Chapter 3, I understand the process of epistemic violence to be the work of discourse in delegitimating knowledge. The family physician stressed that it is important to manage patient and community expectations and to establish healthy boundaries to achieve an appropriate level of work-life balance. Patients obviously prefer being delivered by the practitioner who regularly sees them but in many 
Indigenous communities, resources are stretched and there is often a single physician for the whole community so this is not realistic nor feasible.

Protecting the provider goes hand in hand with protecting your women. If you isolate yourself, you're gonna burnout and that's where we are right now in the western medical model completely supports burn-out because you're isolated by yourself, not in a community and you're not in a position to go and teach the people coming up after you. It's for free that I'm teaching medical students, I don't get a dollar; in fact, I'm putting out my own money so that medical students can come here and learn so there's this total disincentive to teaching. (Interview with family physician; July 16, 2017)

Speaking from her own experience, the Aboriginal Midwife stated that, "the burn out is coming from constantly butting heads, lateral violence, not working together and continuously having to defend this title [Aboriginal Midwife]" adding an important level of nuance to the unique circumstances faced by Aboriginal Midwives (Interview with Aboriginal Midwife; July 23, 2017). Addressing the everyday scale of epistemic violence, one Registered Midwife underscored that, "when you work this hard to support something that is this close to your heart in a system that is basically, was designed to eradicate you, burnout is inevitable" (Interview with Registered Midwife, Anishinaabe (Algonquin); August 26, 2017). 


\section{4 "The place that belongs to me": Understanding the return of birth to community as an act of anti-colonial activism}

For the Knowledge Holders interviewed in this thesis, returning birth to community is understood to be an integral component of achieving Indigenous sovereignty. It is perceived to symbolize - and indeed, materialize - a shift in governance away from colonial paternalism toward anti-colonial activism. These connections are exemplified by the following story shared by the Aboriginal Midwife:

This [returning birth] is a big deal for nation-building, that it all starts with where you're born. My grandfather told me a story of when he was born [1918]. He was born at home, knew the exact location where, and he pointed it out: 'Right here, this is the place where I was born. This is the exact place.' He said, 'the place that belongs to me'. That was his special place of birth, which is amazing. (Interview with Aboriginal Midwife; July 23, 2017)

Underscoring the desire for sovereign governance, this midwife petitioned to have her Nation's territory included on provincial birth certificates. In the future, she would like to see birth certificates which simply cite the Nation, without also referring to the jurisdiction of the province. She described Indigenous culture as "alive" and inseparable from Indigenous bodies and Indigenous land.

The Director, Indigenous midwifery emphasized that mainstreaming Indigenous midwifery will enable community governments to choose the maternal care providers practising in their communities. This is radically different from the current set-up in many communities, where expectant mothers are often the recipients of top-down, statecontrolled healthcare. She cautioned, however, that there will be challenges in increasing the accessibility and availability of Indigenous midwifery. For example, with respect to the \$6 million federal funding for culturally-safe midwifery, transfer agreements will 
need to be set up to delineate funding from the Ministry of Health to Indigenous/Aboriginal Midwives. These funding arrangements are brokered by community governments. Where community health departments and/or affiliated institutions have long endorsed physician-led maternal care or Registered Midwifery, there could be ambivalence about implementing Aboriginal Midwifery as a maternal care option. She also acknowledged that despite the significance of this funding investment to build midwifery capacity in Indigenous communities, the reality is that Indigenous midwifery is still nested within a recognition-based paradigm:

So we are in the process of self-determination. What does selfdetermination mean in a governance model? What does that look like? Who is making decisions? Who is having partnerships and relationships and what does that look like? But at least now the door has been opened and there is opportunity for Indigenous communities to self-govern. It's still within a colonial structure. Still looking at the government providing funding and having the final decisions on who is funded and who is not. (Interview with Director, Indigenous midwifery; August 5, 2017)

Despite these structural challenges, the Knowledge Holders spoke of their duty to uphold excellent care in the intimate spaces of their one-on-one relationships with clients. It was emphasized that Indigenous midwives prioritize their clients' concerns, customizing care according to their unique needs thereby promoting self-affirmation.

We are in charge of facilitating and holding space for the first relationship, the relationship with your mother. And if you can't get that one right, you probably aren't going to get a whole lot more. Because it's a complicated one. So, you know, all the way back to residential schools, colonialism, it's all tied to this. (Interview with Carol Couchie, RM, Anishinaabe; August 26, 2017) 
The Knowledge Holders consistently destabilized the conflation of midwifery with natural birth, which seems to be mythologized in popular understandings. The following excerpt is a typical example:

But again, that time she [the client] was just like okay I'm just gonna plan an epidural. I know it's what worked. It helped her relax and finally dilate, and her then 11-year-old helped catch the baby at that birth, right. And it's like that wouldn't have happened if I had been so married to this like second wave white feminist ideal of how you should birth and what makes a good birth and that natural is always best. I don't know. For me, it's more about treating people with dignity. And even you have clients who joke when they get into active labour like oh dignity's out the window. And I always correct them, I say modesty's out the window. Dignity is always here, right. Like you can be buck naked on all fours roaring like an animal and have your dignity. You don't have a shred of modesty left. But they're different things. (Interview with Registered Midwife, Anishinaabe (Algonquin); August 26, 2017)

Reflecting on the healing of Indigenous peoples from colonial trauma, Carol Couchie paraphrased Elder Mohawk Midwife Katsi Cook stating that, "the opposite of addiction is not sobriety, it's relationship" (Interview with Carol Couchie, RM, Anishinaabe; August 26, 2017).

\subsubsection{Birth is ceremony}

Because birth is not something to be feared. Like birth should be a celebration. Birth should be like when you feel so powerful as a woman, as a person giving birth. (Interview with Registered Midwife, Anishinaabe (Algonquin); August 26, 2017)

The Knowledge Holders expressed the view that birth is understood by many Indigenous peoples to be a ceremony that brings joy to the community and restores balance. The Knowledge Holders stressed that this ceremony can happen anywhere:

I believe that birth is a ceremony and that ceremony happens with the delivery of a baby. It doesn't matter where that happens. If it happens in a Caesarian section on an operating table, then that's 
where it happens but that's the ceremony. And of course, if that can happen at home or a birthing centre outside of the hospital, then that's ideal. But that can't always happen. So, wherever that birth happens, that's where I'm gonna be. And if it's on the moon, then that's where I'll go, you know what I'm saying? Doesn't matter to me. (Interview with Carol Couchie, RM, Anishinaabe; August 26, 2017)

Reiterating this point, the Aboriginal Midwife that I interviewed put it this way: "We support the client's individuality throughout the process, to whatever degree of cultural components they choose to use. Every bit of their journey is valued and safeguarded. If they're satisfied with the outcome, to me, that's the ceremony." (Interview with Aboriginal Midwife; July 23, 2017).

When asked about her ideal birth, the family physician explained that she would prefer to be close to a hospital with emergency obstetric services because she had a history of difficult deliveries. Even so, she was adamant that she would have liked to incorporate more traditional ceremony over the course of her maternal care. Overall, there was a spectrum of views expressed in terms of how Knowledge Holders had approached their own births or visualised their ideal births, but when it came to their clients, they advocated for whatever the client prioritised.

The Knowledge Holders advised that incorporating ceremony does not automatically suggest the involvement of all family members. In fact, they relayed experiences where the presence of family members during clients' labour generated undue stress because they did not have a role and were unhelpful. Additionally, Knowledge Holders mentioned that some of their clients experience Intimate Partner Violence or lateral violence and they must always be prepared to adjust their care to these potential circumstances. Reiterating the role of education as being integral to their 
practice, however, many of the Knowledge Holders mentioned including younger family members in the birth, when circumstances are appropriate, so that they can learn not to be afraid and celebrate in the ceremony.

\subsection{What I heard}

Applying the theoretical framework developed in Chapter 3, I will argue that the process of legislating midwifery has produced the distinct spatio-legal identities (Daigle, 2016; Hunt, 2014b) of Registered Midwife and Aboriginal Midwife. As a result of this (neo)colonial categorization (Hunt, 2014b), tensions and fractures have surfaced in the Indigenous midwifery community; professional regulation has (ironically, if not altogether awkwardly) reproduced a knowledge hierarchy that appears to marginalize Aboriginal Midwives. This marginalization operates discursively through the concepts of risk and competency as well as materially by precluding access to state funding. The legalization of midwifery can be understood to have generated topologies of exception (Belcher, Martin, Secor, Simon, \& Wilson, 2008) which are still nested (Alfred, 1995; A. Simpson, 2014) within the jurisdiction of state law.

The goal of the movement to legalize midwifery was to solicit recognition of competency from the Canadian state. As Nestel's (2006) analysis reveals, this movement represented the select interests of an elite group of white, affluent midwives. Following from this conclusion, the movement was not representative of the rich body of knowledge long embodied by Indigenous midwives or the sets of practices for governing midwifery that already existed within systems of Indigenous law. Sarah Hunt (2014b) situates such erasure within the machinery of colonialism:

Canadian law bulldozed over pre-existing Indigenous geographies, yet Indigenous jurisdiction was never ceded. Rather, 
Canadian legal representations of space came to be given certain performative power through the violence of law, where

Indigenous spatial representations continued to be lived upon the land but were not successfully performative. In other words, while Indigenous people's socio-legal practices of living their obligations and relations within their traditional territories continues to this day, the spatial relations they produce remain unrecognized within dominant operations of power. (pp. 65-66)

It would be largely misleading, however, to suggest that in the contemporary landscape of maternal care governance, Indigenous midwives engage a tidy set of ontologies and epistemologies that is somehow separate or distinct from the knowledge base informing other communities of midwives. (Neo)colonial identity politics would have Indigenous practitioners choose between a western mode of practice or a traditional one, as if it were possible for these categories to map neatly onto the mess of everyday life. This teems with "settler manageability in biopolitical states of care" (A. Simpson, 2014, p. 10), a rhetoric frequently invoked to justify the structural violence of the state; the disproportionate (mis)apprehensions of Indigenous children by child welfare carried out under the guise of protection serve as a chilling reminder (Gough, Trocmé, Brown, Knoke, \& Blackstock, 2005). With respect to this structural violence, Sarah de Leeuw (2016) contends that it is

through the categorization and spatio-legal control of Indigenous bodies and lives - often young, vulnerable bodies and lives in the care of women as mothers - that colonial power reproduces itself. Further, the slow and diffuse nature of these biopolitical forms of governance allows colonial violence to remain unseen as it unfolds in intimate and micro-scale domestic spaces. (p. 21)

My interview data suggests that Indigenous practitioners are pushing against this (neo)colonial categorization and excavating the grounds of its legitimacy. 
I would now like to share with you an excerpt from one of my interviews where this resistance to categorization is foregrounded. I hesitated to share this quote in the previous chapter, fearing that without the proper scaffolding its meaning might be misconstrued as corroborating (mis)perceptions that endemic lateral violence is an 'Indian problem'. Audra Simpson $(2014,2017)$ instructs us to refuse to write the story that renders Otherness legible, cautioning that our worded re-presentations can further entrench marginalization if we are not careful. Similarly, Sarah de Leeuw (2017) asserts that "comprehension [...] would be a second violence to a story beyond telling" (p. 313). So, indulging your willingness to sit with the "productively confusing" (Hunt, 2014a, p. 31), I share this quote to attend to the messiness of everyday life, crystallizing the incompatibility of prescriptive blanket policies to govern maternal care in Indigenous communities.

\subsection{On speaking things unsaid}

I feel like life is messy. Everything is dysfunctional on some level somewhere. What is a functional community and what is a dysfunctional community? So you want to identify what that is. And I think the only person who can identify that for herself is a pregnant Indigenous woman who's walking that path. And what is dysfunctional for her and what is functional for her? So her normalisation of someone let's say in her life who is causing her stress, whether it's somebody who is controlling, they could be physically violent or sexually abusive or whatever it is, for her that might be normal. I've worked with many women where that's accepted, that's understood because of intergenerational trauma. You know in our communities, that's something that's just, it's not teased out as something that is abnormal. You know? I think that people don't want to openly judge other people for having relationships that aren't necessarily really healthy. But then you think to yourself, look at our communities and look at where we have come from with residential schools. Like who am I to say that that woman doesn't derive some kind of support from that person? Who am I to judge and say he/they should leave, you 
know what I mean? I work with people where they're at. It is using a trauma-informed lens to all of your work.

\section{$[\ldots]$}

One of the issues people won't say out loud when they're leaving their communities is lots of women are afraid to go because they are leaving other children behind. And in someone else's care, they may not be totally safe. Whether it's your aunties or uncles or partners or whoever.

(Interview with Director, Indigenous midwifery; August 5, 2017)

$$
[\ldots]
$$

In this powerful statement, the Director, Indigenous midwifery depicts Indigenous women's experiences of maternal care as messy and nested, pushing against the neatness and order issuing from official discourses of state protection by the First Nations and Inuit Health Branch. This information is not easy to digest. Readers may wonder; doesn't this admission of lateral violence reinforce the naturalization of violence as the product of 'reserved space' (Hunt, 2014b)? Reading this story through a decolonizing lens (see for example interpretations of decolonizing scholarship in Kornelsen et al., 2011; Lawford, 2017; Olson, 2013), however, I understand this statement as articulating the profound resilience and resistance of Indigenous women, who continue to assert their agency even in the face of tremendous adversity. In mandating the practice of evacuation, the guise of protection compromises the safety and well-being of Indigenous families in ways that one would deem truly horrible and unthinkable. In the scenario described above, women must choose whether to safeguard the well-being of their children who are living or their children who are not yet born. 


\section{Chapter: Afterbirth}

\subsection{What I learned: Where do we go from here?}

Knowledge Holders agreed that Indigenous midwifery will play a central role in returning birth to community. They emphasized that increasing accessibility to culturally relevant midwifery education and long-term, ongoing funding are critical components of building Indigenous midwifery capacity. These mandates seem simple enough. However, if one argues that state funding signals an official recognition of competency, and that this stamp of competency references the western biomedical normative standard, then a system of nested sovereignty becomes visible. As was discussed previously in Chapter 3 regarding the politics of recognition, the goals of anti-colonial resistance and the goals of the state are enmeshed in the pursuit of conflicting ends. Audra Simpson (2014) reminds us that, "[i]n situations in which sovereignties are nested and embedded, one proliferates at the other's expense; the United States and Canada can only come into political being because of Indigenous dispossession” (p. 12).

I am of course in no way advocating for the diversion of state funds away from Indigenous midwifery programs. But with the understanding that money often comes with strings attached, I am suggesting that decisions with respect to funding allocation and metrics for program evaluation should be careful to reflect interpretations according to Indigenous law (see for e.g. John Borrows in Chris Beckett \& Cameron, 2015). Given that the contemporary system of maternal care governance serving Indigenous communities is arguably located both "within and apart from settler governance" (A. Simpson, 2014, p. 11), I contend that we should be prepared for mutual incompatibility. Sarah Hunt (2014b) warns us that spatio-legal identities do not necessarily translate well 
across modes of governance or map onto each other, which can lead to the "categorizing [of] Indigenous legal practices as 'cultural beliefs' and Canadian law as 'truth'” (p. 69). The (re)production of (neo)colonial violence will likely persist if maternal care governance reflects singular interpretations of state law. If we instead begin with the understanding that the many Nations occupying this territory govern themselves according to sovereign legal orders, we might open up space for the possibility of reconciliation.

\subsection{Unraveling...}

In the territories now known collectively as Canada, the longstanding government practice of evacuating Indigenous women away from their communities to give birth threatens to perpetuate colonial dis-place-ment. The movement to return birth to community challenges the naturalization and normalization of evacuation; it is an effort to (re)place Indigenous maternal care, back in the hands of the most competent and relevant practitioners, and to honour the agency of Indigenous women and their families. The Knowledge Holders interviewed for this thesis emphasized the central role of Indigenous midwifery in advancing this movement.

However, analysis of interview data identified two important barriers to building Indigenous midwifery capacity; (1) midwifery education needs to be more accessible and culturally relevant to prospective Indigenous students and (2) funding for Indigenous midwifery needs to be ongoing and long-term. Tackling these barriers will necessitate a closer look at how maternal care is governed in this country on an 'inter-national'18 scale. And while the findings of this thesis cannot be generalized, it is my hope that the

\footnotetext{
${ }^{18}$ In reference to Leanne Betasamosake Simpson's use of the term in As We Have Always Done: Indigenous Freedom through Radical Resistance (L. B. Simpson, 2017)
} 
analytical framework developed here may be of use to practitioners and policymakers to continue this work.

In this thesis, I have interpreted maternal care governance using a geographical methodology. The knowledge generated from my interviews with providers speaks to the lived-in tension of constantly having to navigate a complex colonialscape (Hunt, 2014b) of nested sovereignty (Alfred, 1995; A. Simpson, 2014). In their day-to-day practice, providers of Indigenous maternal care are negotiating their spatio-legal identities (Daigle, 2016; Hunt, 2014b) within the interrelated modes of governance rooted in Indigenous and Canadian law. These brave and tenacious women are not 'subjects' of one or the other rule of law but powerful 'legal actors' who continually remake ontologies of governance (Hunt, 2014b). From this perspective, this research speaks to "everyday relational geographies of resurgence" (Daigle, 2016, p. 261).

It is my hope that these pages have honoured the testimony of the six Knowledge Holders who have so deftly and meticulously articulated the (re)production of (neo)colonial relations as entrenching contemporary health inequities in the provision of maternal care for Indigenous families. As I neared the end of my writing, an awful tragedy crystallized the extent of the horrific structural violence facing Indigenous peoples in this country. Within the confines of the colonial architecture, there was no justice for the murders of Colten Boushie and Tina Fontaine. These gross injustices resonate with the poignancy of Audra Simpson's (2017) assertion that, "Indigenous peoples are grappling with the fiction of justice and its comingling with recognition while pushing for justice and its comingling with the failures of recognition" (p. 6). 
In summary, discussions around returning birth to community are typically framed in terms of mitigating risk and ensuring competency; the important advantage of listening to provider testimony through a geographical methodology is that it solidifies the core assertion that colonialism is about land (place). This allows for the (re)positioning of connections to Birth-Place as powerful pathways to healing from colonial violence. In line with these conclusions, this thesis advocates for the development of policy instruments which not only reflect but are informed by Indigenous ontologies and epistemologies of place and governance, shifting the discussion from mitigating the potential for harm to strengthening opportunities for healing from "soul loss" (Cajete quoted in Walters et al., 2011, p. 174). Put another way, how would policymaking about Indigenous maternal care be different if it sought out interpretations from the perspective of Indigenous law?

\subsection{Study limitations}

In my research, I did not interview any Inuit maternal care providers. While two of the Knowledge Holders had completed locums in the Nunavik region, they did not work out of Inukjuak, Puvirnituq, Salluit or Kuujjuaq on a long-term basis. More primary data collection is needed to contextualize the dearth of written information about the unique spatio-legal dimensions of maternal care governance in the Nunavik region of Québec. Furthermore, there is even less information available with respect to the specific context of maternal care governance experienced by Métis peoples; Métis peoples are recognized as Aboriginal by the Constitution Act, 1982, but healthcare delivery for Métis peoples does not fall within the jurisdiction of FNIHB. Additionally, I did not interview individuals who opposed the return of birth to community. This is a necessary piece of 
the overarching narrative and these contrary perceptions should be addressed in future research. Primary data reflecting the experiences of clients of care, in addition to that of providers, is needed to contextualize these research findings.

Secondly, this study cannot resonate with the diversity of Indigenous experiences of maternal care across Canada. In no way are experiences of isolation and alienation limited to places that are deemed rural or remote. An unintended consequence of the framing of this study may be a perceived bifurcation of on- versus off-reserve and rural versus urban Indigenous experience. I have not adequately resisted these dualisms, especially as they play out in complex and multi-faceted landscapes of healthcare. Regrettably, I have not been able to address the disparities in maternal care affecting Indigenous peoples in off-reserve and/or urban areas (see for e.g. Wiebe, Barton, Auger, Pijl-Zieber, \& Foster-Boucher, 2015).

\subsection{To-do list}

In this research project, I have examined only the relevant sociopolitical dimensions of midwifery legalization in the provinces of Ontario (and to a lesser extent Québec). As we have seen, the legislative and policy implications of the professional regulation of midwifery were an important aspect of this research. Based on these preliminary findings, I suggest that a comprehensive spatio-legal analysis across other jurisdictions is critical to contribute important nuances to this present discussion of returning birth.

The second line of inquiry that is pertinent to this research is a compendium of relevant case studies to describe existing Indigenous governance models for maternal care delivery. Whereas I have more or less focussed on the ways that (neo)colonial 
governance is implicated in impeding advocacy efforts, this should not be extrapolated as a lack of successful Indigenous governance models. Case studies provide valuable information for what works well and what doesn't, and there are a number of pertinent examples for this topic; in Ontario: Dilico Family Health Team Clinic in Fort William First Nation, K'Tigaaning Midwives in Powassan, Kenhte:ke Midwives in Tyendinaga Mohawk Territory, Onkwehon:we Midwives in Akwesasne ${ }^{19}$, Shkagamik-Kwe Health Centre in Sudbury, Southwest Ontario Aboriginal Health Access Centre in London (Association of Ontario Midwives, 2018) and in Québec (Nunavik): the Inuulitsivik Health Centre, which consists of the Inukjuak, Puvirnituq, and Salluit maternities, and the Ungava Tulattavik Health Centre in Kuujjuaq (Ordre des sage-femmes du Québec, n.d.c).

\subsection{Final thoughts}

Recapitulating the discussion presented earlier in Chapter 4, this research has not produced a "tidy conclusion" (de Leeuw, 2017, p. 311), which in view of the literature that informs this work is, in fact, appropriate (see for e.g. de Leeuw, 2017; Hunt, 2014a). Instead, I have re-presented some of the reasons why Indigenous maternal care providers are advocating for the return of birth to community. Additionally, I have re-presented some of the barriers impeding these advocacy efforts. My analysis attempted to situate these knowledges within a geographical framework and position them as vital for informing alternatives to the hegemonic paradigm of (neo)colonial maternal care governance which is typified by longstanding endorsement of the federal evacuation policy.

\footnotetext{
19 The lands of the Akwesasne Mohawk Nation transcend the Ontario/Québec and Canada/USA borders.
} 
On this research journey, I have learned that returning birth to community is understood by many Indigenous maternal care providers to be a celebration of the creation power of the Earth and of the Feminine. For the Knowledge Holders interviewed in this thesis, returning birth signals a break with (neo)colonial governance and a crucial step toward Indigenous sovereignty. With this goal of sovereign governance in mind, I suggest that interpreting maternal care delivery through the lens of Indigenous law, thus tapping into the rich body of knowledge that pre-dates and has survived settlercolonialism, will be an important future research direction. 


\section{Bibliography}

About Markham. (2014). Retrieved 20 March 2018, from

https://www.markham.ca/wps/portal/Markham/AboutMarkham/

Adelson, N. (2005). The embodiment of inequity: Health disparities in Aboriginal Canada. Canadian Journal of Public Health, 96, S45-S61.

Agamben, G. (2005). State of exception. Chicago, IL: University of Chicago Press.

Alfred, G. T. (1995). Heeding the voices of our ancestors: Kahnawake Mohawk politics and the rise of native nationalism. New York, NY: Oxford University Press.

Association of Ontario Midwives. (2018). Indigenous midwifery [Policy]. Retrieved 13 June 2018, from https://www.ontariomidwives.ca/indigenous-midwifery

Austad, K., Chary, A., Martinez, B., Juarez, M., Martin, Y. J., Ixen, E. C., \& Rohloff, P. (2017). Obstetric care navigation: A new approach to promote respectful maternity care and overcome barriers to safe motherhood. Reproductive Health, 14. doi:10.1186/s12978-017-0410-6

Barad, K. (2007). Meeting the universe halfway: Quantum physics and the entanglement of matter and meaning. Durham, NC: Duke University Press.

Barclay, L., Kornelsen, J., Longman, J., Robin, S., Kruske, S., Kildea, S., ... Morgan, G. (2016). Reconceptualising risk: Perceptions of risk in rural and remote maternity service planning. Midwifery, 38, 63-70.

Beckett, C., \& Cameron, S. D. (2015). John Borrows: The profound lessons of Indigenous law [Video]. San Francisco, CA: Kanopy. Retrieved from https://kanopy.com/video/profound-lessons-indigenous-law-john-borrows 
Belcher, O., Martin, L., Secor, A., Simon, S., \& Wilson, T. (2008). Everywhere and nowhere: The exception and the topological challenge to geography. Antipode, 40, 499-503.

Bellrichard, C. (2014, July 10). Midwifery program with core Aboriginal mandate halted. CBC News. Retrieved from http://www.cbc.ca/news/indigenous/midwiferyprogram-with-core-aboriginal-mandate-halted-1.2701685

Birch, J., Ruttan, L., Muth, T., \& Baydala, L. (2009). Culturally competent care for Aboriginal women: A case for culturally competent care for Aboriginal women giving birth in hospital settings. Journal of Aboriginal Health, 4, 24-34.

Bird, H. (2017, April 12). In swift policy change, pregnant Nunavut women to get escorts when travelling to give birth. $C B C$ News. Retrieved from http://www.cbc.ca/news/canada/north/pregnant-women-health-canada-nunavut1.4067761

Bonesteel, S. (2008). Canada's relationship with Inuit: A history of policy and program development. (E. Anderson, Ed.). Ottawa, ON: Minister of Public Works and Government Services Canada. Retrieved from http://www.aadncaandc.gc.ca/eng/1100100016900/1100100016908

Braun, V., \& Clarke, V. (2006). Using thematic analysis in psychology. Qualitative Research in Psychology, 3, 77-101.

Braun, V., \& Clarke, V. (2014). What can "thematic analysis" offer health and wellbeing researchers? International Journal of Qualitative Studies on Health and WellBeing, 9. doi:10.3402/qhw.v9.26152 
Brown, H., Varcoe, C., \& Calam, B. (2011). The birthing experiences of rural Aboriginal women in context: Implications for nursing. Canadian Journal of Nursing Research, 43, 100-117.

Browne, A. J., Smye, V. L., \& Varcoe, C. (2005). The relevance of postcolonial theoretical perspectives to research in Aboriginal health. Canadian Journal of Nursing Research, 37, 16-37.

Browne, A. J., Varcoe, C., Smye, V., Reimer-Kirkham, S., Lynam, M. J., \& Wong, S. (2009). Cultural safety and the challenges of translating critically oriented knowledge in practice. Nursing Philosophy, 10, 167-179.

Cancer Care Ontario. (2017, June 28). Aboriginal Navigators [Healthcare services]. Retrieved 26 June 2018, from https://www.cancercareontario.ca/en/find-cancerservices/aboriginal-navigators

Carroll, D., \& Benoit, C. (2004). Aboriginal midwifery in Canada: Merging traditional practices and modern science. In I. L. Bourgeault, C. Benoit, \& R. Davis-Floyd (Eds.), Reconceiving Midwifery (pp. 263-286). Montréal, QC: McGill-Queen’s University Press.

CBC News. (2016, June 28). Midwifery students 'left high and dry' after hearing courses likely won't continue this fall. $C B C$ News. Retrieved from http://www.cbc.ca/news/canada/manitoba/manitoba-ucn-midwifery-courses1.3657028

Clarke, V., \& Braun, V. (2017). Thematic analysis. The Journal of Positive Psychology, $12,297-298$. 
College of Midwives of Ontario. (2018). Applicants: Eligibility for registration as a midwife in Ontario [Midwifery regulation]. Retrieved 29 May 2018, from http://www.cmo.on.ca/registration/applicants/

Couchie, C., \& Sanderson, S. (2007). A report on best practices for returning birth to rural and remote Aboriginal communities. Journal of Obstetrics and Gynaecology Canada, 29, 250-254.

Coulthard, G. (2007). Subjects of empire: Indigenous peoples and the 'politics of recognition' in Canada. Contemporary Political Theory, 6, 437-460.

Coulthard, G. (2010). Place against empire: Understanding Indigenous anti-colonialism. Affinities: A Journal of Radical Theory, Culture, and Action, 4, 79-83.

Coulthard, G. (2014). Red skin, white masks: Rejecting the colonial politics of recognition. Minneapolis, MN: University of Minnesota Press.

Daigle, M. (2016). Awawanenitakik: The spatial politics of recognition and relational geographies of Indigenous self-determination. The Canadian Geographer / Le Géographe Canadien, 60, 259-269.

de Leeuw, S. (2015). Activating place: Geography as a determinant of Indigenous peoples' health and well-being. In M. Greenwood, S. de Leeuw, N. M. Lindsay, \& C. Reading (Eds.), Determinants of Indigenous peoples' health in Canada: Beyond the social (pp. 90-103). Toronto, ON: Canadian Scholars' Press. de Leeuw, S. (2016). Tender grounds: Intimate visceral violence and British Columbia's colonial geographies. Political Geography, 52, 14-23. 
de Leeuw, S. (2017). Writing as righting: Truth and reconciliation, poetics, and new geographing in colonial Canada. The Canadian Geographer / Le Géographe Canadien, 61, 306-318.

de Leeuw, S., \& Greenwood, M. (2017). Turning a new page: Cultural safety, critical creative literary interventions, truth and reconciliation, and the crisis of child welfare. AlterNative: An International Journal of Indigenous Peoples, 13, 142151.

de Leeuw, S., Greenwood, M., \& Lindsay, N. M. (2013). Troubling good intentions. Settler Colonial Studies, 3, 381-394.

de Leeuw, S., Lindsay, N. M., \& Greenwood, M. (2015). Introduction: Rethinking determinants of Indigenous peoples' health in Canada. In M. Greenwood, S. de Leeuw, N. M. Lindsay, \& C. Reading (Eds.), Determinants of Indigenous peoples' health in Canada: Beyond the social (pp. xi-xxix). Toronto, ON: Canadian Scholars' Press.

Deerchild, R. (2018, February 24). The politics of citation: Is the peer review process biased against Indigenous academics? Unreserved. Canadian Broadcasting Corporation. Retrieved from http://www.cbc.ca/radio/unreserved/the-politics-ofcitation-is-the-peer-review-process-biased-against-indigenous-academics1.4547468

Deloria Jr., V. (1992). God is red: A Native view of religion. Golden, CO: Fulcrum Publishing. 
Department of Finance Canada. (2017). Budget 2017: Building a strong middle class. Her Majesty the Queen in Right of Canada. Retrieved from https://www.budget.gc.ca/2017/docs/plan/toc-tdm-en.html

Douglas, V. K. (2010). The Inuulitsivik Maternities: Culturally appropriate midwifery and epistemological accommodation. Nursing Inquiry, 17, 111-117.

Douglas, V. K. (2011). The Rankin Inlet Birthing Centre: Community midwifery in the Inuit context. International Journal of Circumpolar Health, 70, 178-185.

Dyck, I., \& Kearns, R. (1995). Transforming the relations of research: Towards culturally safe geographies of health and healing. Health \& Place, 1, 137-147.

First Nations and Inuit Health Branch, Health Canada. (2005, July). 2005 Non-Insured Health Benefits (NIHB) medical transportation policy framework. Health Canada. Retrieved from http://www.fnha.ca/Documents/Medical-Transportation-PolicyFramework.pdf

First Nations and Inuit Health Branch, Health Canada. (2011). Clinical practice guidelines for nurses in primary care. Health Canada. Retrieved from https://www.canada.ca/en/indigenous-services-canada/services/first-nations-inuithealth/health-care-services/nursing/clinical-practice-guidelines-nurses-primarycare.html

First Nations and Inuit Health Branch, Health Canada. (2018, January). 2018 NonInsured Health Benefits (NIHB) medical transportation policy framework (interim) [Policy]. Retrieved 16 May 2018, from https://www .canada.ca/en/indigenous-services-canada/services/first-nations-inuithealth/reports-publications/non-insured-health-benefits/non-insured-health- 
benefits-nihb-medical-transportation-policy-framework-july-2005-first-nationsinuit-health.html

First Nations Information Governance Centre. (2018). The First Nations principles of OCAP [Nonprofit organization]. Retrieved 21 March 2018, from http://fnigc.ca/ocapr.html

Fletcher, C. (1994). The Innuulisivik Maternity Centre: Issues around the return of Inuit midwifery and birth to Povungnituk, Quebec (Research Program of the Royal Commission on Aboriginal Peoples).

Gage, G. J., Kipke, D. R., \& Shain, W. (2012). Whole animal perfusion fixation for rodents. Journal of Visualized Experiments. doi:10.3791/3564

Gerlach, A. J. (2012). A critical reflection on the concept of cultural safety. Canadian Journal of Occupational Therapy, 79, 151-158.

Gough, P., Trocmé, N., Brown, I., Knoke, D., \& Blackstock, C. (2005). Pathways to the overrepresentation of Aboriginal children in care (CECW Information Sheet No. \#23E). Toronto, ON: Centre of Excellence for Child Welfare, University of Toronto.

Health Canada. (2015, January 6). Clinical practice guidelines for nurses in primary care [Policy]. Retrieved 12 June 2018, from https://www.canada.ca/en/indigenousservices-canada/services/first-nations-inuit-health/health-careservices/nursing/clinical-practice-guidelines-nurses-primary-care.html Health Canada. (2017, June 19). Government of Canada announces funding for First Nations and Inuit midwifery: Recognizing the remarkable difference that midwives make in the lives of mothers, babies and families [News release]. 
Retrieved 15 May 2018, from https://www.canada.ca/en/healthcanada/news/2017/06/government_of_canadaannouncesfundingforfirstnationsand inuitmidwi.html

Hiebert, S. (2003). NCN Otinawasuwuk (Receivers of Children): Taking control of birth in Nisichawayasihk Cree Nation. University of Manitoba, Winnipeg, MB.

Hole, R. D., Evans, M., Berg, L. D., Bottorff, J. L., Dingwall, C., Alexis, C., ... Smith, M. L. (2015). Visibility and voice: Aboriginal people experience culturally safe and unsafe health care. Qualitative Health Research, 25, 1662-1674.

Horn-Miller, K. (2016). Distortion and healing: Finding balance and a "good mind" through the rearticulation of Sky Woman's journey. In N. Kermoal \& I. Altamirano-Jiménez (Eds.), Living on the land: Indigenous women's understanding of place (pp. 19-38). Edmonton, AB: Athabasca University Press.

Hunt, S. (2014a). Ontologies of Indigeneity: The politics of embodying a concept. Cultural Geographies, 21, 27-32.

Hunt, S. (2014b). Witnessing the Colonialscape: Lighting the intimate fires of Indigenous legal pluralism. Simon Fraser University, Burnaby, BC.

Hunt, S., \& Holmes, C. (2015). Everyday decolonization: Living a decolonizing queer politics. Journal of Lesbian Studies, 19, 154-172.

Ingram, T. (2016, July 7). Midwifery students rally for cancelled program. The Manitoban. Retrieved from http://www.themanitoban.com/2016/07/midwiferystudents-rally-for-cancelled-program/28606/

Inuit Tapiriit Kanatami. (2018). About Canadian Inuit: Inuit regions of Canada. Retrieved 13 June 2018, from https://www.itk.ca/about-canadian-inuit/ 
Jasen, P. (1997). Race, culture, and the colonization of childbirth in northern Canada. Social History of Medicine, 10, 383-400.

Jennings Linehan, S. (1992). Giving birth the 'white man's way'. Healthsharing: A Canadian Women's Health Quarterly, 13, 11-15.

Kahealani Pacheco, A. M., \& Konsmo, E. M. (2016). Violence on the land, violence on our bodies: Building an Indigenous response to environmental violence.

Women's Earth Alliance \& Native Youth Sexual Health Network. Retrieved from http://landbodydefense.org/home

Katsi Cook. (2018). [Nonprofit organization]. Retrieved 15 March 2018, from https://www.ourbodiesourselves.org/about/contributors/katsi-cook/

Kaufert, P. A., \& O’Neil, J. D. (1990). Cooptation and control: The reconstruction of Inuit birth. Medical Anthropology Quarterly, 4, 427-442.

Kildea, S. (2006). Risky business: Contested knowledge over safe birthing services for Aboriginal women. Health Sociology Review, 15, 387-396.

Kirkup, K. (2017, April 10). Indigenous women who leave home to give birth won't have to go alone. Huffington Post Canada. Retrieved from http://www.huffingtonpost.ca/2017/04/10/indigenous-womenbirth_n_15913928.html

Kornelsen, J., \& Grzybowski, S. (2004). The costs of separation: The birth experiences of women in isolated and remote communities in British Columbia. Canadian Woman Studies, 24, 75-80.

Kornelsen, J., \& Grzybowski, S. (2012). Cultures of risk and their influence on birth in rural British Columbia. BMC Family Practice, 13. doi:10.1186/1471-2296-13-108 
Kornelsen, J., Kotaska, A., Waterfall, P., Willie, L., \& Wilson, D. (2010). The geography of belonging: The experience of birthing at home for First Nations women. Health \& Place, 16, 638-645.

Kornelsen, J., Kotaska, A., Waterfall, P., Willie, L., \& Wilson, D. (2011). Alienation and resilience: The dynamics of birth outside their community for rural First Nations women. Journal of Aboriginal Health, 7, 55-64.

Kornelsen, J., \& MacKie, C. (2013). The role of risk theory in rural maternity services planning. Rural and Remote Health, 13. Retrieved from www.rrh.org.au/journal/article/2206

Law, J. (2004). And if the global were small and noncoherent? Method, complexity, and the baroque. Environment and Planning D: Society and Space, 22, 13-26.

Lawford, K. (2011). First Nations women's evacuation during pregnancy from rural and remote reserves. University of Ottawa, Ottawa, ON.

Lawford, K. (2016). Locating invisible policies: Health Canada's evacuation policy as a case study. Atlantis, 37, 147-160.

Lawford, K. (2017). Understanding the experiences and processes of Health Canada's evacuation policy for pregnant First Nations women in Manitoba. University of Ottawa, Ottawa, ON.

Lawford, K., \& Giles, A. (2012a). An analysis of the evacuation policy for pregnant First Nations women in Canada. AlterNative: An International Journal of Indigenous Peoples, 8, 329-342.

Lawford, K., \& Giles, A. (2012b). Marginalization and coercion: Canada's evacuation policy for pregnant First Nations women who live on reserves in rural and remote 
regions. Pimatisiwin: A Journal of Aboriginal and Indigenous Community Health, $10,327-340$.

Liamputtong, P. (2007). Researching the vulnerable: A guide to sensitive research methods. London, UK: SAGE.

Loppie, C. (2007). Learning from the Grandmothers: Incorporating Indigenous principles into qualitative research. Qualitative Health Research, 17, 276-284.

Merrick, C. (2017, February 14). Chief Catherine Merrick (Chief, Pimicikamak

Okimawin) at the Indigenous and Northern Affairs Committee. Retrieved 20

March 2018, from https://openparliament.ca/committees/aboriginal-affairs/421/44/chief-catherine-merrick-1/only/

Midwifery Act, 1991, SO 1991, c 31. Retrieved from https://www.ontario.ca/laws/ statute/91m31

Midwives Act, CQLR 2018, c S-0.1. Retrieved from http://legisquebec.gouv.qc.ca/en/ ShowDoc/cs/S-0.1

Mol, A. (2006). Proving or improving: On health care research as a form of selfreflection. Qualitative Health Research, 16, 405-414.

National Aboriginal Health Organization. (2008). Celebrating birth: Aboriginal midwifery in Canada. Ottawa, ON: National Aboriginal Health Organization. Retrieved from http://www.deslibris.ca/ID/219162

Nestel, S. (2000). Delivering subjects: Race, space, and the emergence of legalized midwivery in Ontario. Canadian Journal of Law and Society, 15, 187-215. 
Nestel, S. (2006). Obstructed labour: Race and gender in the re-emergence of midwifery. Vancouver, BC: UBC Press. Retrieved from books1.scholarsportal.info/viewdoc.html?id=36142

Nunkoosing, K. (2005). The problems with interviews. Qualitative Health Research, 15, 698-706.

Olson, R. (2013). Relocating childbirth: The politics of birth place and Aboriginal midwifery in Manitoba, Canada. University of Sussex, Brighton, UK.

Olson, R., \& Couchie, C. (2013). Returning birth: The politics of midwifery implementation on First Nations reserves in Canada. Midwifery, 29, 981-987.

Ordre des sage-femmes du Québec. (n.d.-a). Graduates from France [Midwifery regulation]. Retrieved 29 May 2018, from http://www.osfq.org/admission/diplomees-en-france/?lang=en

Ordre des sage-femmes du Québec. (n.d.-b). Graduates from UQTR [Midwifery regulation]. Retrieved 29 May 2018, from http://www.osfq.org/admission/inscription/?lang=en

Ordre des sage-femmes du Québec. (n.d.-c). The Practice in Nunavik [Midwifery regulation]. Retrieved 29 May 2018, from http://www.osfq.org/admission/travailler-au-quebec/?lang=en

Pauktuutit: Inuit Women's Association of Canada. (1995). A special report on traditional midwifery (Newsletter No. 10(1)). Ottawa, ON: Pauktuutit.

Pratt, G. (2005). Abandoned women and spaces of the exception. Antipode, 37, 10521078. 
Razack, S. (2002). Race, space, and the law: Unmapping a white settler society. Toronto, ON: Between the Lines.

Reading, C. (2015). Structural determinants of Aboriginal peoples' health. In M.

Greenwood, S. de Leeuw, N. M. Lindsay, \& C. Reading (Eds.), Determinants of Indigenous peoples' health in Canada: Beyond the social (pp. 3-15). Toronto, ON: Canadian Scholars’ Press.

Regulated Health Professions Act, 1991, SO 1991, c 18. Retrieved from https:// www.ontario.ca/laws/statute/91r18

Richmond, C. (2015). The relatedness of people, land, and health: Stories from Anishinabe Elders. In M. Greenwood, S. de Leeuw, N. M. Lindsay, \& C. Reading (Eds.), Determinants of Indigenous peoples' health in Canada: Beyond the social (pp. 47-63). Toronto, ON: Canadian Scholars' Press.

Richmond, C., \& Ross, N. A. (2009). The determinants of First Nation and Inuit health: A critical population health approach. Health \& Place, 15, 403-411.

Ritenburg, H., Leon, A. E. Y., Linds, W., Nadeau, D. M., Goulet, L. M., Kovach, M., \& Marshall, M. (Meri). (2014). Embodying decolonization: Methodologies and indigenization. AlterNative: An International Journal of Indigenous Peoples, 10, $67-80$.

Simonds, V. W., \& Christopher, S. (2013). Adapting western research methods to Indigenous ways of knowing. American Journal of Public Health, 103, 21852192.

Simpson, A. (2014). Mohawk Interruptus: Political life across the borders of settler states. Durham, NC: Duke University Press. 
Simpson, A. (2017). The ruse of consent and the anatomy of 'refusal': Cases from indigenous North America and Australia. Postcolonial Studies, 20. doi:10.1080/13688790.2017.1334283

Simpson, L. B. (2017). As we have always done: Indigenous freedom through radical resistance. Minneapolis, MN: University of Minnesota Press.

Skye, A. D. (2010). Aboriginal midwifery: A model for change. Journal of Aboriginal Health, 6, 28-37.

Smith, L. T. (2012). Decolonizing methodologies: Research and Indigenous peoples (Second). London, UK: Zed Books.

Smithers Graeme, C., \& Mandawe, E. (2017). Indigenous geographies: Research as reconciliation. The International Indigenous Policy Journal, 8. doi:10.18584/iipj.2017.8.2.2

SOGC. (2010). Returning birth to Aboriginal, rural, and remote communities. Journal of Obstetrics and Gynaecology Canada, 32, 1186-1188.

St John, T. (2017). Keeping together.

Stote, K. (2012). The coercive sterilization of Aboriginal women in Canada. American Indian Culture and Research Journal, 36, 117-150.

Tamas, S. (2009a). Sketchy rendering: Seeing an Other. Qualitative Inquiry, 15, 607617.

Tamas, S. (2009b). Three ways to lose your epistemology. International Review of Qualitative Research, 2, 43-60.

Tamas, S. (2013). Researcher as hostess: Power, gender, loss, and cookies. Feminist Studies, 39, 484-493. 
Tamas, S. (2014). Certain uncertainties: Living unlearning. Emotion, Space and Society, $11,1-5$.

Tamas, S. (2016). Ghost stories. Emotion, Space and Society, 19, 40-44.

Todd, Z. (2016). An Indigenous feminist's take on the ontological turn: 'Ontology' is just another word for colonialism. Journal of Historical Sociology, 29, 4-22.

UCN Midwifery (KOBP) 2011-2014 [archived]. (n.d.). Retrieved 13 June 2018, from https://sites.google.com/site/ucnmidwifery/home

Van Wagner, V., Epoo, B., Nastapoka, J., \& Harney, E. (2007). Reclaiming birth, health, and community: Midwifery in the Inuit villages of Nunavik, Canada. Journal of Midwifery \& Women's Health, 52, 384-391.

Walters, K. L., Beltran, R., Huh, D., \& Evans-Campbell, T. (2011). Dis-placement and dis-ease: Land, place, and health among American Indians and Alaska Natives. In L. M. Burton, S. P. Kemp, M. Leung, S. A. Matthews, \& D. T. Takeuchi (Eds.), Communities, neighborhoods, and health: Expanding the boundaries of place (pp. 163-199). New York, NY: Springer-Verlag.

Watts, V. (2013). Indigenous place-thought \& agency amongst humans and non-humans (First Woman and Sky Woman go on a European world tour!). Decolonization: Indigeneity, Education \& Society, 2, 20-34.

Wiebe, A. D., Barton, S., Auger, L., Pijl-Zieber, E., \& Foster-Boucher, C. (2015). Restoring the blessings of the morning star: Childbirth and maternal-infant health for First Nations near Edmonton, Alberta. Aboriginal Policy Studies, 5, 47-68.

Wilson, E. A. (2015). Gut feminism. Durham, NC: Duke University Press. 
Wilson, S. (2008). Research is ceremony: Indigenous research methods. Halifax, NS: Fernwood Publishing. 


\section{Appendices}

\section{Appendix A Data Collection}

\section{A.1 Letter of recruitment}

Carleton

1125 Colonel By Drive

Ottawa, Ontario K1S 5B6

613-520-2560

\section{Letter of Recruitment}

\section{[DATE]}

Hello,

My name is Monika Krzywania and I am a master's student in the Department of Geography \& Environmental Studies at Carleton University in Ottawa, Ontario. I am currently working on a project called, "Protecting the Providers of Indigenous Maternal Care", supervised by Professor Sophie Tamas. In this letter, I would like to tell you about my project to find out if you might be interested in participating.

In my master's research, I am trying to gain a better understanding of the working conditions of service providers delivering maternal care in Indigenous communities in Ontario and Quebec. I am particularly interested in the impact of returning low-risk births to communities and how this policy shift may have influenced your experience of providing maternal care. I would like to ask you about the challenges you face in your line of work, the opportunities you see for improving your own working conditions, and your perspectives on how to guarantee that every woman has access to a safe and nurturing environment for childbirth.

For this project, I am looking to speak to 4-7 providers in a range of maternal care roles: midwives, nurses, physicians, and policy experts who have worked closely with Indigenous communities in Ontario and Quebec. The project will happen in two phases: Phase 1 will consist of one-on-one, semi-structured interviews lasting approximately 60- 
90 minutes and Phase 2 will consist of an optional focus group discussion involving all participants.

If you choose to participate, I will take every precaution necessary to ensure your comfort, safety, and security during this project. Your participation is completely voluntary and you may withdraw at any time before the completion date of [DATE]. While your participation is primarily a huge benefit to me and my project, it might offer you:

- Access to a positive forum and safe space to discuss work-related challenges and factors which contribute to stress.

- Opportunities to mobilize your own suggestions and recommendations for improving your workplace and advancing community development.

- Networking opportunities to organize around shared experiences and a common vision for improving maternal care while building on existing ties.

- External recognition, with your consent, for your contributions to policy improvement and community development.

- Research findings may also provide lobbying power for securing future funding.

If you are interested in participating in this project, I invite you to email me at monikakrzywania@cmail.carleton.ca. I will go over the project with you in detail and address any questions or concerns you may have. With your permission, I would also be happy to follow-up with you directly over email or over the phone, if you prefer. If this arrangement suits you better, please indicate your assent to the recruiter (including your preferred method of contact \& relevant contact information) and I will get in touch with you promptly. If you decide to participate, we will negotiate your consent orally or in writing, outlining all possible risks and the measures I will take to off-set them to ensure your comfort, safety, and security for the duration of this project. As a token of appreciation, refreshments will be provided during the interview and focus group discussion. If required, childcare and transportation reimbursements will also be made available upon your request.

This research has been cleared by Carleton University Research Ethics Board-A (clearance \#106326).

Thank you very much for taking the time to read my letter. I look forward to hearing from you, and the possibility of working with you to learn from your lived experiences to improve maternal care for Indigenous women.

With much gratitude, Principal Researcher Monika Krzywania

Department of Geography \& Environmental Studies

Carleton University

Ottawa, Ontario, Canada

monikakrzywania@cmail.carleton.ca 
Academic Supervisor

Dr. Sophie Tamas

Assistant Professor

Department of Geography \& Environmental Studies and School of Indigenous \&

Canadian Studies

Carleton University

Ottawa, Ontario, Canada

sophie.tamas@carleton.ca

If you have any ethical concerns with this study, please contact:

Dr. Andy Adler, Chair, Carleton University Research Ethics Board-A

613-520-2600 ext. 2517

ethics@ carleton.ca 


\title{
A.2 Oral Consent Script
}

\section{Carleton $\mid$ Oongeography \& U N I V E R S I T Y Environmental Studies}

\author{
1125 Colonel By Drive \\ Ottawa, Ontario K1S 5B6 \\ 613-520-2560
}

\section{Oral Consent Script}

\section{[DATE]}

Hello,

My name is Monika Krzywania and I am the principal researcher for the project, "Protecting the Providers of Indigenous Maternal Care". Having discussed the project in detail and confirmed your interest in participating, I would now like to negotiate your informed consent to participate.

First, I will go over the possible risks associated with your participation in this project and the measures I will take to off-set these risks. Next, I will explain how data will be collected, stored, published, and disposed of to establish your preferred level of identifiability.

Please feel free to stop me at any point to ask questions or seek further clarification. Also, please know that I will keep checking in with you for the duration of this project on an ongoing basis to ensure that you always feel comfortable, safe, and secure.

\section{A. Risk of Psychological Harm}

During the one-on-one, semi-structured interview, I will ask you if you have experienced work-related stress. If you become uncomfortable or distressed at any point during the interview, I encourage you to let me know. You may request a break or stop the interview at any time. If you find a particular topic to be sensitive, I will not press on without your explicit consent to do so. Your participation in this study is completely voluntary and you may withdraw from the study up until its completion date of [DATE]. I will not be asking you directly about encounters that raise the possibility of a legal duty to report. If such information comes up, I will address it directly with you. 
At this time, do you feel that you fully understand the risk of psychological harm associated with this project and are you satisfied with the measures I will take to off-set these risks?

Yes

\section{B. Risk of Social and/or Economic Harm}

During the one-on-one, semi-structured interview, I will ask you about your perspectives on specific policies, the challenges and opportunities arising out of your own set of lived experiences, and your personal recommendations for improving care. I will ask you to specify your preferred level of identifiability for this project; you may consent to the inclusion of identifying information, choose to use a pseudonym, or request complete anonymity.

I will always respect the level of identifiability that you request; however, due to the small size of the Indigenous maternal care network and the rural locations in which some individuals practice, I cannot guarantee that you will not be recognized indirectly. In order to off-set this risk, I will ask you how you would like me to describe your community in written publications.

The focus group discussion is open to all participants. I will ask all those who attend to exercise full discretion and keep the proceedings in confidence; however, I am unable to guarantee complete anonymity given the group structure of this session. Individuals who would like to retain complete anonymity may choose not to participate in the focus group discussion.

At this time, do you feel that you fully understand the risk of social and/or economic harm associated with this project and are you satisfied with the measures I will take to off-set these risks?

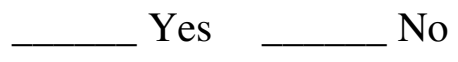

\section{Participant Identifiability}

I will now ask you about your preferred level of identifiability during the research process.

With your consent, I would like to record the one-on-one interview using a digital recorder. Within two weeks of the interview, I will transcribe the audio recording.

If all participants agree, the focus group discussion will also be audio recorded and transcribed. You will have the option to Skype in for the focus group discussion; if you 
choose this option, your conversation may be subject to surveillance by the US government.

Do you consent to participation in an audio-recorded one-on-one, semi-structured interview?

$$
\text { Yes }
$$

What is your preferred location for the one-on-one, semi-structured interview: home, workplace, or other public place?

Do you consent to participation in an audio-recorded focus group discussion?<smiles>[18O]=N[Mg][Mg]</smiles>

Do you consent to the disclosure of your participation to other participants? Yes No

Do you agree to keep the proceedings of the focus group discussion in confidence?

Yes

Would you like to Skype in for the focus group discussion?

Yes No

If yes, do you acknowledge that your Skype call may be subject to surveillance by the US government? Yes

How would you like to be identified in transcripts for the interview and focus group discussion: participant identifiers included, pseudonym, or complete anonymity?

With your consent, I will store audio recordings of the interview and focus group discussion on a password-protected hard drive, accessible only by myself. I will store any physical copies of field notes or transcripts in a locked drawer in my desk. 
Do you consent to the terms of data storage?

Yes No

Audio recordings will be deleted immediately after I defend my thesis. Anonymized transcripts will be retained for two years for possible use in future publications.

Do you consent to the terms of data disposition?

Yes No

How would you like to be identified in written publications arising out of this study: participant identifiers included, pseudonym, or complete anonymity?

How would you like me to describe your community in written publications?

Name of participant/pseudonym/initials:

Signature of Monika Krzywania, Principal Researcher:

Date:

Principal Researcher

Monika Krzywania

Department of Geography \& Environmental Studies

Carleton University

Ottawa, Ontario, Canada

monikakrzywania@cmail.carleton.ca 
Academic Supervisor

Dr. Sophie Tamas

Assistant Professor

Department of Geography \& Environmental Studies and School of Indigenous \&

Canadian Studies

Carleton University

Ottawa, Ontario, Canada

sophie.tamas@carleton.ca

If you have any ethical concerns with this study, please contact:

Dr. Andy Adler, Chair, Carleton University Research Ethics Board-A

613-520-2600 ext. 2517

ethics@carleton.ca 


\title{
A.3 Written Consent Form
}

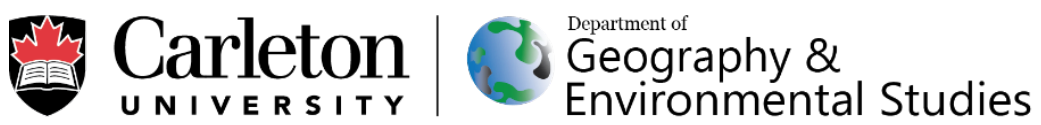

\author{
1125 Colonel By Drive \\ Ottawa, Ontario K1S 5B6 \\ 613-520-2560
}

\section{Written Consent Form \\ Research Project: Protecting the Providers of Indigenous Maternal Care}

Date of Ethics Clearance: February 8, 2017

Ethics Clearance for the Collection of Data Expires: February 28, 2018

I , choose to participate in this study on maternal care delivery for Indigenous women. This study will seek to evaluate the working conditions of service providers delivering maternal care in Indigenous communities in Ontario and Quebec, in order to better understand the outcomes of a policy shift to return birth to communities. The researcher for this study is Monika Krzywania in the Department of Geography \& Environmental Studies at Carleton University in Ottawa, ON. She is working under the supervision of Professor Sophie Tamas in the Department of Geography \& Environmental Studies and the School of Indigenous \& Canadian Studies at Carleton University in Ottawa, ON.

This consent form provides a detailed overview of your participation in this study, including possible risks and the measures the researcher will take to off-set these risks. It explains how data will be collected, stored, published, and disposed of to establish your preferred level of identifiability in research data and publications.

\section{A. Overview of Study Participation}

Your participation in this study will consist of a 60-90 minute one-on-one, semi-structured interview, followed by an optional focus group discussion with all interested participants. You will have the option to Skype in for the focus group discussion; if you choose this option, your conversation may be subject to surveillance by the US government. As a token of appreciation, refreshments will be provided during the interview and focus group discussion. If required, childcare and transportation reimbursements will also be made available upon your request. 
With your consent, the one-on-one interview will be audio-recorded. With the consent of all participants in attendance, the focus group discussion will also be audio-recorded. All audio recordings will be transcribed within two weeks of the interview and focus group discussion; audio recordings will be securely retained on a password-protected and encrypted hard drive until the researcher has successfully defended her thesis. Any hard copies of data (including any handwritten notes or USB keys) will be kept in a locked cabinet at Carleton University. Research data will only be accessible by the researcher and the research supervisor.

You have the right to end your participation in the study at any time, for any reason, up until the study completion date of [DATE]. You can withdraw by emailing the researcher or the research supervisor. If you withdraw from the study, all information you have provided will be immediately destroyed.

Do you consent to participation in an audio-recorded one-on-one, semi-structured interview?

Yes No

What is your preferred location for the one-on-one, semi-structured interview: home, workplace, or other public place?

Do you consent to participation in an audio-recorded focus group discussion?

Yes No

Do you consent to the disclosure of your participation to other participants?

$$
\text { Yes }
$$
No

Do you agree to keep the proceedings of the focus group discussion in confidence?

Yes No

Would you like to Skype in for the focus group discussion?

Yes No

If yes, do you acknowledge that your Skype call may be subject to surveillance by the US government?

Yes No

How would you like to be identified in transcripts for the interview and focus group discussion: participant identifiers included, pseudonym, or complete anonymity? 
How would you like to be identified in written publications arising out of this study: participant identifiers included, pseudonym, or complete anonymity?

How would you like the researcher to describe your community in written publications?

With your consent, audio recordings of the interview and the focus group discussion will be kept until immediately after the thesis defense. Anonymized transcripts will be securely retained on a password-protected and encrypted hard drive for two years for possible use in future publications. At the end of two years, all research data will be securely destroyed (electronic data will be erased).

Do you consent to the terms of data storage and disposition?

Yes No

\section{B. Risk of Psychological Harm}

During the one-on-one, semi-structured interview, the researcher will ask you if you have experienced work-related stress. If you become uncomfortable or distressed at any point during the interview, you are encouraged to let the researcher know. You may request a break or stop the interview at any time. If you find a particular topic to be sensitive, the researcher will not press on without your explicit consent to do so. You will not be asked directly about encounters that raise the possibility of a legal duty to report. If such information comes up, the researcher will address it directly with you.

At this time, do you feel that you fully understand the risk of psychological harm associated with this project and are you satisfied with the measures the researcher will take to off-set these risks?<smiles>[Mg][W]=[W]</smiles>

\section{Risk of Social and/or Economic Harm}

During the one-on-one, semi-structured interview, the researcher will ask you about your perspectives on specific policies, the challenges and opportunities arising out of your own set of lived experiences, and your personal recommendations for improving care. In Section A of this consent form, the researcher has asked you to specify your preferred level of identifiability for this project; inclusion of identifying information, use of a pseudonym, or request for complete anonymity.

The researcher will always respect the level of identifiability that you request; however, due to the small size of the Indigenous maternal care network and the rural locations in which some individuals practice, the researcher cannot guarantee that you will not be recognized indirectly. In order to off-set this risk, the researcher has asked how you would like your working community to be described in written publications. 
The focus group discussion is open to all participants. The researcher will ask all those who attend to exercise full discretion and keep the proceedings in confidence; however, the researcher is unable to guarantee complete anonymity given the group structure of this session. Individuals who would like to retain complete anonymity may choose not to participate in the focus group discussion.

At this time, do you feel that you fully understand the risk of social and/or economic harm associated with this project and are you satisfied with the measures the researcher will take to offset these risks?

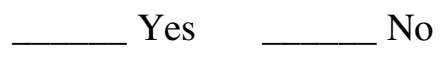

If you would like a copy of the finished research project, you are invited to contact the researcher to request an electronic copy which will be provided to you.

The ethics protocol for this project was reviewed by the Carleton University Research Ethics Board, which provided clearance to carry out the research. If you have any ethical concerns with the study, please contact Dr. Andy Adler, Chair, Carleton University Research Ethics Board-A (by phone at 613-520-2600 ext. 2517 or via email at ethics@carleton.ca).

Principal Researcher

Monika Krzywania

Department of Geography \& Environmental Studies

Carleton University

Ottawa, Ontario, Canada

monikakrzywania@cmail.carleton.ca

Academic Supervisor

Dr. Sophie Tamas

Assistant Professor

Department of Geography \& Environmental Studies and School of Indigenous \& Canadian

Studies

Carleton University

Ottawa, Ontario, Canada

sophie.tamas@carleton.ca

Signature of participant

Date

Signature of researcher

Date 


\title{
A.4 Interview Guide
}

\section{Carleton 2 , Geography \& \\ U N I VE R S I T Y Environmental Studies}

\author{
1125 Colonel By Drive
}

Ottawa, Ontario K1S 5B6

613-520-2560

\section{Interview Guide}

Research Project: Protecting the Providers of Indigenous Maternal Care

\section{[DATE]}

\section{To begin:}

I will thank participants for their time. I will introduce myself, my research interests, and project aims in greater detail. Having negotiated consent orally at the time of recruitment, I will check in with participants again, recapitulating the goals of the project, and providing further clarification if needed. Participants will be reminded that their participation is completely voluntary, that they may take a break or stop the interview at any point, and that they may withdraw from the study before the completion date of [DATE]. When all questions and concerns have been addressed, I will proceed with the interview.

\section{Outline of interview questions:}

\section{THEME 1: Mapping geographies of care}

1. Could you describe your role as a maternal care provider?

- Which duties do you prioritize in your practice?

- What do you find most rewarding about your career?

2. Could you tell me about your path to your current role?

- What type of education, formal or informal, did you receive in preparing for your current role?

- Did you find that this education prepared you well for your current role?

- Are there other experiences besides education that helped you prepare for your current role?

3. How often would you say that you feel stressed on the job?

- What steps do you take to deal with day-to-day stress?

- Have you encountered burnout in your career as a maternal care provider? 
4. Do you find that place has an influence on your practice?

- Where do you feel most or least at home when you are providing maternal care?

- How does the community impact maternal care?

5. Can you describe for me your ideal birth situation?

- Where is it?

- Who is there? What things are in the room?

THEME 2: Navigating the current healthcare system

1. What does medical and cultural competence mean to you?

2. Do you feel that you have enough support to do your job well? Where do (or don't) you find support?

3. In 2010, the Society of Obstetricians and Gynaecologists of Canada made an official recommendation to return low-risk births to Indigenous communities.

- Have you noticed any effects of this policy shift on your practice?

- How do you assess risk in your line of work?

- In your experience, what is the approximate proportion of low to high risk births?

THEME 3: Charting future directions for Indigenous maternal care

1. What factors lead to positive experiences for mothers before/during/after childbirth? Similarly, are there factors that typically lead to negative experiences for mothers?

2. What do you think is the most important priority for improving care?

3. Who are the key actors and organizations of influence? What is their role in the system?

4. Do you think that the maternal care needs of Indigenous women are different from the needs of non-Indigenous women? If so, how do you respond to these needs?

\section{To conclude:}

I will thank participants for their time and emphasize the significance of their participation. I will address any final questions or concerns. 


\section{Appendix B Midwifery legislation in Ontario and Québec}

\section{B.1 Midwifery Act, 1991, SO 1991, c 31, s 8, "Restricted titles". Retrieved from \\ https://www.ontario.ca/laws/statute/91m31}

\section{Restricted titles}

8 (1) No person other than a member shall use the title "midwife", a variation or abbreviation or an equivalent in another language. 1991, c. 31, s. 8 (1).

Representations of qualification, etc.

(2) No person other than a member shall hold himself or herself out as a person who is qualified to practise in Ontario as a midwife or in a specialty of midwifery. 1991, c. 31, S. $8(2)$.

\section{Exception for aboriginal midwives}

(3) An aboriginal person who provides traditional midwifery services may,

(a) use the title "aboriginal midwife", a variation or abbreviation or an equivalent in another language; and

(b) hold himself or herself out as a person who is qualified to practise in Ontario as an aboriginal midwife. 1991, c. 31, s. 8 (3).

\section{Definition}

(4) In this section,

"abbreviation" includes an abbreviation of a variation. 1991, c. 31, s. 8 (4).

(C) Queen's Printer for Ontario, 1991.

[This excerpt has been reproduced in accordance with the terms of the copyright of the Queen's Printer for Ontario for the informational purposes of this thesis only. This copy does not have official status.] 


\section{B.2 Regulated Health Professions Act, 1991, SO 1991, c 18, s 35, "Exemption,}

aboriginal healers and midwives". Retrieved from https://www.ontario.ca/ laws/statute/91r18

\section{Exemption, aboriginal healers and midwives}

35 (1) This Act does not apply to,

(a) aboriginal healers providing traditional healing services to aboriginal persons or members of an aboriginal community; or

(b) aboriginal midwives providing traditional midwifery services to aboriginal persons or members of an aboriginal community.

\section{Jurisdictions of Colleges}

(2) Despite subsection (1), an aboriginal healer or aboriginal midwife who is a member of a College is subject to the jurisdiction of the College.

\section{Definitions}

(3) In this section,

"aboriginal healer" means an aboriginal person who provides traditional healing services; ("guerisseur autochtone")

"aboriginal midwife" means an aboriginal person who provides traditional midwifery services. ("sage-femme autochtone") 1991, c. 18, s. 35.

(C) Queen's Printer for Ontario, 1991.

[This excerpt has been reproduced in accordance with the terms of the copyright of the Queen's Printer for Ontario for the informational purposes of this thesis only. This copy does not have official status.] 


\section{B.3 Midwives $A t^{20}$, CQLR 2018, c S-0.1, ss 12-13, "Illegal Practice”. Retrieved from http://legisquebec.gouv.qc.ca/en/ShowDoc/cs/S-0.1}

\section{ILLEGAL PRACTICE}

12. Subject to the rights and privileges granted by law to other professionals, no person may perform an act described in section 6 unless the person is a midwife.

In particular, section 6 shall not be construed as prohibiting nurses from providing a woman and her child with the nursing care required during pregnancy, labour and delivery and the postnatal period.

The provisions of the first paragraph do not apply to an act performed by a person acting in accordance with

(1) a regulation made under paragraph $\mathrm{h}$ of section 94 of the Professional Code (chapter C-26);

(2) an agreement between the Government and a Native nation represented by the band councils of all the communities forming the Native nation, a Native community represented by its band council or by its council in the case of a Northern village, a group of communities so represented or any other Native group, allowing a Native person who is not a member of the Order to perform acts described in section 6 in the territory defined in the agreement, in accordance with the conditions fixed therein and to the extent that the terms of the agreement are observed.

1999, c. 24, s. 12.

13. Every person who contravenes section 12 is liable, for each offence, to the penalties prescribed in section 188 of the Professional Code (chapter C-26).

1999, c. 24, s. 13.

(c) Éditeur officiel du Québec, 2018.

[This excerpt has been reproduced with the permission of the Service de la gestion des droits d'auteur for the informational purposes of this thesis only. This copy does not have official status.]

\footnotetext{
${ }^{20}$ Prior to its consolidation and inclusion in the Compilation of Québec Laws and Regulations (CQLR), the Annual Statute (the first version of this Act) was found in chapter 24 of the Statutes of Québec 1999 (Midwives Act, SQ 1999, c 24). Sections 12 and 13 have not been amended in subsequent versions.
} 
Appendix C Non-Insured Health Benefits (NIHB) Medical Transportation Policy

Framework - Client Escort Policy

\title{
C.1 Non-Insured Health Benefits (NIHB) Medical Transportation Policy
}

\author{
Framework; Effective July 2005 (First Nations and Inuit Health Branch, Health
}

Canada, 2005)

\section{Client Escorts}

5.1 Medical transportation benefits may include the provision of transportation, accommodation and meals for medical or non-medical escorts for clients travelling to access medically required health services.

5.2 The use of an escort must be preauthorized by FNIHB or a First Nations or Inuit Health Authority or organization. The length of time for which the escort is authorized will be determined by the client's medical condition or legal requirements.

5.3 Medical transportation benefits do not include the payment of a fee, honorarium or salary to medical or non-medical escorts.

\section{Medical Escorts}

5.4 Medical escorts, either a physician or registered nurse, may be approved in cases which involve a client with a health condition where monitoring and/or stabilization are required during travel and such services are not covered by the provincial/territorial health or social program, other publicly funded program or private insurance.

\section{Non-Medical Escorts}

5.5 The provision of a non-medical escort may be approved, following a doctor's or community health professional's request, only when there is a legal or medical requirement such as:
a) Where the client has a physical/mental disability of a nature that he or she is unable to travel unassisted;
b) Where the client is medically incapacitated;
c) Where the client has been declared "mentally incompetent" by a court of competent jurisdiction and assistance to access medically required health services, legal consent or help with activities of daily living is required;
d) When there is a need for legal consent by a parent or guardian;
e) To accompany a minor (as determined by provincial/territorial legislation) who is accessing medically required health services; 
f) When a language barrier exists to access medically required health services and these services are not available at the referred location; or

g) To receive instructions on specific and essential home medical/nursing procedures that cannot be given to the client only.

5.6 When an escort has been authorized, the following criteria should be considered in selecting the escort:

a) A family member who is required to sign consent forms or provide a patient history;

b) A reliable member of the community;

c) Physically capable of taking care of themselves and the client and not requiring assistance or an escort themselves;

d) Proficient in translating from local language to English/French;

e) Able to share personal space to support client;

f) Interested in the well being of the client; and

g) Able to serve as driver when client is unable to transport him/herself to or from appointment.

5.7 Unless there is a medical or legal requirement for an escort to stay longer, or it is more practical financially to have the escort stay longer, the escort shall return to the community by the earliest and most economical reasonable means.

First Nations and Inuit Health Branch, Health Canada. (2005, July). 2005 Non-Insured Health Benefits (NIHB) medical transportation policy framework. Health Canada. Retrieved from http://www.fnha.ca/Documents/Medical-Transportation-Policy-Framework.pdf

[This excerpt has been reproduced for the informational purposes of this thesis only. This copy does not have official status.] 


\section{C.2 Non-Insured Health Benefits (NIHB) Medical Transportation Policy \\ Framework (Interim); Effective January 2018 (First Nations and Inuit Health}

Branch, Health Canada, 2018)

\section{Client Escorts}

5.1 Medical transportation benefits may include coverage for transportation, accommodations and meals for medical or non-medical escorts for clients travelling to access medically required health services.

5.2 Escorts must be preauthorized by FNIHB or a First Nations or Inuit Health Authority or organization and meet the criteria for coverage of an escort (outlined below).

5.3 Medical transportation benefits do not include the payment of a fee, honorarium or salary to medical or non-medical escorts.

\section{Medical Escorts}

5.4 Medical escorts, either a physician or registered nurse, may be approved in cases which involve a client with a health condition where monitoring and/or stabilization are required during travel and such services are not covered by the provincial/territorial health or social program, other publicly funded program or private insurance.

\section{Non-Medical Escorts}

5.5 Coverage for a non-medical escort may be approved when there is a legal or medical requirement that results in the client being unable to travel alone, such as where the client:

a. Is a minor;

b. Requires alternative legal consent/decision making;

c. Requires assistance with activities of daily living (e.g. assistance with dressing, eating, bathing etc.);

d. Faces a language barrier (i.e. health services at the referred location are not available in the clients spoken language(s));

e. Is to receive instruction on specific and essential home medical/nursing procedures that cannot be given to the client only;

f. Is undergoing a medical procedure (e.g. outpatient general anesthetic) or has a medical condition that will result in the client requiring assistance during the trip; and/or

g. Is a pregnant woman whose trip is for the purpose of childbirth (including being closer to care while awaiting childbirth). 
Requests for coverage for non-medical escorts must be made / supported by a community health professional except where:

a. The client is a minor (based on the date of birth, all minors will be provided with coverage for a non-medical escort);

b. The client is a pregnant woman whose trip is for the purpose of childbirth (all such clients will be provided with coverage for a non-medical escort)

c. The client will receive outpatient sedation as part of a medical procedure and will be unable to travel home unaccompanied following the procedure; or

d. There is existing documentation in the client's file that supports the continuing need for a non-medical escort such as:

- language barrier,

- escort travel previously approved as part of a series of related treatments,

- client has a permanent condition and as a result will always require assistance while travelling.

Details of the medical condition are not required. However, additional justification may be required in exceptional circumstances (such as for clients requiring more than one escort).

5.6 When coverage for an escort has been authorized, the escort must be capable and willing to provide the assistance that the client needs, for the duration it is required. Depending on the client's needs, for example, the escort is:

a. Able to sign consent forms or provide a patient history;

b. Able to provide the required physical and/or other required care when the client needs it. An escort should not require assistance for his or her own needs during the trip (this is important where the client may be admitted to hospital, leaving the escort on his or her own);

c. Proficient in translating between indigenous language and English/French;

d. Able to drive if the role includes providing ground transportation; and

e. Able to share personal space to support client.

5.7 Escorts should continue to be covered as long as the medical or legal requirement continues to exist. In some cases, it may be more practical financially to have the escort stay longer.

First Nations and Inuit Health Branch, Health Canada. (2018, January). 2018 Non-Insured Health Benefits (NIHB) medical transportation policy framework (interim) [Policy]. Retrieved 16 May 2018, from https://www.canada.ca/en/indigenous-services-canada/services/first-nations-inuit-health/reportspublications/non-insured-health-benefits/non-insured-health-benefits-nihb-medical-transportationpolicy-framework-july-2005-first-nations-inuit-health.html

[This excerpt has been reproduced for the informational purposes of this thesis only. This copy does not have official status.] 